ANL-18/11

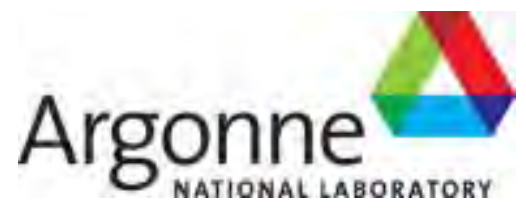

\title{
HPHT 17TR8 Test Articles: Post-Test Characterization Following Pressure Burst Testing (Final)
}

Examination of F22 Materials Following Plastic Deformation from Controlled Pressure Testing Energy Systems Division

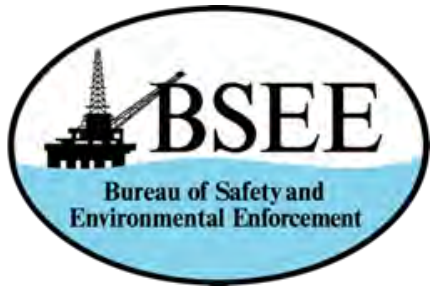




\title{
Report Authors
}

This report was prepared by the Global Energy Solutions (GES) Center team under the direction of Dan M. Fraser.

\author{
About Argonne National Laboratory \\ Argonne is a U.S. Department of Energy laboratory managed by UChicago Argonne, LLC \\ under contract DE-AC02-06CH11357. The Laboratory's main facility is outside Chicago, at \\ 9700 South Cass Avenue, Argonne, Illinois 60439. For information about Argonne \\ and its pioneering science and technology programs, see www.anl.gov.
}

\section{DOCUMENT AVAILABILITY}

Online Access: U.S. Department of Energy (DOE) reports produced after 1991 and a growing number of pre-1991 documents are available free via DOE's SciTech Connect (http://www.osti.gov/scitech/).

\author{
Reports not in digital format may be purchased by the public from the \\ National Technical Information Service (NTIS): \\ U.S. Department of Commerce \\ National Technical Information Service \\ 5301 Shawnee Rd \\ Alexandria, VA 22312 \\ www.ntis.gov \\ Phone: (800) 553-NTIS (6847) or (703) 605-6000 \\ Fax: (703) 605-6900 \\ Email: orders@ntis.gov
}

Reports not in digital format are available to DOE and DOE contractors from the Office of Scientific and Technical Information (OSTI):

U.S. Department of Energy

Office of Scientific and Technical Information

P.O. Box 62

Oak Ridge, TN 37831-0062

www.osti.gov

Phone: (865) 576-8401

Fax: (865) 576-5728

Email: reports@osti.gov

Disclaimer

This report was prepared as an account of work sponsored by an agency of the United States Government. Neither the United States Government nor any agency thereof, nor UChicago Argonne, LLC, nor any of their employees or officers, makes any warranty, express or implied, or assumes any legal liability or responsibility for the accuracy, completeness, or usefulness of any information, apparatus, product, or process disclosed, or represents that its use would not infringe privately owned rights. Reference herein to any specific commercial product, process, or service by trade name, trademark, manufacturer, or otherwise, does not necessarily constitute or imply its endorsement, recommendation, or favoring by the United States Government or any agency thereof. The views and opinions of document authors expressed herein do not necessarily state or reflect those of the United States Government or any agency thereof, Argonne National Laboratory, or UChicago Argonne, LLC.

This report was prepared by Argonne National Laboratory (ANL) under contract to the Department of Energy (DOE) through an interagency agreement between the Department of the Interior, Bureau of Safety and Environmental Enforcement (BSEE) and the DOE. The opinions, findings, conclusions, and recommendations expressed in the report are those of the authors and they do not necessarily reflect the views or policies of BSEE. 


\section{HPHT 17TR8 Test Articles: Post-Test Characterization Following Pressure Burst Testing (Final)}

Examination of F22 Materials Following Plastic Deformation from Controlled Pressure Testing

Prepared by

Bruce P. Miglin

Adica, LLC

Roy A. Lindley

Energy Systems Division, Argonne National Laboratory

Prepared for the U.S. Department of the Interior, Bureau of Safety and Environmental Enforcement

April 30, 2018 


\section{CONTENTS}

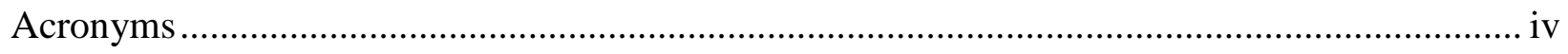

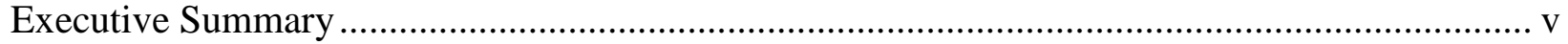

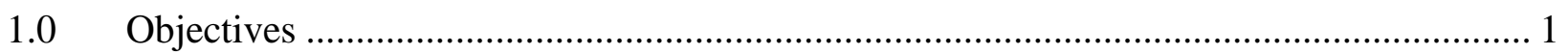

2.0 Material Evaluation Approach ....................................................................................... 2

$2.1 \quad$ Hardness Examinations and Results ............................................................................ 4

2.2 Sulfide Stress Cracking Examinations and Results ........................................................ 8

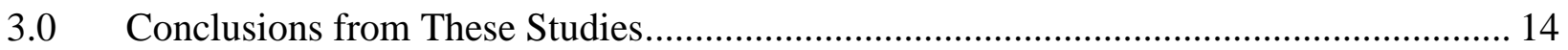

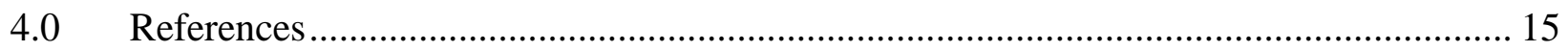

Appendix A: Exova Detailed Report on Metallurgical Examinations............................................... 16

Appendix B: Omni Cutting Diagram for SSC Data................................................................... 70

\section{LIST OF FIGURES}

Figure 1 Schematic Diagrams of the Two F22 Test Pieces ............................................................ 3

Figure 2 Schematic Diagram of Location of Samples of the Throat Regions Investigated by

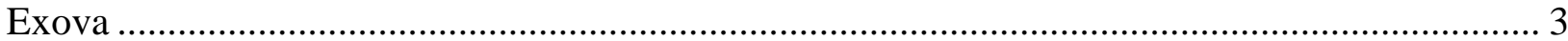

Figure 3 Summary of Hardness Data Determined by Microhardness Measurements at the

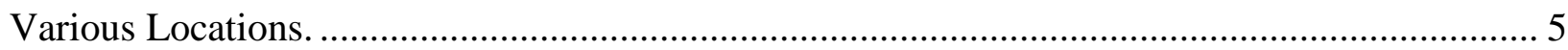

Figure 4 Microhardness Measurements for ID to OD of Surface for Base Case Specimen; Top at Burst Location; Middle Circumferentially 180 Degrees from Burst; Bottom Circumferentially 180 Degrees from Burst at End of Throat...................................................................................... 6

Figure 5 Microhardness Measurements from ID to OD of Surface for Reduced Case Specimen; Top at Burst Location; Middle Circumferentially 180 Degrees from Burst; Bottom Circumferentially 180 Degrees from Burst and at End of Throat ............................................... 7

Figure 6 Plot of KISSC Versus Material Hardness for Wrought OCTG Steels (2) ........................ 8

Figure 7 Schematic Diagram of a DCB Specimen .................................................................... 9 Figure 8 Plot of NACE Method D Results for F22 Forging Material and Compared to Wrought

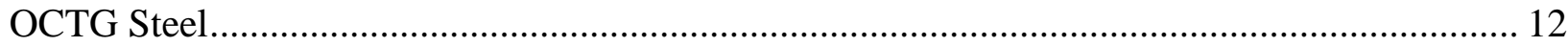




\section{LIST OF TABLES}

Table 1 Hardness (HRc) for DCB Specimens Used in Test Program ......................................... 10

Table 2 SCC Results for DCB Specimens Tested in the Standard Environment ........................ 10

Table 3 SCC Results for DCB Specimens Tested in the Mild Environment ............................. 12

Table 4 Comparison of Compositions of the F22 Versus a Typical C90 .................................... 13 


$\begin{array}{ll}\text { Acronyms } & \\ \text { DCB } & \text { Double Cantilever Beam (Specimens) } \\ \text { HRc } & \text { Hardness Rockwell C scale } \\ \text { Hv } & \text { Vickers microhardness } \\ \text { HPHT } & \text { High-pressure high temperature } \\ \text { ID } & \text { Inside Diameter } \\ \text { KISSC } & \text { Unit of environment sulfide stress cracking resistance } \\ \text { NACE } & \text { formerly: National Association of Corrosion Engineers } \\ \text { OCTG } & \text { Oil Country Tubular Goods } \\ \text { OD } & \text { Outside Diameter } \\ \text { RA } & \text { Reduction in Area } \\ \text { SSC } & \text { Sulfide Stress Cracking } \\ \text { UTS } & \text { Ultimate Tensile Strength } \\ \text { YS } & \text { Yield Strength }\end{array}$




\section{Executive Summary}

The objective of this study was to investigate whether F22 forging material's properties change near the failure location, in the event that two full-scale test pieces are intentionally taken to burst failure. ${ }^{1}$ The two full-scale test pieces were created per high-pressure high-temperature guidelines in API 17TR8 and ASME Section VIII references in those guidelines.

Extensive metallurgical analysis determined the following:

1. Microstructure analysis showed that grain size average results varied between 6 and 7 . Microstructure was observed as tempered martensite, and the "At Burst" locations showed elongated grain structures.

2. Hardness tests revealed that strain hardening caused higher hardness values at the burst and 180 degrees from burst locations (26.5 -27.5 HRc at burst location and 24.3 to 24.9 HRc at $180^{\circ}$ to burst location versus approximately $22.0 \mathrm{HRc}$ pretest).

3. Electron microscope examination found no evidence of machining or material defects. Dimple rupture was revealed at 400X and 1500X magnification.

4. Even at the same hardness values, the F22 forging material is more susceptible to Sulfide Stress Cracking (SSC) than sour ${ }^{2}$ application grades of Oil-country Tubular Goods (OCTG) in the standard NACE test environment.

5. Even at the same hardness values, the F22 forging material in the mild environment (KISSC-39 to $52 \mathrm{ksi} \sqrt{i n}$ ) is considerably less susceptible to SSC than in the standard test environment (KISSC- 19.6 to 24.4 ksi $\sqrt{ }$ in).

6. Forging material should not be considered a sour service environment material even for hardness values less than $22 \mathrm{HRc}$.

7. Any intended exposure of the $\mathrm{F} 22$ forging material to $\mathrm{H}_{2} \mathrm{~S}$ conditions would require further evaluations to determine SSC susceptibility.

In addition to the findings listed above, analyses of the data showed how hardness varied among burst locations and across the wall (from ID to OD surfaces) from those locations.

\footnotetext{
${ }^{1}$ F22 is a common oil and gas industry material used for subsea components. Details of the design, analysis and testing are reported in Reference 1 (Evaluation of Pressure Rating Methods Recommended by API RP 17TR8) ${ }^{2}$ Sour meaning presence of hydrogen sulfide in the well bore with the hyrdrocarbons and thus an acidic service environment.
} 
This report recommends that standard NACE tests should be performed to determine the sulfide stress cracking performance of the forging material and test results compared to published data on wrought steel products used for casing in sour wells. 


\subsection{Objectives}

The objectives of this work were twofold:

1. To investigate if the properties of an F22 forging material changed in the event that two full-scale test pieces were intentionally taken to burst failure; and

2. To determine the sulfide stress cracking susceptibility of the as-tested material.

Full details about the metallurgical testing program used for these burst tests are provided in Appendix A. The samples for data in this report were taken from two test articles representative of shapes and sizes encountered in subsea components. Both were designed and fabricated in accordance with high-pressure high temperature (HPHT) guidelines established in the first edition of API 17TR8 and referenced sections of the ASME Boiler and Pressure Vessel Code (BPVC) in that edition. One test article's plastic collapse criteria was analyzed using finite element analysis techniques per ASME Section VIII Division 2 with the other from elastic-plastic analytical methods in ASME Section VIII Division 3. Test article material was unclad F22, a chrome-molybdenum alloy, as used often for subsea equipment. Design pressure was 20,000 psi with a 30\% design margin added by the design engineer to be consistent with his normal practice of accommodating loading uncertainties. Details on the design and testing to failure of these two test articles that were the source of the metallurgical samples provided in this report appear in Reference 1. 


\subsection{Material Evaluation Approach}

Figure 1 shows a schematic diagram of the two test pieces ${ }^{3}$. Note that the difference between the pieces is the throat region. The thicker throat sample is per ASME Boiler and Pressure Vessel Code Section VIII Division 2 (from API 17TR8) has a wall thickness of 1.34 inches and is designated the "base case." The throat region of the other sample is per Section VIII Division 3, the "reduced case," has a wall thickness of 0.94 inches. When these samples experienced burst failure, failure occurred as an inside diameter (ID)-initiated longitudinal "fish mouth" crack in the throat portions the two specimens.

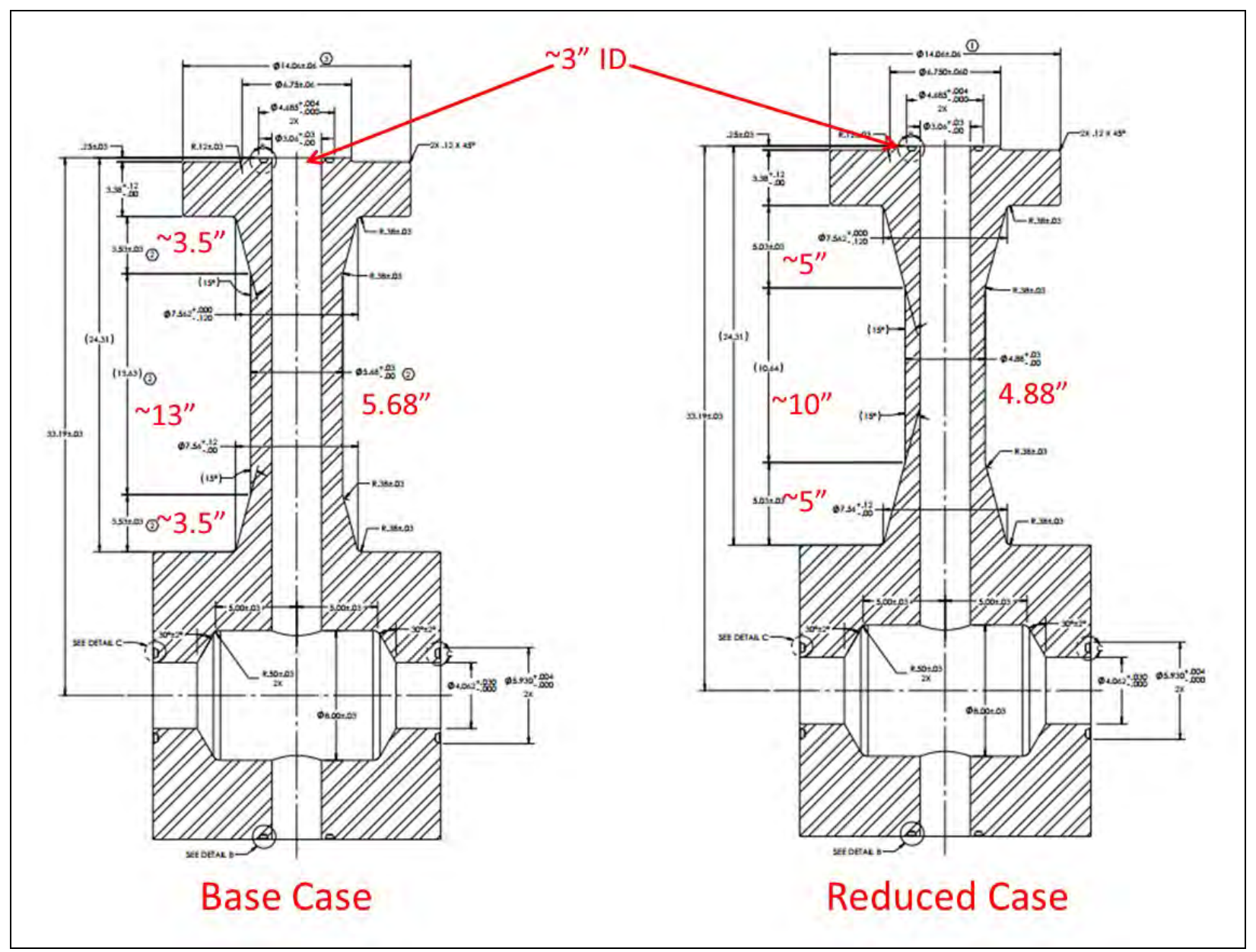

${ }^{3}$ Described in Reference 1. 


\section{Figure 1 SCHEMATIC Diagrams OF THE TWO F22 TEST PIECES}

After failure, the throat regions of the two samples were removed from the test bodies. These throat sections were sent to Exova Test Labs in Houston, Texas. Exova performed three tasks (Figure 2):

1. Compare the microstructures of the F22 materials at three locations on the throat

2. Determine if the burst failures were due to preexisting defects

3. Make microhardness measurements across the wall thickness at the same three locations as item A

Side View
$\begin{aligned} & \text { At each of } 3 \text { locations, prepare } \\ & \text { metallographic mount and measure } \\ & \text { microhardnesses traces OD-to-ID. Also } \\ & \text { at each location prepare metallographic } \\ & \text { mounts for each of three orthogonal planes } \\ & \text { to document grain structure and to measure } \\ & \text { grain size. }\end{aligned}$
$\begin{aligned} & \text { Locations: } \\ & \text { A - At the burst location } \\ & \text { B- } 180^{\circ} \text { around circumference from A } \\ & \mathrm{C} \text { - } 180^{\circ} \text { around circumference from A, but in larger diameter section }\end{aligned}$
FIGURE 2 SCHEMATIC DIAGRAM OF LOCATION OF SAMPLES OF THE THROAT REGIONS
INVESTIGATED BY EXOVA




\subsection{Hardness Examinations and Results}

In the industry, it is widely known that sulfide stress cracking (SSC) susceptibility increases with the yield strength of the material (2). As yield strength increases, so, too, does material hardness. From a practical perspective, it is easier to determine a component's hardness than to determine its yield strength value. As a result, qualitative comparisons of SSC susceptibilities are often made using relative hardness. This particular study utilized Vickers microhardness (Hv) measurements. In contrast, the oil and gas industry typically uses the Rockwell $\mathrm{C}$ hardness (HRc) scale to measure hardness. The technical discussions in this section will use the HRc scale. The following formula converts between the Hv and HRc scales:

$$
\mathrm{HRc}=0.1376(\mathrm{Hv})-10.913
$$

The hardness data gathered by Exova are presented in Appendix A. A simple visual summary of Exova's data (in HRc) is shown in Figure 3 and requires some explanation. The main points from the Exova report are:

1. Microstructure analysis showed that grain size average results varied between 6 and 7 and were consistent across both samples. Microstructure was observed as tempered martensite, and the "At Burst" locations showed elongated grain structures.

2. Hardness tests revealed that strain hardening caused higher hardness values at the burst location and 180 degrees from burst locations.

3. SEM examination found no evidence of machining or material defects. Dimple rupture was revealed at $400 \mathrm{X}$ and $1500 \mathrm{X}$ magnifications.

Figure 3 shows the range and average hardness at the three chosen locations for both samples. The bar represents the range of measurements made at a location; the number associated with each bar is the average value at that location. Note the horizontal, dashed line at HRc $=22.0$. Below this hardness level, material is considered fully NACE compliant, as defined by ISO 15156/NACE MR0175. Materials above the line can be used if it can be demonstrated that they are fit-for-purpose (FFP) for specific temperatures, pressures, $\mathrm{pH}$, and $\mathrm{H}_{2} \mathrm{~S}$ concentrations. As shown in Figure 3, the thick material away from the burst location has hardness values showing complete compliance with ISO 15156/NACE MR0175. Near the burst location, where plastic deformation occurred, hardness can be as high at HRc 30.0. 


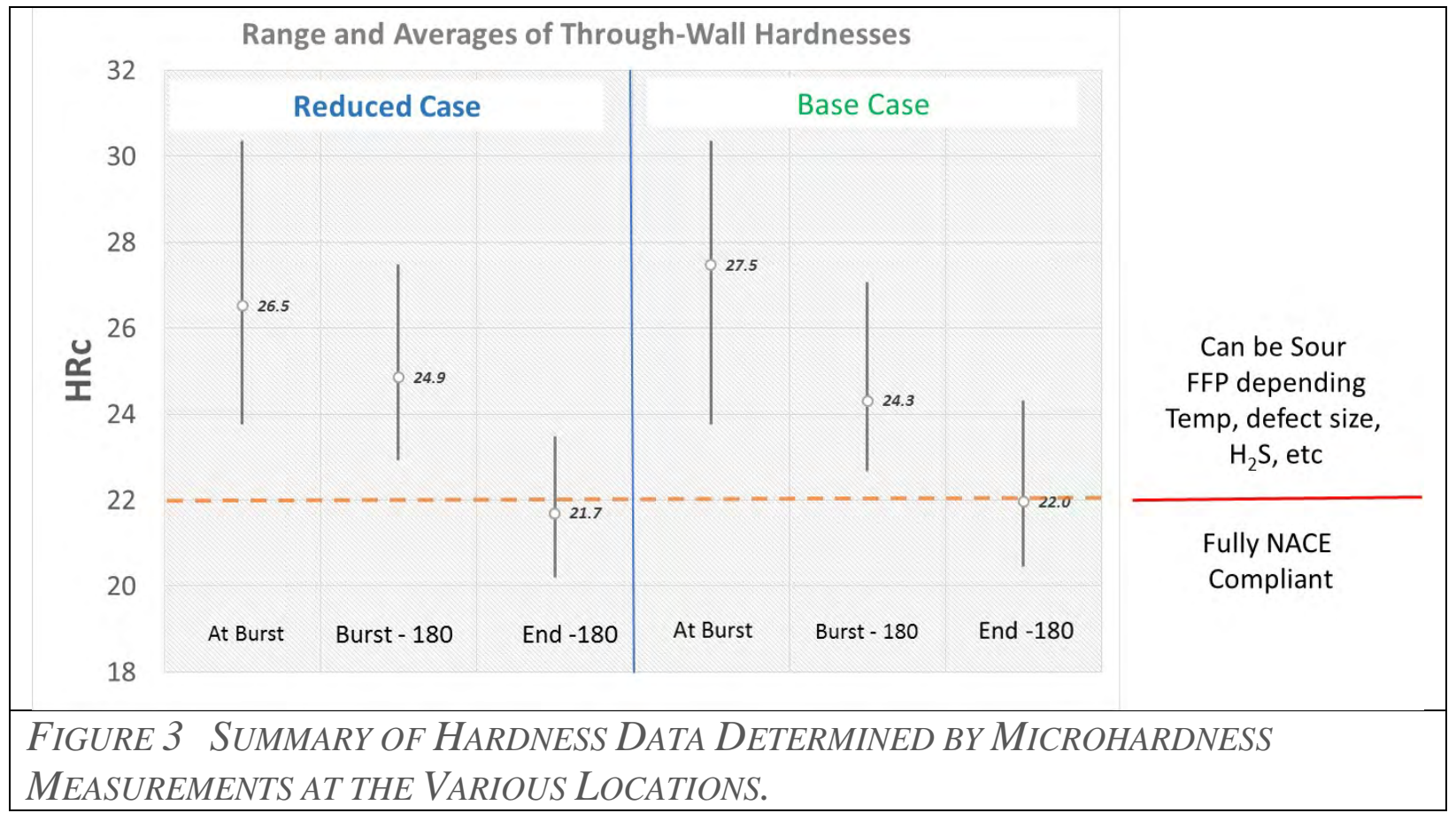

Although Figure 3 is a good visual summary of hardness measurements, it does not indicate how hardness varies from the ID to the OD surface of the throat sections. Such an indication is desirable, since fracture mechanics analysis could be employed at defects where the material is harder than HRc 22. Figures 4 and 5 show the variation of hardness across the wall thickness from the ID to the OD. These two figures show hardness values in Hv units. An HRc of 22 corresponds to an $\mathrm{Hv}$ value of 240 and is shown as a horizontal red line in each plot.

Close examination of Figures 4 and 5 reveals that only the ends of the throat regions (i.e., region C of Figure 2) have material values softer than Hv 240. It should be remembered, though, that the other two material regions are plastically deformed and would not be expected to deform in actual service conditions. For the throat end locations, the value of $\mathrm{Hv} 240$ is fairly deep into the wall thickness. For the base case, it is $20 \mathrm{~mm}$ from the ID surface; for the reduced case, values greater that 240 are found completely through the wall.

One requirement for a fracture mechanics assessment of the component would be material property data. Figure 6, for example, shows material property data for steels that are in the wrought condition and that are used for oil country tubular goods (OCTG). 


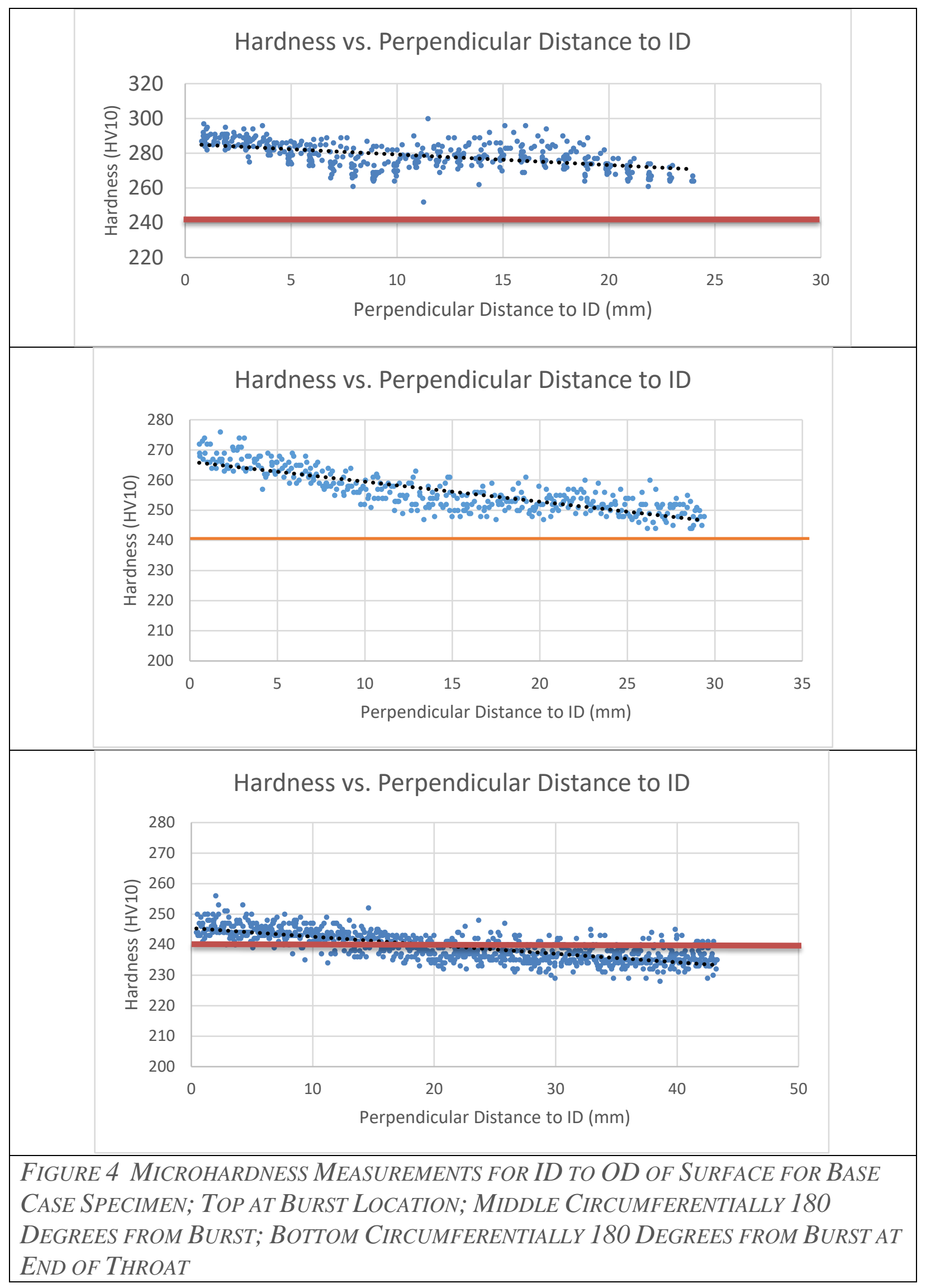




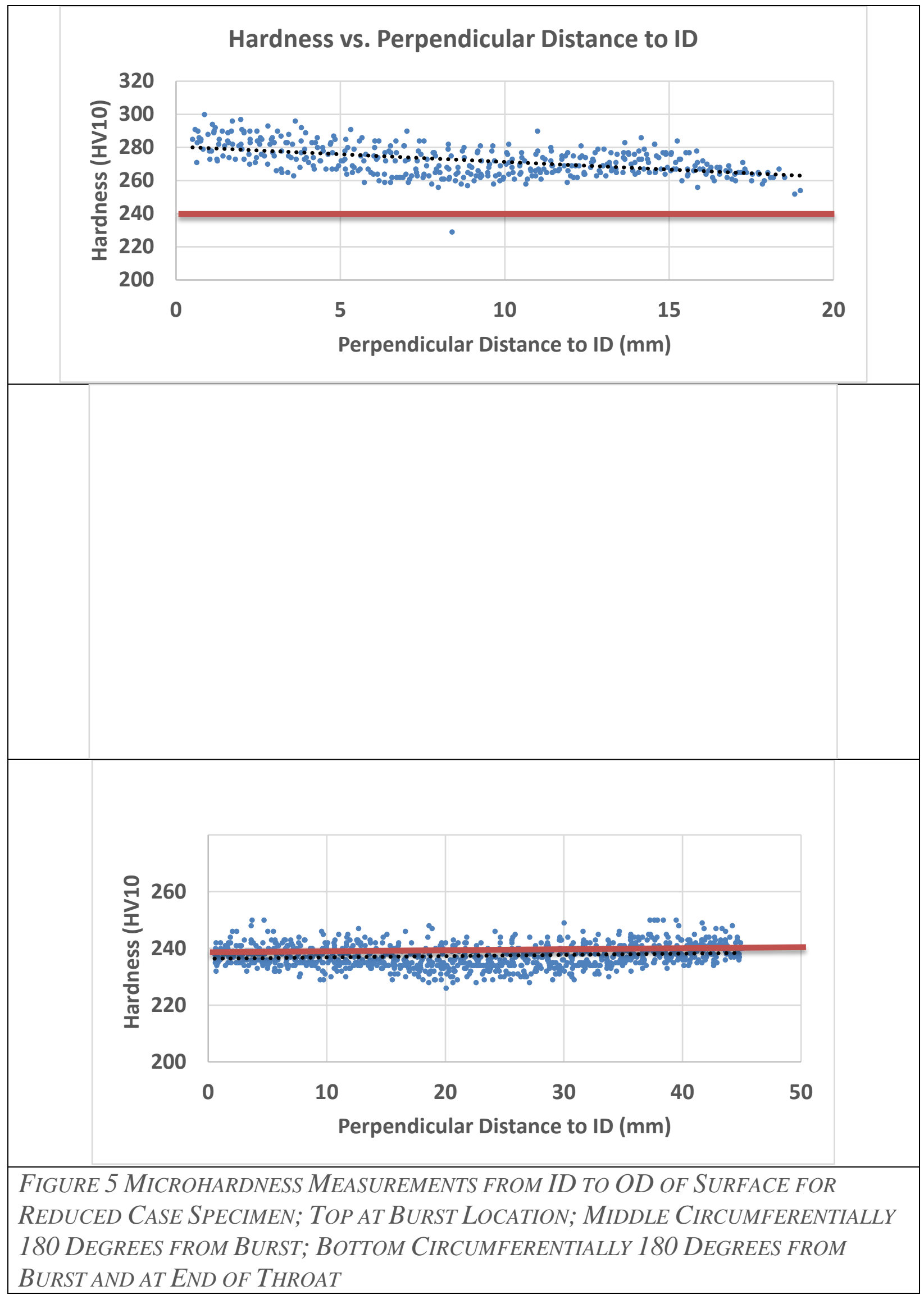




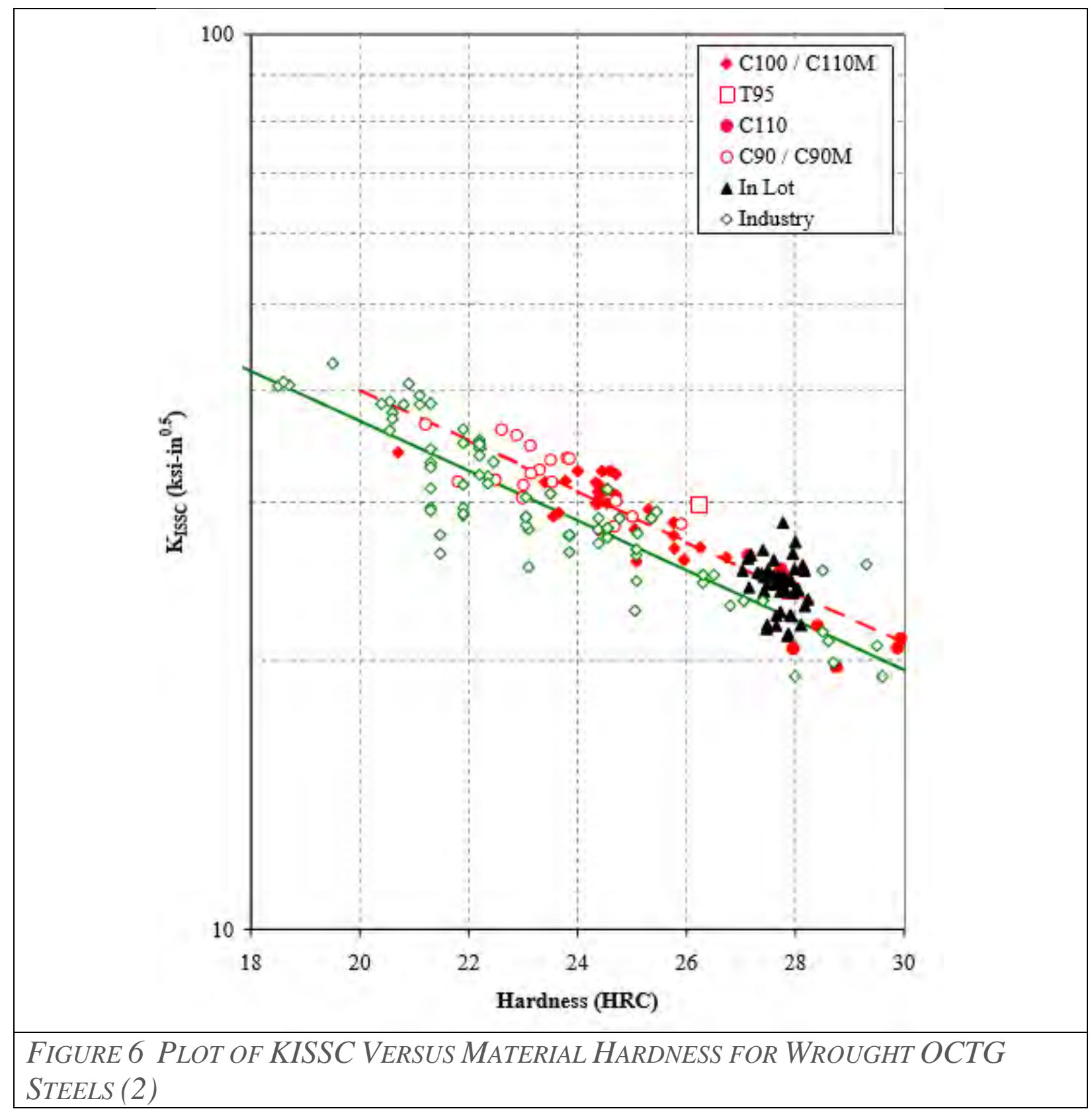

\subsection{Sulfide Stress Cracking Examinations and Results}

Omni Metals Laboratory (Ann Arbor, MI) was contracted to determine the sulfide cracking behavior (SSC) of the forged F22 material. Specifically, Omni was provided the remnants of the two throat regions Exova had used in their metallurgical assessment studies. Omni obtained at least 30 double cantilevered beam (DCBs; see Figure 7) specimens from the throat region remnants and tested them per NACE TM0177-2016 Method D. Omni got the largest range in hardness values possible from the pieces provided to them. Lastly, Omni conducted two sulfide stress cracking evaluations, one in the standard test environment $\left(100 \% \mathrm{H}_{2} \mathrm{~S}\right.$, initial $\mathrm{pH}$ of $\left.2.7,75^{\circ} \mathrm{F}\right)$ and the other in a mild environment $\left(7 \% \mathrm{H}_{2} \mathrm{~S}\right.$, initial $\mathrm{pH}$ of $\left.4.0,75^{\circ} \mathrm{F}\right)$. 


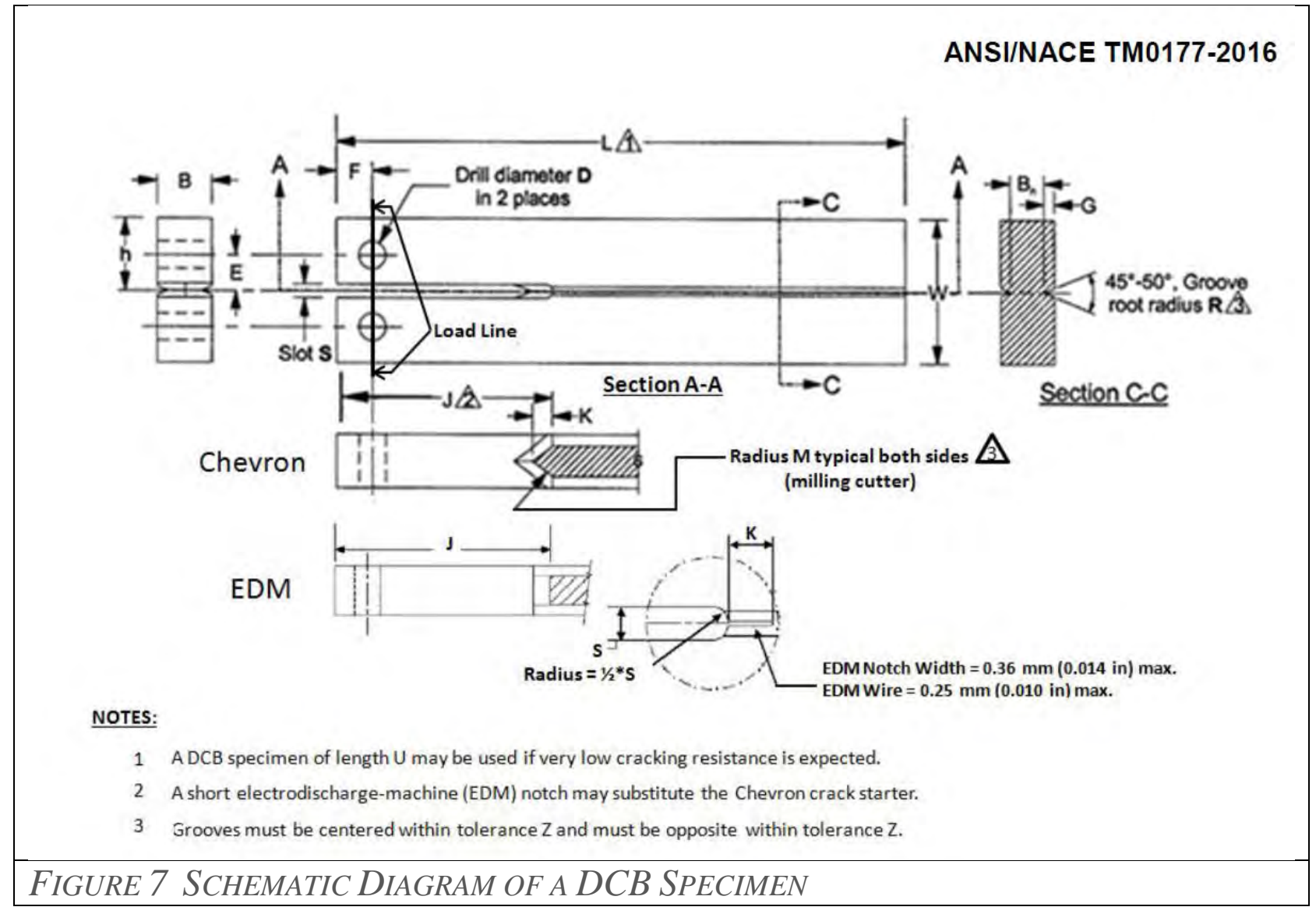

Since chemical composition was consistent for the two burst test pieces, obtaining a plot of hardness versus SSC performance did not require the restriction of specimen extraction from either specific burst piece. Rather, specific knowledge of specimen hardness was needed prior to testing. Omni Metals provided a cutting diagram and hardness measurements. The cutting diagram is included in Appendix B; the hardness measurements are provided in Table 1. As noted earlier, NACE TM0177-2016 Method D procedures for testing included pre-test and post-test requirements. 
TABLE 1 HARDNESS (HRC) FOR DCB SPECIMENS USED IN TEST PROGRAM

\begin{tabular}{|c|c|c|c|c|c|}
\hline & Specimen \# & HRC & & Specimen \# & HRC \\
\hline \multirow{16}{*}{$\begin{array}{l}\text { Specimens } \\
\text { from Ends of } \\
\text { Burst Pieces }\end{array}$} & 2RO-1 & 19.92 & \multirow{16}{*}{$\begin{array}{l}\text { Specimens } \\
\text { from Mid- } \\
\text { Sections of } \\
\text { Burst Pieces }\end{array}$} & B1-ID & 22.1 \\
\hline & 2RO-2 & 19.98 & & B1-OD & 20.57 \\
\hline & $2 \mathrm{RO}-3$ & 19.83 & & B2 & 22.37 \\
\hline & 2RO-4 & 20.07 & & B3 & 20.5 \\
\hline & $2 \mathrm{RI}-1$ & 20.37 & & C1-ID & 23.57 \\
\hline & $2 \mathrm{RI}-2$ & 20.55 & & C1-OD & 21.9 \\
\hline & $2 \mathrm{RI}-3$ & 20.77 & & $\mathrm{C} 2$ & 22.72 \\
\hline & $2 \mathrm{RI}-4$ & 20.55 & & D1 & 22.79 \\
\hline & $1 \mathrm{LI}-1$ & 19.25 & & D2 & 22.58 \\
\hline & $1 \mathrm{LI}-2$ & 19.28 & & D3 & 24.82 \\
\hline & $1 \mathrm{RI}-1$ & 1.928 & & E1-ID & 24.53 \\
\hline & $1 \mathrm{RI}-2$ & 19.27 & & E1-OD & 22.47 \\
\hline & 1LO-1 & 19.32 & & E2-ID & 23.67 \\
\hline & $1 \mathrm{LO}-2$ & 19.67 & & E2-OD & 22.78 \\
\hline & 1RO-1 & 19.85 & & E3-ID & 24.44 \\
\hline & $1 \mathrm{RO}-2$ & 19.5 & & E3-OD & 22.79 \\
\hline
\end{tabular}

The results of the SSC evaluation of F22 material from the burst test pieces are shown in Table 2 for the standard environment and Table 3 for the mild environment.

\section{TABLE 2 SCC RESULTS FOR DCB SPECIMENS TESTED IN THE STANDARD ENVIRONMENT}

\begin{tabular}{|c|c|c|}
\hline $\begin{array}{c}\text { Specimen } \\
\#\end{array}$ & HRC & KISSC (ksivin) \\
\hline 1L-I-1 & 19.25 & 22.0 \\
\hline 1L-I-2 & 19.28 & 21.5 \\
\hline 1R-O-2 & 19.50 & 24.4 \\
\hline 2 R-O-3 & 19.83 & 21.9 \\
\hline 2R-O-2 & 19.98 & 24.3 \\
\hline 2R-I-1 & 20.37 & 22.1 \\
\hline 2R-1-2 & 20.55 & 20.4 \\
\hline B1-OD & 20.57 & 19.6 \\
\hline C1-OD & 21.90 & 21.5 \\
\hline B2 & 22.37 & Non-Planar \\
\hline D2 & 22.58 & Side-Arm Break \\
\hline E2-OD & 22.78 & Side-Arm Break \\
\hline E3-OD & 22.79 & Side-Arm Break \\
\hline E2-ID & 23.67 & Side-Arm Break \\
\hline E1-ID & 24.53 & Too Short \\
\hline
\end{tabular}


Per the NACE TM0177-2016 test method, there are requirements regarding how much a corrosion crack must grow to be a valid test result. There are also post-test requirements regarding the visual appearance of the crack. If a numerical KISSC value is not reported, the test is invalid.

The best way to discuss these results is in a relative sense. A plot of the data is illustrative. Figure 8 is a plot of valid test results and the corresponding data shown in Tables 2 and 3. It also includes data for sour grades of oil country tubulars (OCTG) taken from Figure 6.

The heavy, solid green line in Figure 8 is the same as the line labelled "industry" in Figure 6. This heavy, solid line shows a lower bound in SSC performance for sour grades of OCTG. As noted in the legend of Figure 8, environmental conditions were the same for the OCTG materials and for the F22 materials in the standard test solution. Also plotted in Figure 8 are the data for the F22 forging material tested under mild conditions. Two observations from Figure 8 are quite apparent:

1. The SSC performance of F22 material is greatly improved if the standard environment (i.e., $100 \% \mathrm{H}_{2} \mathrm{~S}$ with initial $\mathrm{pH}$ of 2.7) is substituted with the mild environment (i.e., $7 \% \mathrm{H}_{2} \mathrm{~S}$ with initial $\mathrm{pH}$ of 4.0).

2. The forged F22 material performed poorly (i.e., lower KISSC values- range of 20-25 ksi $\sqrt{ }$ in) in the standard environment compared to the OCTG materials (OCTG standard NACE minimum range is 3340 ksi $\sqrt{ }$ in). The forged F22 and wrought OCTG materials had the same general microstructure (i.e., quenched and tempered martensite) and were tested at some of the same hardnesses (i.e., HRc values > 22.0). 
TABLE 3 SCC RESULTS FOR DCB SPECIMENS TESTED IN THE MILD ENVIRONMENT

\begin{tabular}{|c|c|c|}
\hline $\begin{array}{c}\text { Specimen } \\
\#\end{array}$ & HRC & KISSC (ksivin) \\
\hline 1R-I-2 & 19.27 & 50.8 \\
\hline 1L-O-1 & 19.32 & 52.1 \\
\hline 1L-O-2 & 19.67 & Edge Cracks \\
\hline 2R-O-1 & 19.92 & 53.8 \\
\hline 2R-O-4 & 20.07 & 54.4 \\
\hline B3 & 20.50 & No Crack \\
\hline 2R-I-4 & 20.55 & 45.9 \\
\hline 2R-I-3 & 20.77 & Edge Cracks \\
\hline B1-ID & 22.10 & Non-Planar \\
\hline E1-OD & 22.47 & 38.7 \\
\hline C2 & 22.72 & Non-Planar \\
\hline D1 & 22.79 & Non-Planar \\
\hline C1-ID & 23.57 & 41.0 \\
\hline E3-ID & 24.44 & 42.3 \\
\hline D3 & 24.82 & Edge Cracks \\
\hline
\end{tabular}

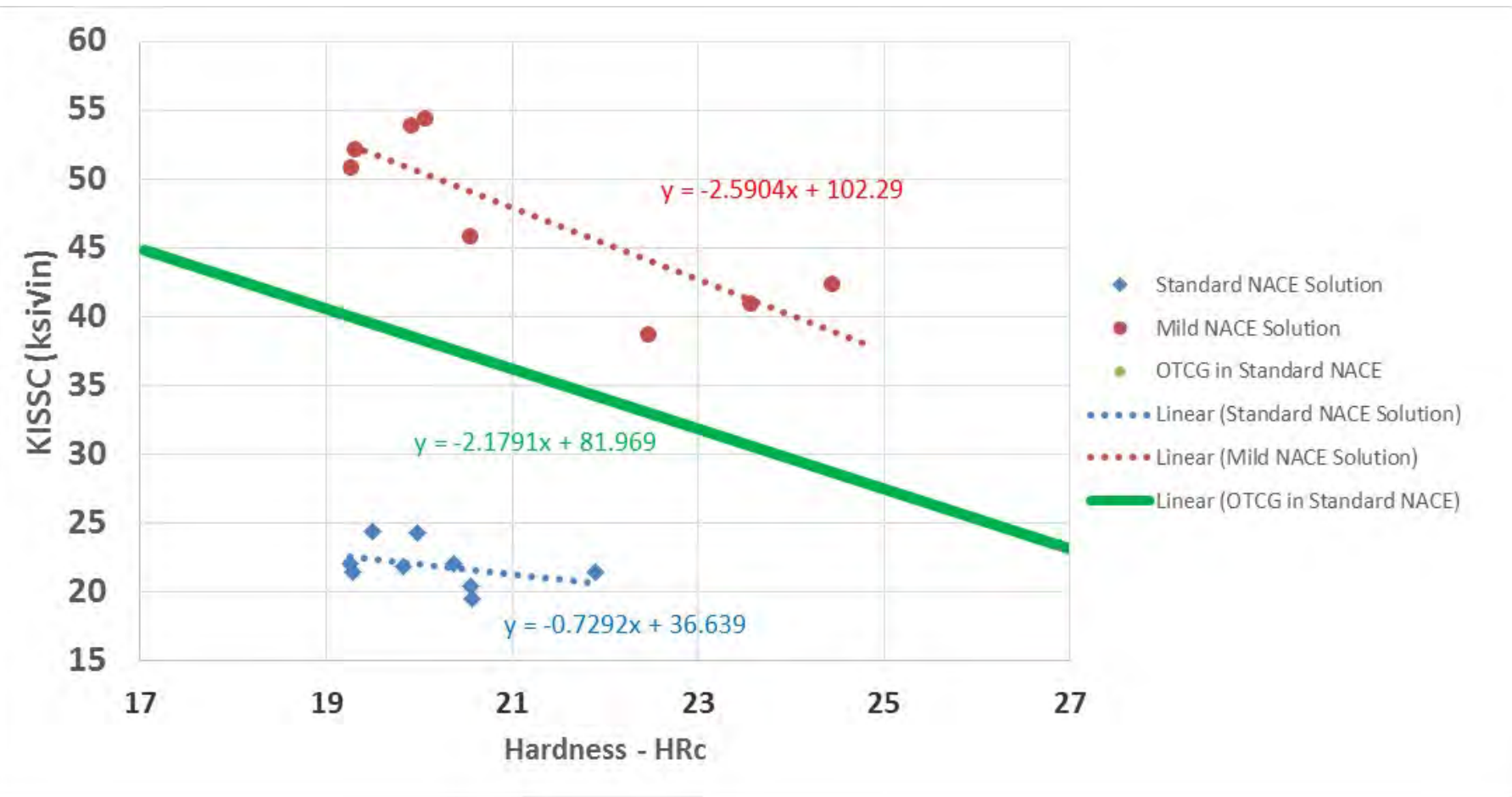

FiguRE 8 Plot of NACE METHOD D RESUltS For F22 Forging MATERIAL AND COMPARED to WROUGHT OCTG STEEL

The first of these observations is not surprising. One would expect a material to have better cracking resistance in less severe conditions. The second observation requires a little more explanation. 
F22 is a forging steel and is not intended for exposure in sour fluid production. In water service with sour conditions, F22 is weld overlaid (clad) for corrosion protection. The steels used for casing and tubing in sour wells are generally Cr-Mo steels like 4130. For this F22, the mechanical properties are:

- Yield Strength (YS): 92.2 ksi,

- Ultimate Tensile Strength (UTS) 111 ksi,

- Elongation: 24\%,

- Reduction of Area (RA): 74.3\%, and

- Hardness 22.0 HRc.

These mechanical properties are comparable to the mechanical properties of OCTG sour grade material C90. The chemistries of the F22 and a typical C90 ae shown in Table 4.

TABLE 4 Comparison of Compositions of the F22 Versus A TyPiCAL C90

\begin{tabular}{|c|c|c|c|c|c|c|c|c|c|}
\hline Material & C & Mn & P & S & Si & Cr & Mo & Ni & Cu \\
\hline F22 & 0.15 & 0.58 & 0.014 & 0.008 & 0.26 & 2.42 & 1.07 & 0.42 & 0.16 \\
\hline $\begin{array}{c}\text { Typical } \\
\text { C90 }\end{array}$ & 0.30 & 0.42 & 0.005 & 0.003 & 0.24 & 1.00 & 0.80 & 0.04 & 0.03 \\
\hline
\end{tabular}

Containing less carbon than a typical C90, the F22 is processed at a lower tempering temperature. The F22 also has higher amounts of Cr, S, and Ni. Since OCTG chemistries are optimized for enhanced SSC resistance, chemistry and processing variations for the F22 result in poorer SSC resistance in the same environment and under the same loading conditions. 
The material property evaluations in this study lead to the following conclusions:

1. Microstructure analysis showed that grain size average results varied between 6 and 7 . Microstructure was observed as tempered martensite, and the "At Burst" locations showed elongated grain structures.

2. Hardness tests revealed that strain hardening caused higher hardness values at the burst and 180 degrees from burst locations (26.5 -27.5 HRc at burst location and 24.3 to $24.9 \mathrm{HRc}$ at $180^{\circ}$ to burst location versus approximately $22.0 \mathrm{HRc}$ pretest).

3. Electron Microscope examination found no evidence of machining or material defects. Dimple structure was revealed at $400 \mathrm{X}$ and $1500 \mathrm{X}$ magnifications.

4. At the same hardness values, the F22 forging material is more susceptible to SSC than sour grades of OCTG in the standard NACE test environment (KISSC-mild environment 39-52 ksi $\sqrt{ }$ in versus 19.6 to 24.4 ksi $\sqrt{ }$ in standard test environment).

5. At the same hardness values, the F22 forging material in the mild environment is considerably less susceptible to SCC than in the standard test environment.

6. The forging material should not be considered a sour service environment material, even for hardness values less than $22 \mathrm{HRc}$.

7. Any intended exposure of the $\mathrm{F} 22$ forging material to $\mathrm{H}_{2} \mathrm{~S}$ conditions would require further evaluations to determine SSC susceptibility. 
1. RA Lindley, WB Aiken, BP Miglin, "Evaluation of Pressure Rating Methods Recommended by API RP 17TR8, (final report with peer review responses),” July 18, 2017.

2. BE Urband, B Garrison, EP Cernocky, A Tallin, DL Sponseller, “The Qualification of C110 High Strength Sour Service Casing - A Statistical Approach to Evaluating Material Data Across a Single Production Heat Lot, “ SPE 97579, presented at SPE HPHT Sour Well Design Applied Technology Workshop held in The Woodlands, TX; May, 2005. 
Appendix A: Exova Detailed Report on Metallurgical Examinations 
This page intentionally blank 
Texas

USA

77040

Testing. Advising. Assuring.
$\mathrm{T}:+\mathrm{I}(281) 848-0270$

$\mathrm{F}_{i}+1$ (281) 848-0275

E. sales@exova.com

W: www.exova.com

Report Reference No: 602731

Order No: 2456-0628-2016

Date: $7 / 19 / 16$

Issue: 01

Aiken Engineering Company

9720 Cypresswood Dr. \#340

Houston, TX 77070

Attention: Gayle DeHay

\author{
SUBJECT \\ 2 VALVE NeCK PIECES \\ 1 Reduced Case, 1 Base Case
}


Reference No: 602731

Issue: 01

At the request of Aiken Engineering Company, Exova - Houston Laboratory performed a metallurgical examination of two valve neck pieces. The following report details our findings.

Should you have any questions or concerns please contact the undersigned at 281-848-0270 or by e-mail at david.chirichello@exova.com at your convenience.

For and on authority of Exova Inc.,

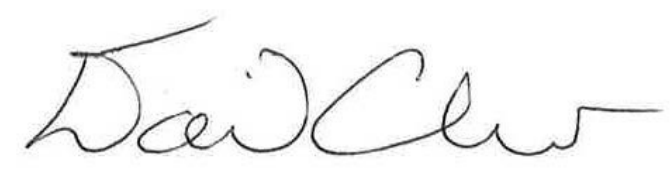

David Chirichello

Engineering Manager - Exova Houston

Unless otherwise directed by the customer, items or samples are retained for $\mathbf{3 0}$ days after completion of the project and then discarded. 
Reference No: 602731

Issue: 01

\section{EXECUTIVE SUMMARY}

- Microstructure analysis showed the grain size average results varied between No.6 and No.7, consistent across both samples. Microstructure was observed as tempered martensite and the At Burst locations showed elongated grain structures.

- Hardness tests revealed strain hardening as a cause for higher hardness values at the Burst and $180^{\circ}$ from Burst locations.

- SEM examination found no evidence of machining or material defects. Dimple rupture was revealed at $400 \mathrm{x}$ and $1500 \mathrm{x}$.

\subsection{INTRODUCTION}

Two fractured valve neck pieces were received by Exova for examination as shown in Figures 1 \& 3. As instructed by the client, microphotos were taken at three different orientations at three locations for each sample.

All samples were analyzed for its microstructure and grain size averages. The results and comments can be found in Tables $1 \& 2$.

For an overview of how the microstructure appears at different orientations, summary composite pictures for all six locations of Samples 1 \& 2 were assembled as shown in Figures 15-20.

Vickers Hardness was performed on all of the Transverse cross-sections. Hardness maps are displayed in Figures 57-62.

Scanning Electron Microscopy was completed to get a closer look at the Fracture Face and the nature of its cause at different locations. The images are shown in Figures 63-76. 
Reference No: 602731

Issue: 01

2.0 AS-RECEIVED DOCUMENTATION

Figures 1 through 4 documents the As Received condition of the valve neck pieces.

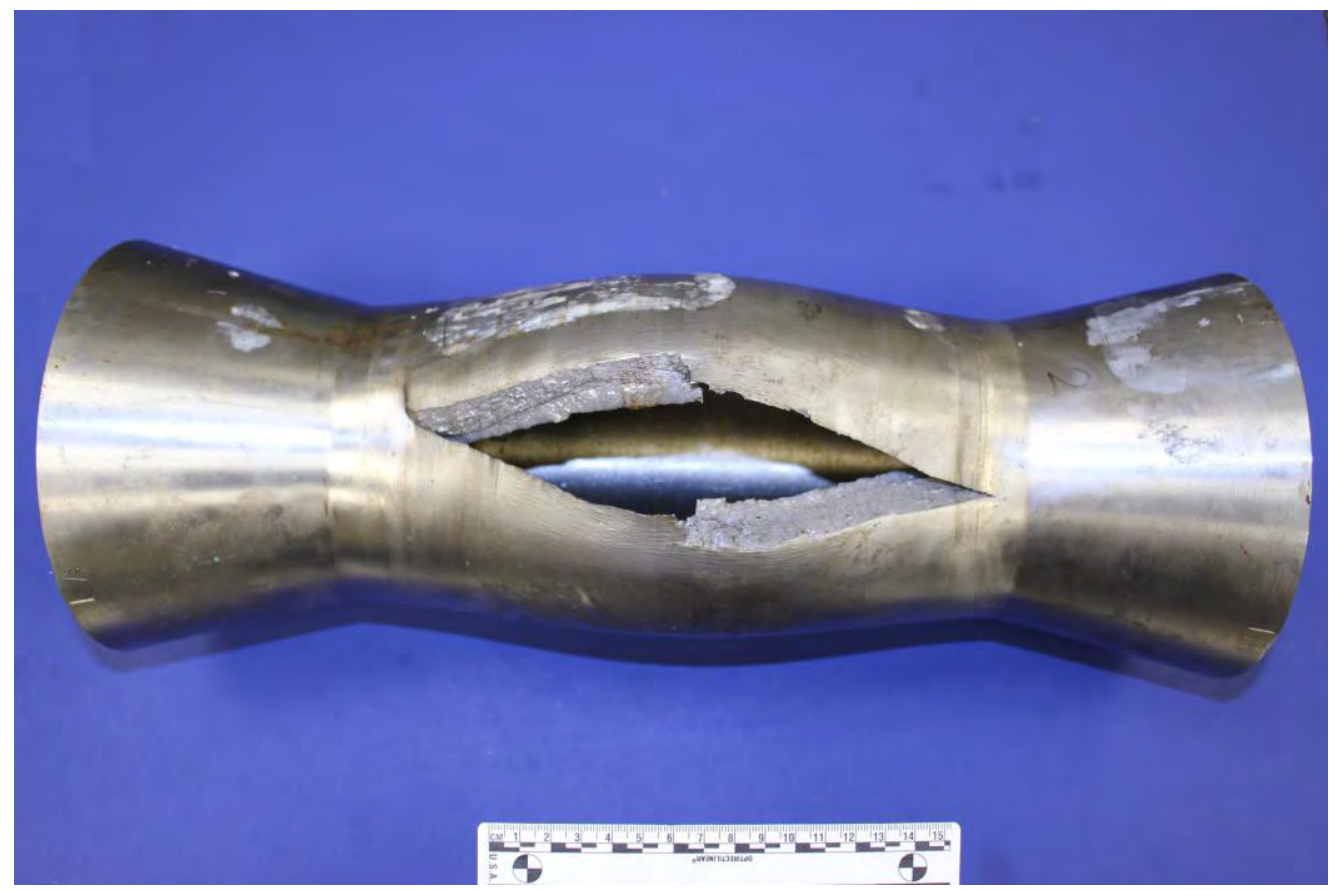

Figure 1: As Received Photograph - Sample 1 - Top View of Reduced Case at Burst (scale in mm)

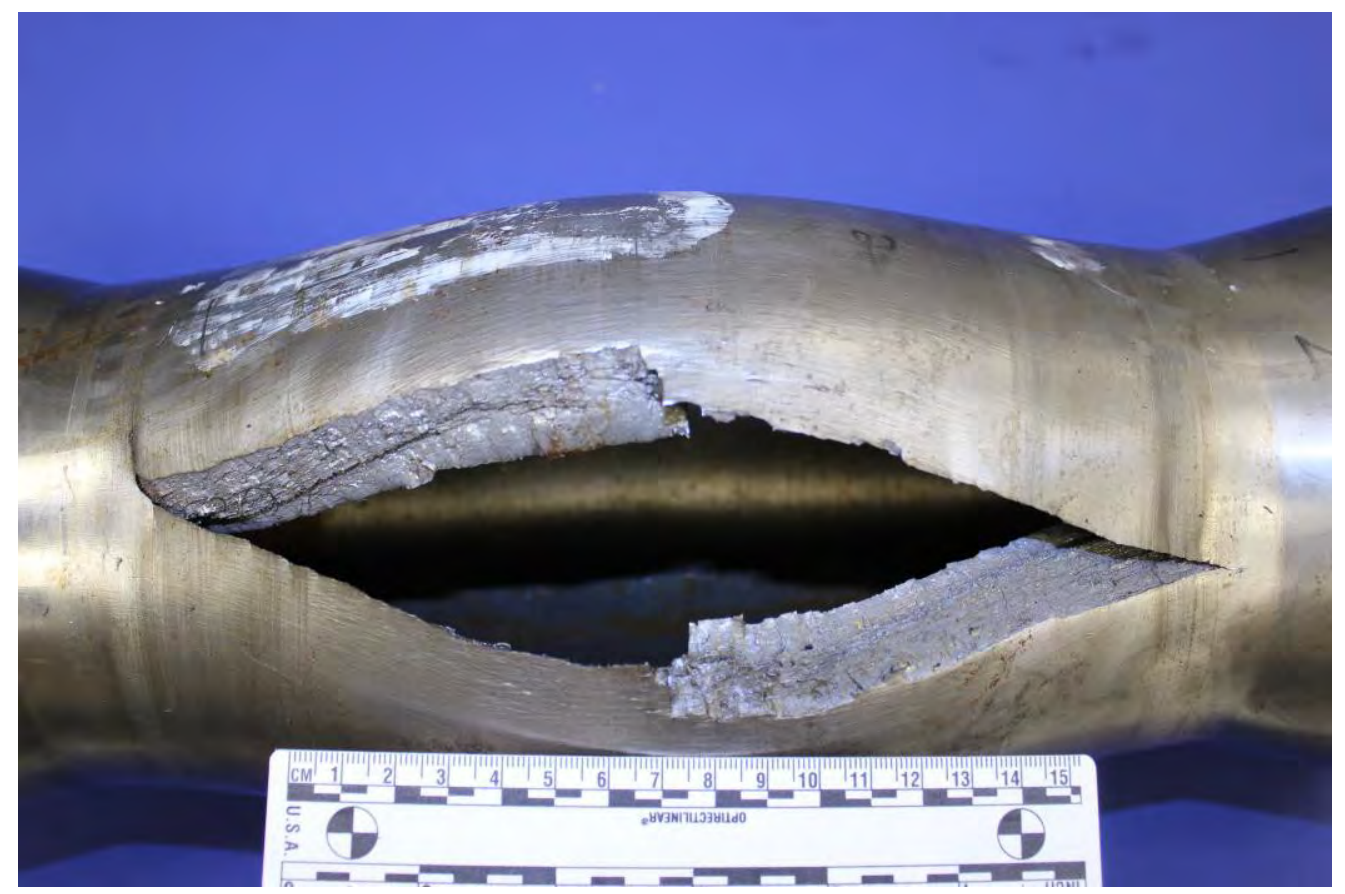

Figure 2: As Received Photograph - Sample 1 - Close-up View at Burst (scale in mm) 
Reference No: 602731

Issue: 01

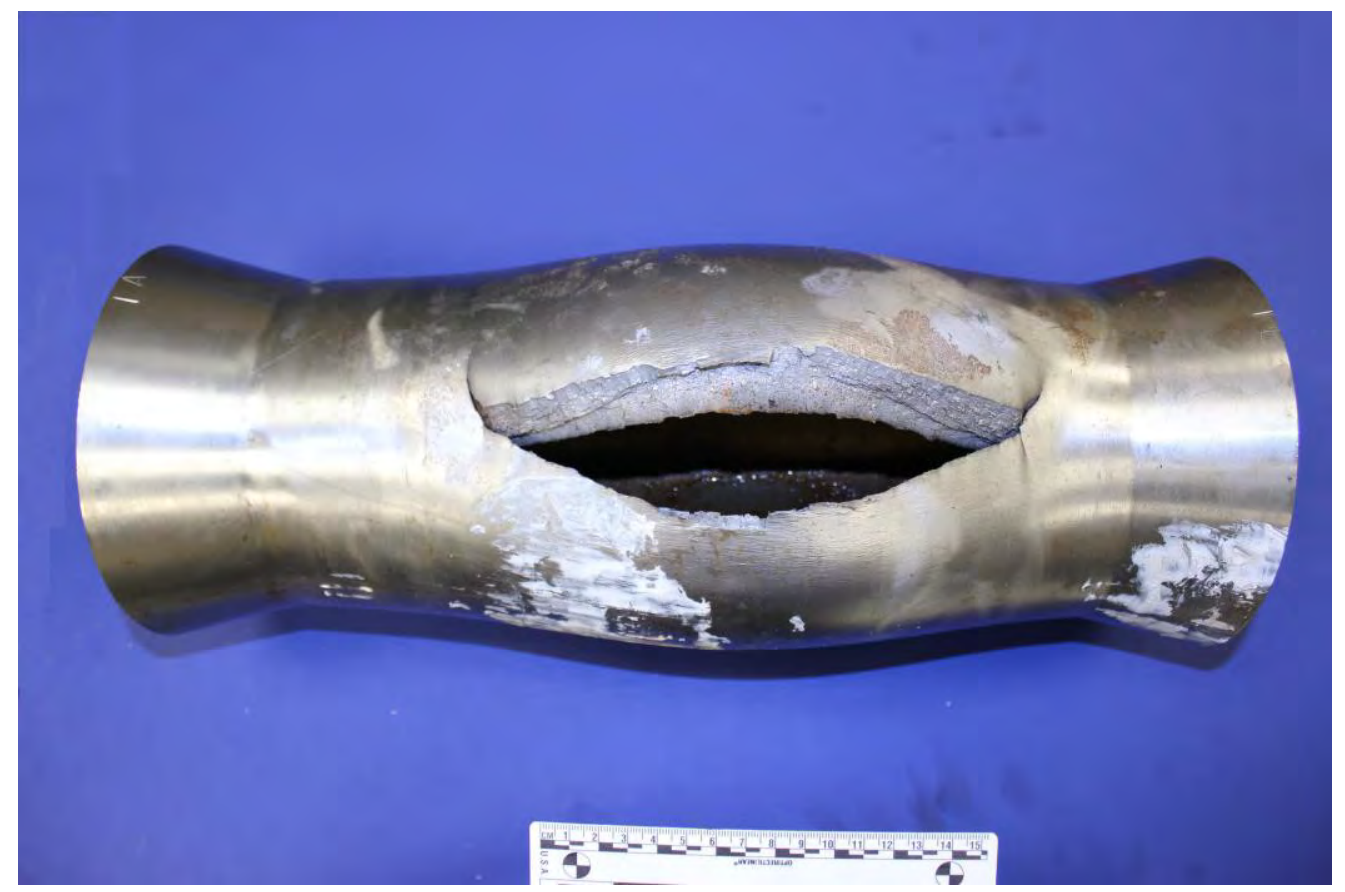

Figure 3: As Received Photograph - Sample 2 - Top View of Base Case at Burst (scale in mm)

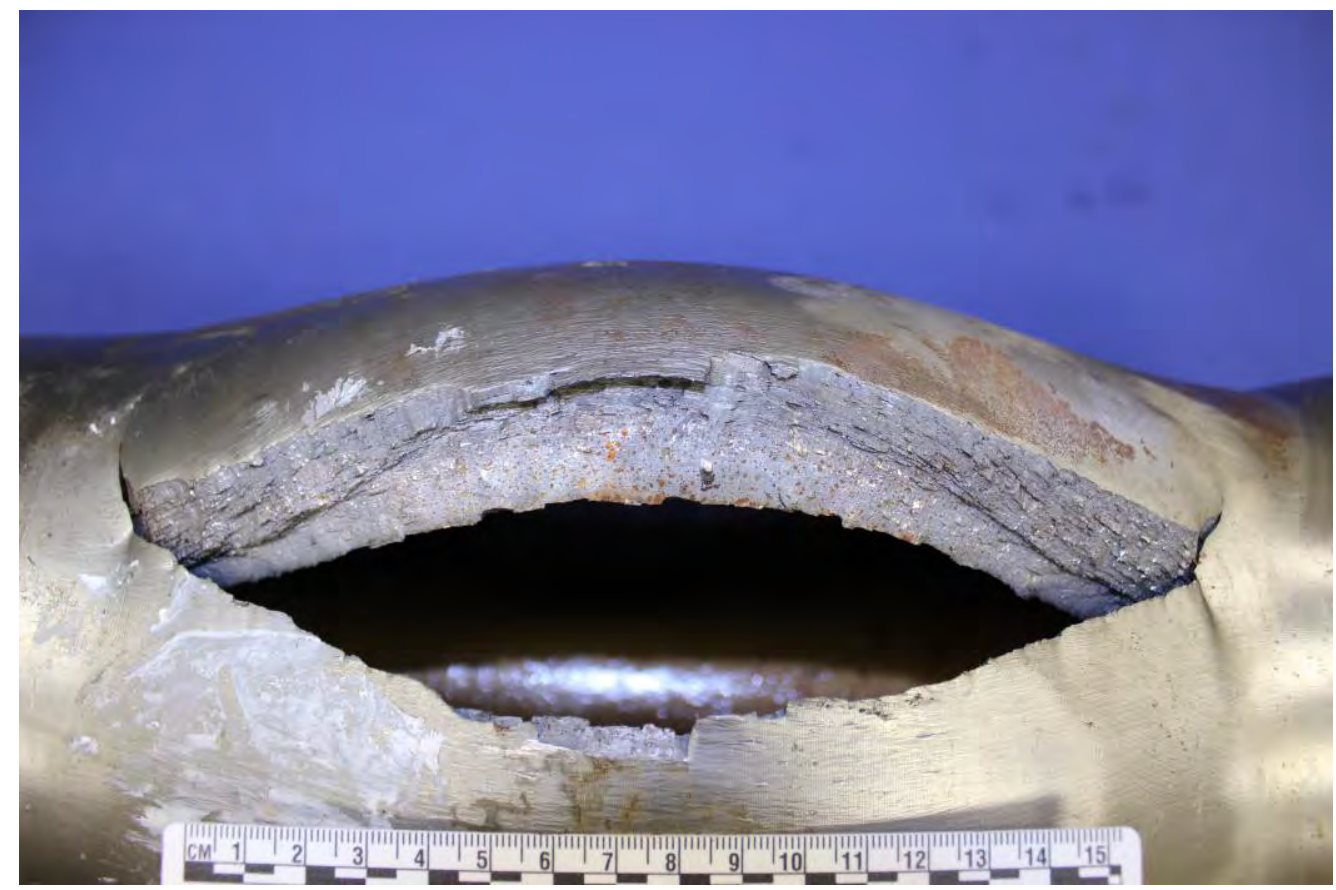

Figure 4: As Received Photograph - Sample 2 - Close-up View at Burst (scale in mm) 
Reference No: 602731

Issue: 01

\subsection{METALLOGRAPHIC EXAMINATION}

A cut plan was made near the center of the burst, $180^{\circ}$ from the burst, and $180^{\circ}$ from the burst at the end in the Layout Photographs presented in Figures 5 and 14. The following orientations were made as macros at each location: Transverse, Longitudinal, and OD Surface.

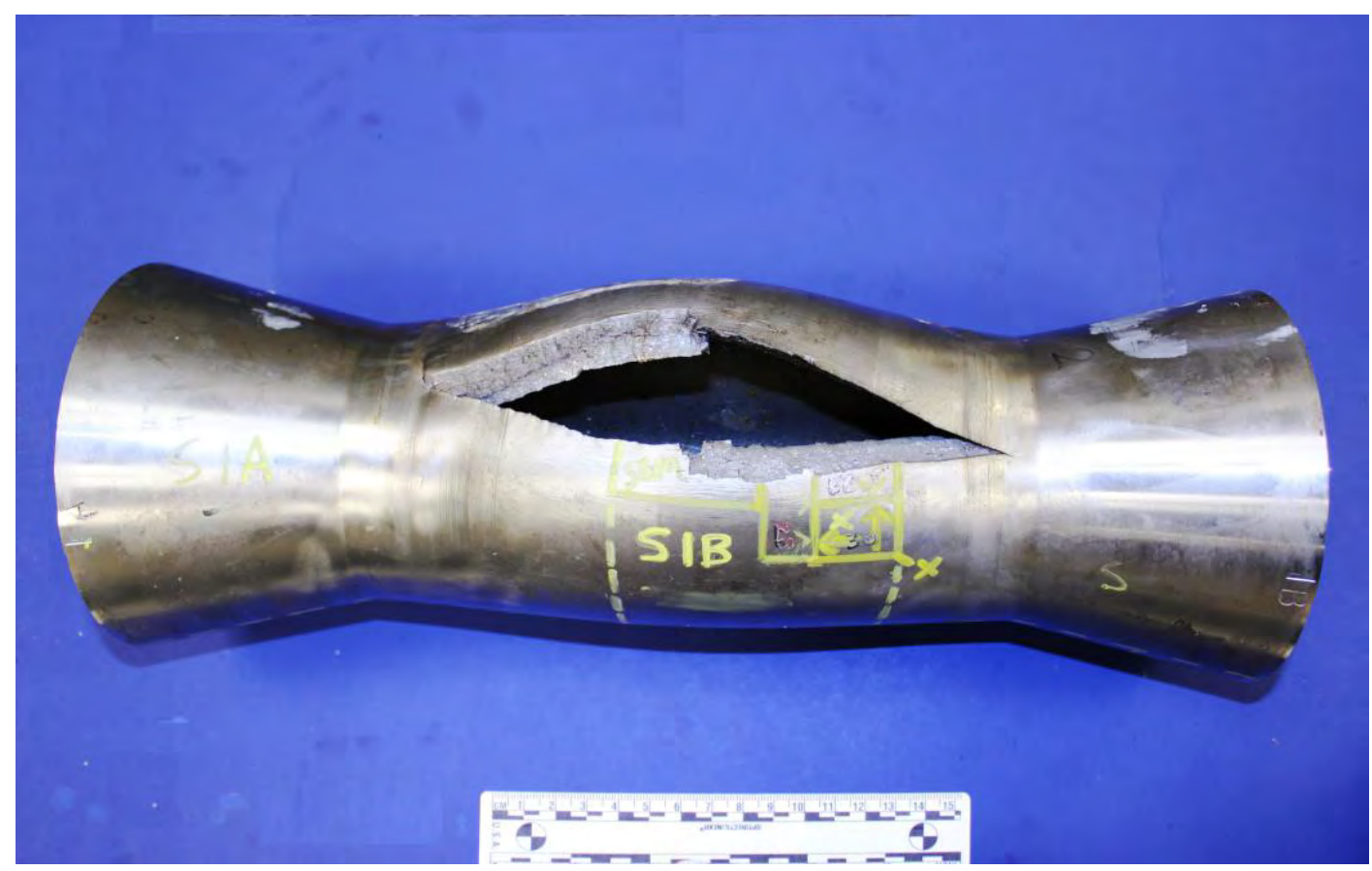

Figure 5: Layout Photograph - Sample 1 - Top View of Reduced Case at Burst (scale in mm) 
Reference No: 602731

Issue: 01

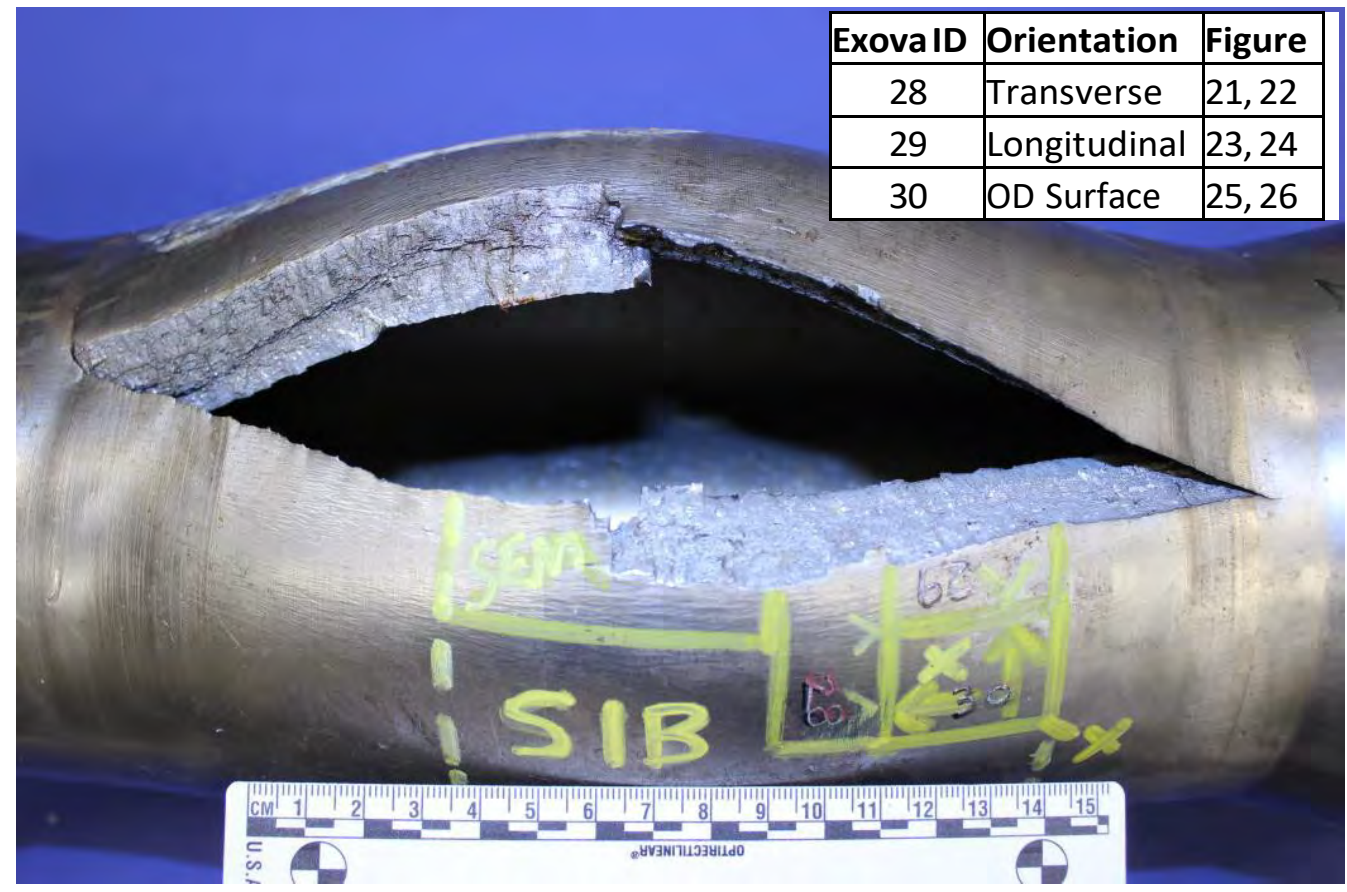

Figure 6: Layout Photograph - Sample 1 - Close-up View at Burst (scale in mm)

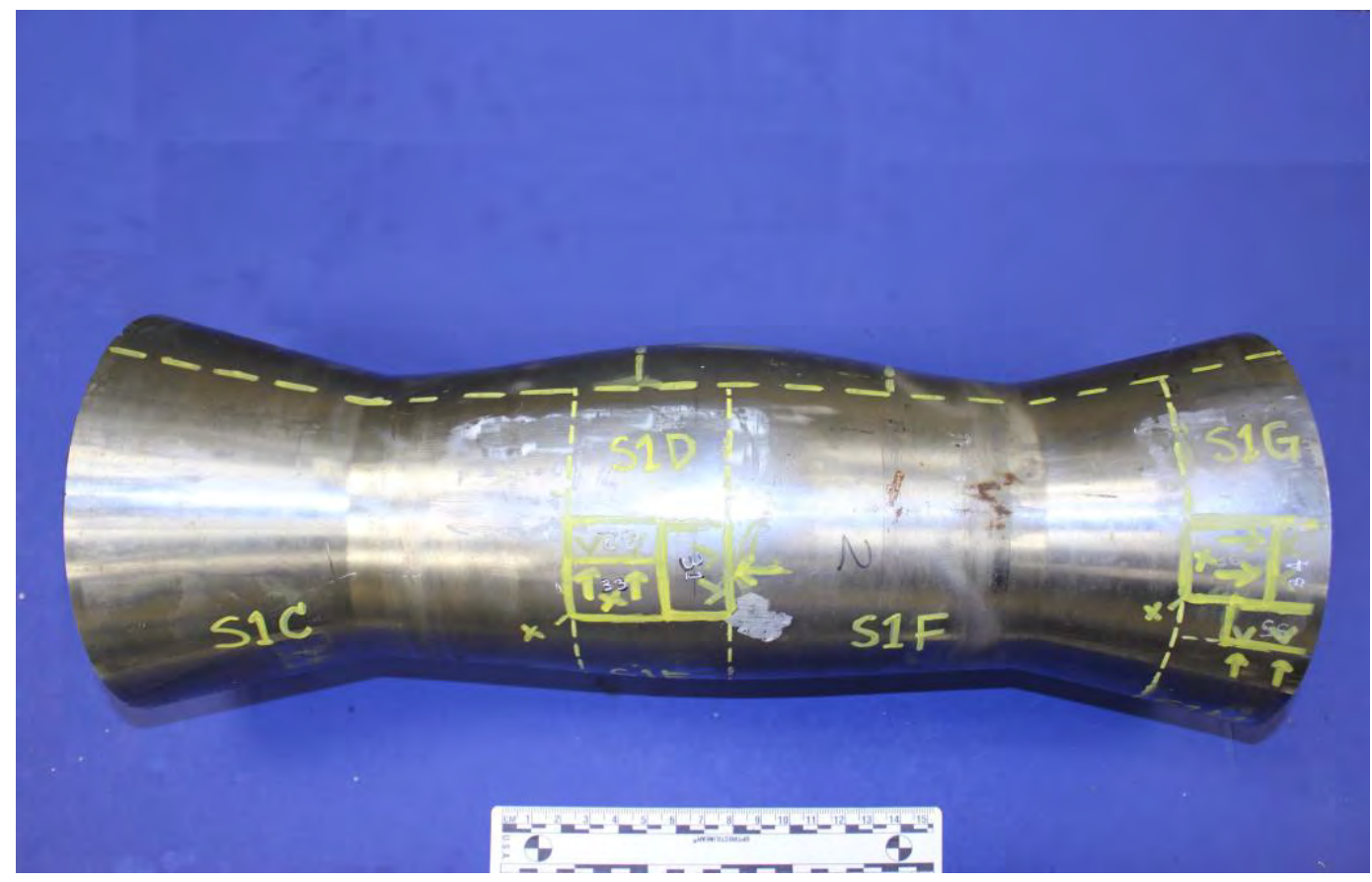

Figure 7: Layout Photograph - Sample 1 - Bottom View of Reduced Case, $180^{\circ}$ from Burst (scale in mm) 
Reference No: 602731

Issue: 01

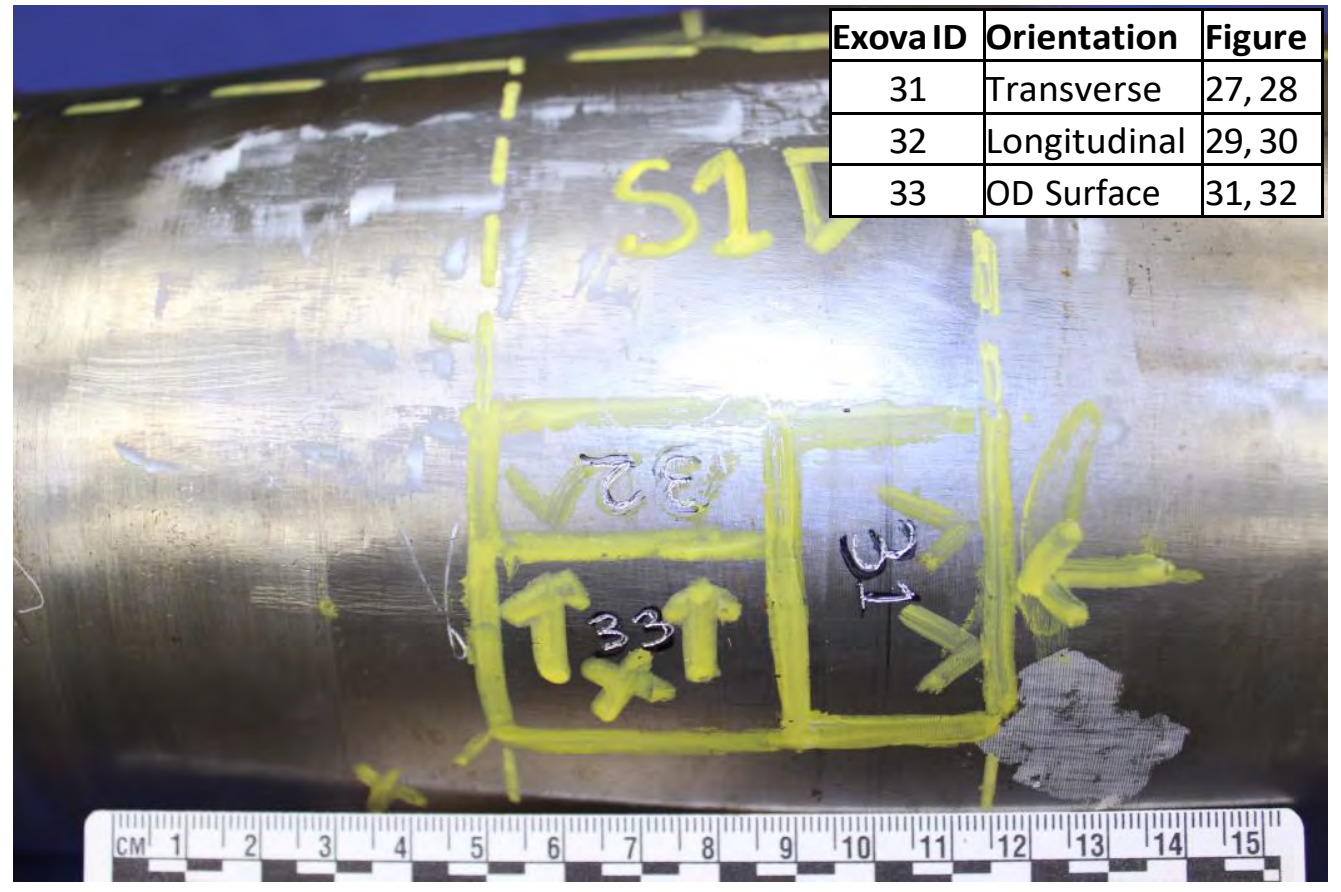

Figure 8: Layout Photograph - Sample 1 - Close-up View at $180^{\circ}$ from Burst (scale in mm)

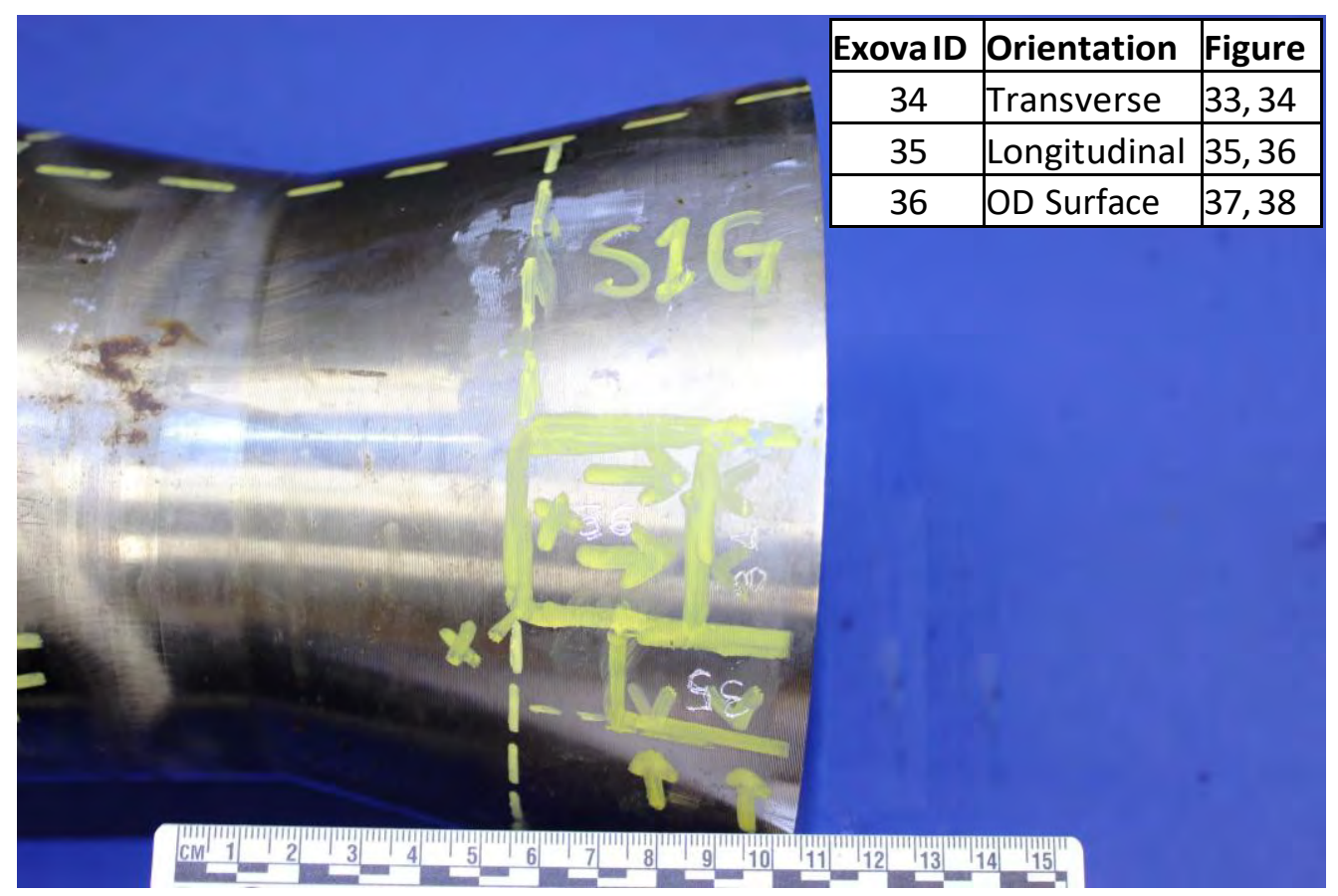

Figure 9: Layout Photograph - Sample 1 - Close-up View at $180^{\circ}$ from Burst at End (scale in mm) 
Reference No: 602731

Issue: 01

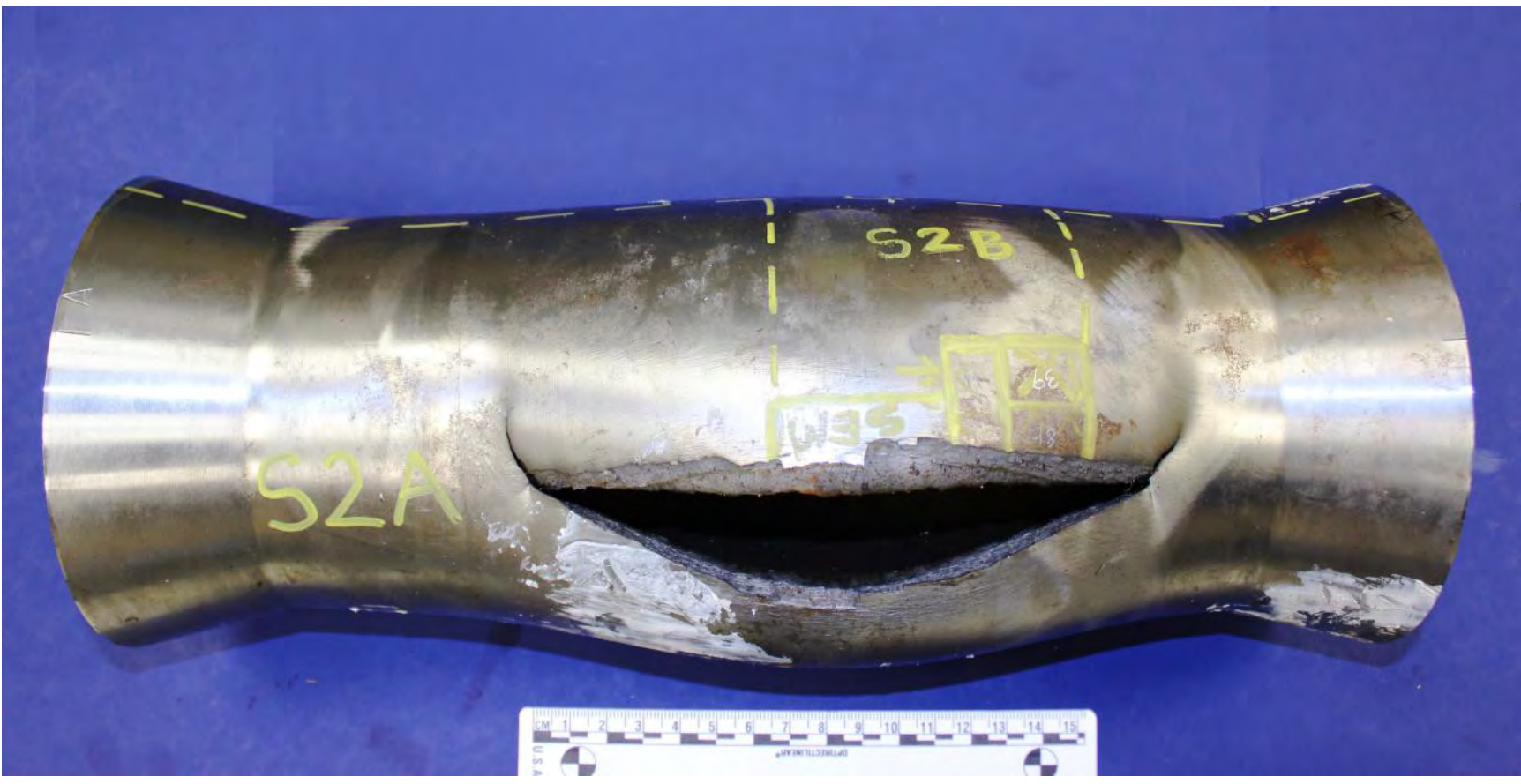

Figure 10: Layout Photograph - Sample 2 - Top View of Base Case at Burst (scale in mm)

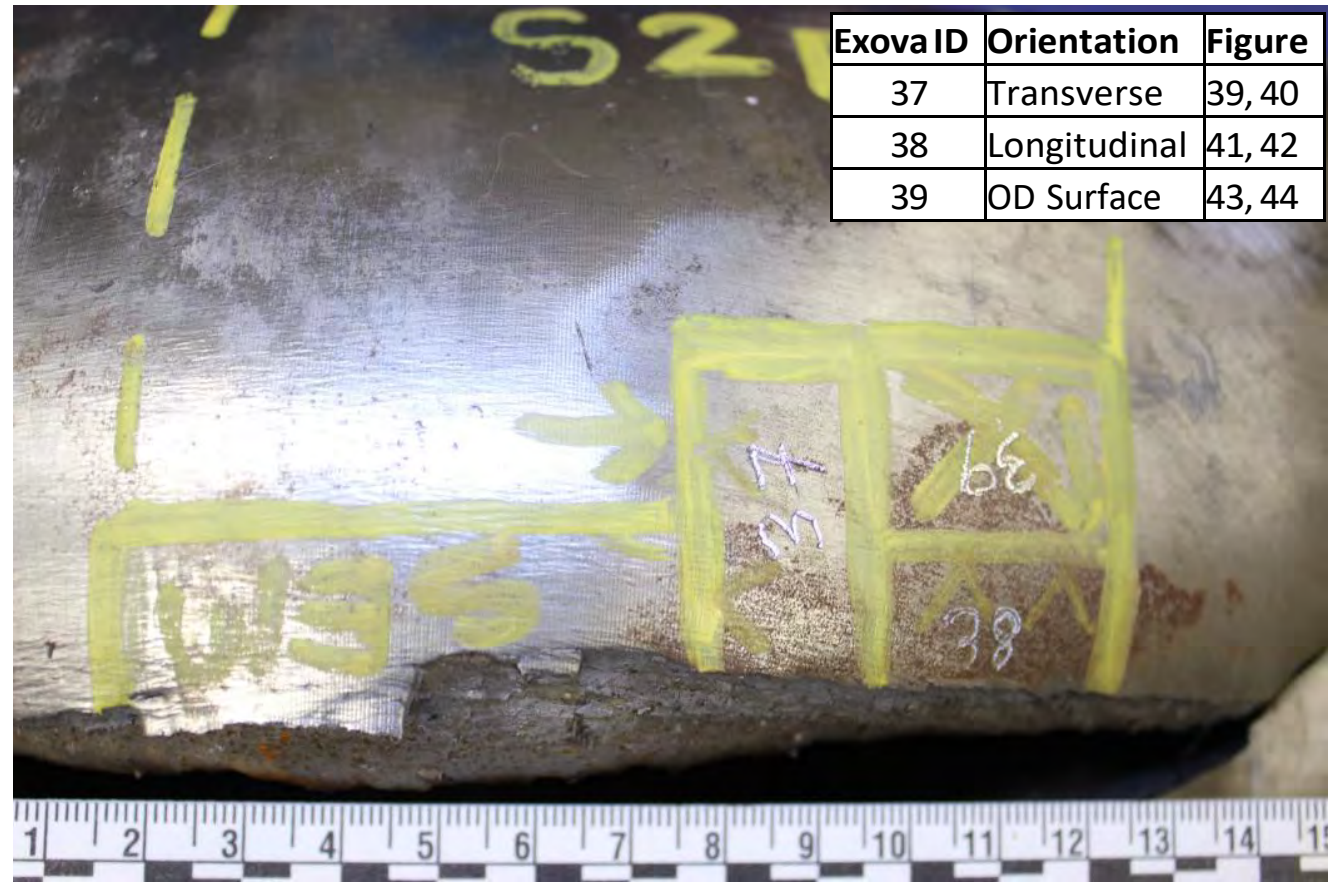

Figure 11: Layout Photograph - Sample 2 - Close-up View at Burst (scale in mm) 
Reference No: 602731

Issue: 01

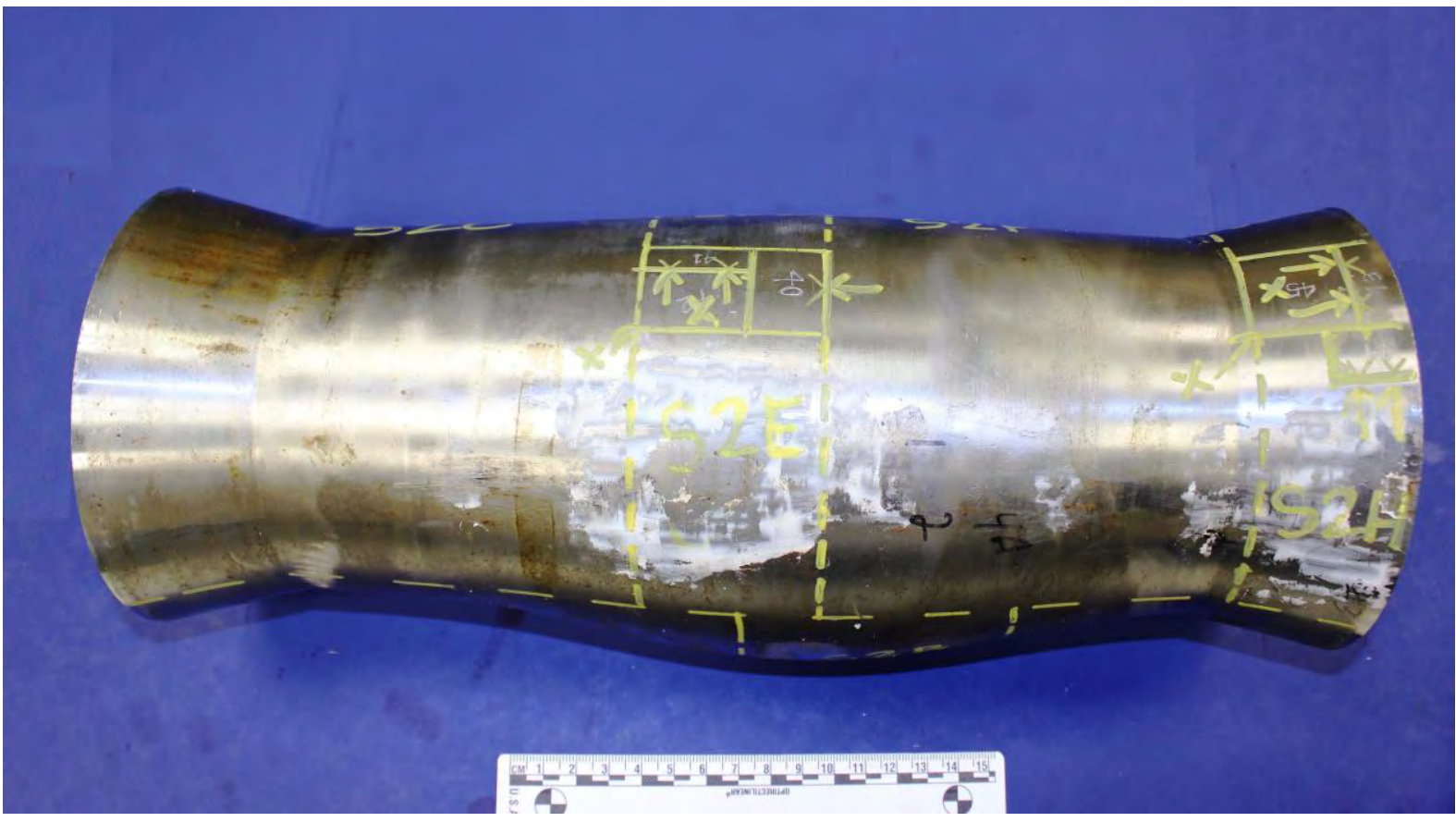

Figure 12: Layout Photograph - Sample 2 - Bottom View of Base Case, $180^{\circ}$ from Burst (scale in mm)

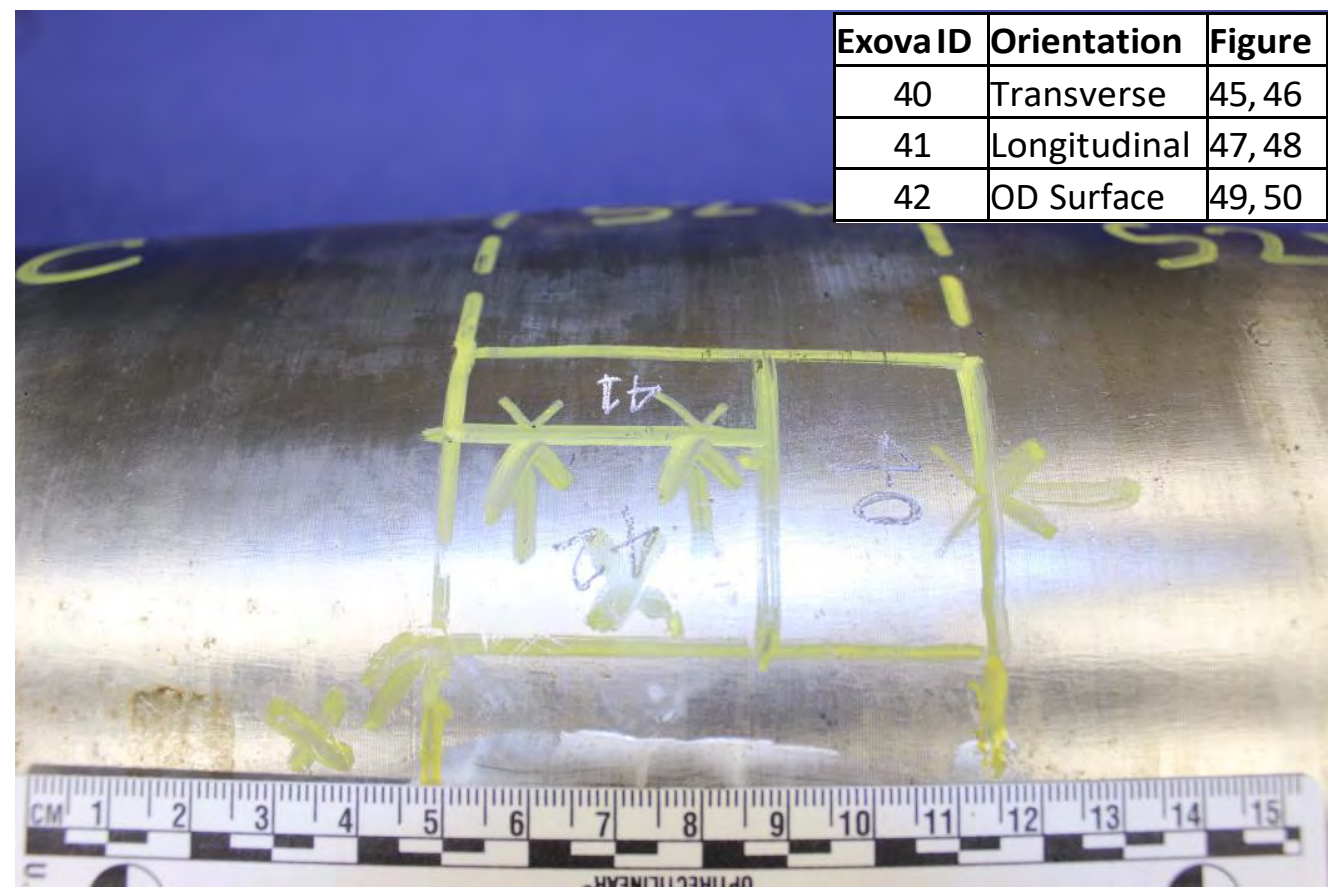

Figure 13: Layout Photograph - Sample 2 - Close-up View at $180^{\circ}$ from Burst (scale in mm) 
Reference No: 602731

Issue: 01

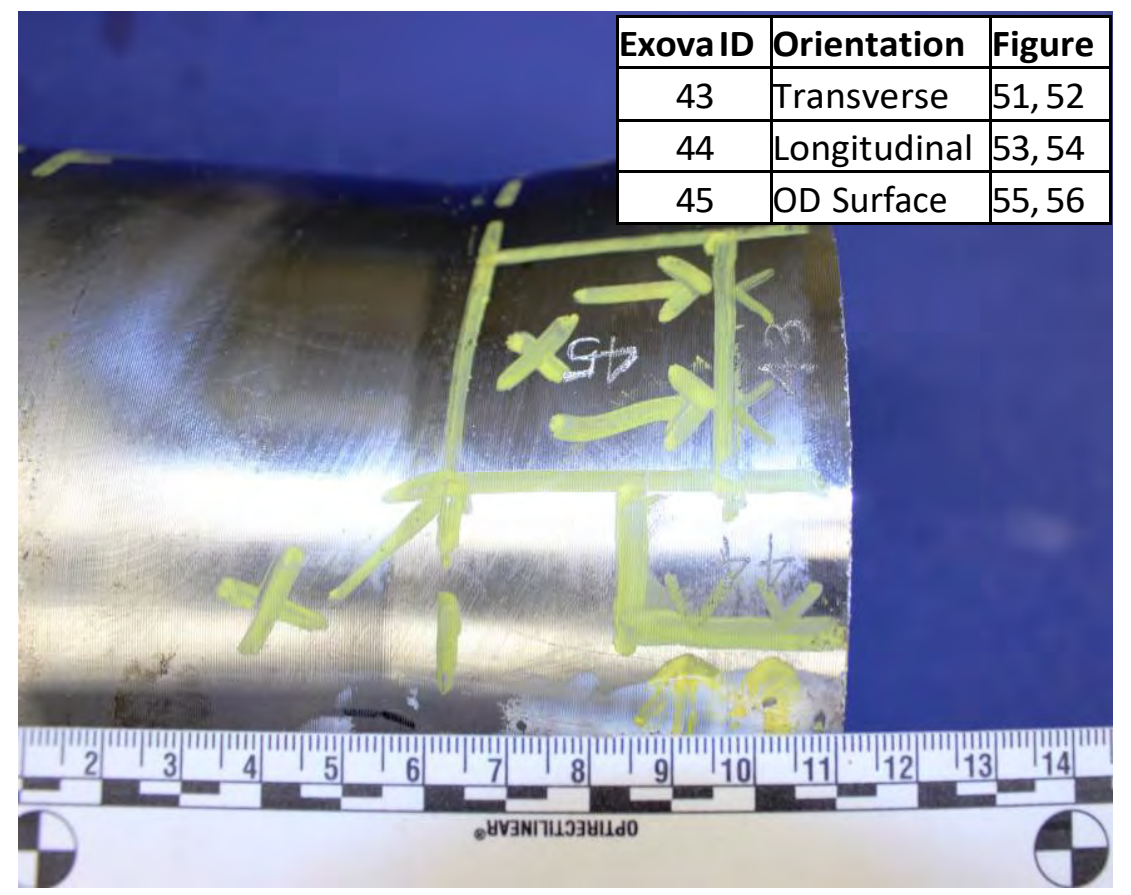

Figure 14: Layout Photograph - Sample 2 - Close-up View at $180^{\circ}$ from Burst at End (scale in mm)

\subsection{GRAIN SIZE EXAMINATION}

The grain size of each sample was analyzed in accordance with ASTM E112. Each sample was etched with $2 \%$ Nital and picric acid. The summary composite photos of the three orthogonal planes at each location of Samples 1 \& 2 are shown in Figures 15-20. The results of grain sizing and comments about the microstructure are found in Tables $1 \& 2$ below. 


\begin{tabular}{|c|c|c|c|c|c|}
\hline \multicolumn{6}{|c|}{ Reduced Case } \\
\hline Exova ID & Location & Orientation & Grain Size Result & Comments & Figures \\
\hline 28 & At Burst & Transverse & No. 7 & Tempered Martensite, elongated grain structures & 21,22 \\
\hline 29 & At Burst & Longitudinal & No. 6 & Tempered Martensite & 23,24 \\
\hline 30 & At Burst & OD Surface & No. 6 & Tempered Martensite & 25,26 \\
\hline 31 & $180^{\circ}$ from Burst & Transverse & No. 6 & Tempered Martensite & 27,28 \\
\hline 32 & $180^{\circ}$ from Burst & Longitudinal & No. 6 & Tempered Martensite & 29,30 \\
\hline 33 & $180^{\circ}$ from Burst & OD Surface & No. 6 & Tempered Martensite & 31,32 \\
\hline 34 & $180^{\circ}$ from Burst At End & Transverse & No. 6 & $\begin{array}{l}\text { Tempered Martensite, noticeably smaller grain structures, } \\
\text { more compact }\end{array}$ & 33,34 \\
\hline 35 & $180^{\circ}$ from Burst At End & Longitudinal & No. 6 & $\begin{array}{l}\text { Tempered Martensite, noticeably smaller grain structures, } \\
\text { more compact }\end{array}$ & 35,36 \\
\hline 36 & $180^{\circ}$ from Burst At End & OD Surface & No. 7 & $\begin{array}{l}\text { Tempered Martensite, noticeably smaller grain structures, } \\
\text { more compact }\end{array}$ & 37,38 \\
\hline
\end{tabular}

Table 1: Grain Size Results and Microstructure Observations for Reduced Case (Sample 1)

\begin{tabular}{|c|c|c|c|c|c|}
\hline \multicolumn{6}{|c|}{ Base Case } \\
\hline Exova ID & Location & Orientation & Grain Size Result & Comments & Figures \\
\hline 37 & At Burst & Transverse & No. 7 & Tempered Martensite, elongated grain structures & 39,40 \\
\hline 38 & At Burst & Longitudinal & No. 7 & Tempered Martensite & 41,42 \\
\hline 39 & At Burst & OD Surface & No. 6 & Tempered Martensite & 43,44 \\
\hline 40 & $180^{\circ}$ from Burst & Transverse & No. 6 & Tempered Martensite & 45,46 \\
\hline 41 & $180^{\circ}$ from Burst & Longitudinal & No. 7 & Tempered Martensite & 47,48 \\
\hline 42 & $180^{\circ}$ from Burst & OD Surface & No. 7 & Tempered Martensite & 49,50 \\
\hline 43 & $180^{\circ}$ from Burst At End & Transverse & No. 7 & $\begin{array}{l}\text { Tempered Martensite, noticeably smaller grain structures, } \\
\text { more compact }\end{array}$ & 51,52 \\
\hline 44 & $180^{\circ}$ from Burst At End & Longitudinal & No. 7 & $\begin{array}{l}\text { Tempered Martensite, noticeably smaller grain structures, } \\
\text { more compact }\end{array}$ & 53,54 \\
\hline 45 & $180^{\circ}$ from Burst At End & OD Surface & No. 7 & $\begin{array}{l}\text { Tempered Martensite, noticeably smaller grain structures, } \\
\text { more compact }\end{array}$ & 55,56 \\
\hline
\end{tabular}

Table 2: Grain Size Results and Microstructure Observations for Base Case (Sample 2) 


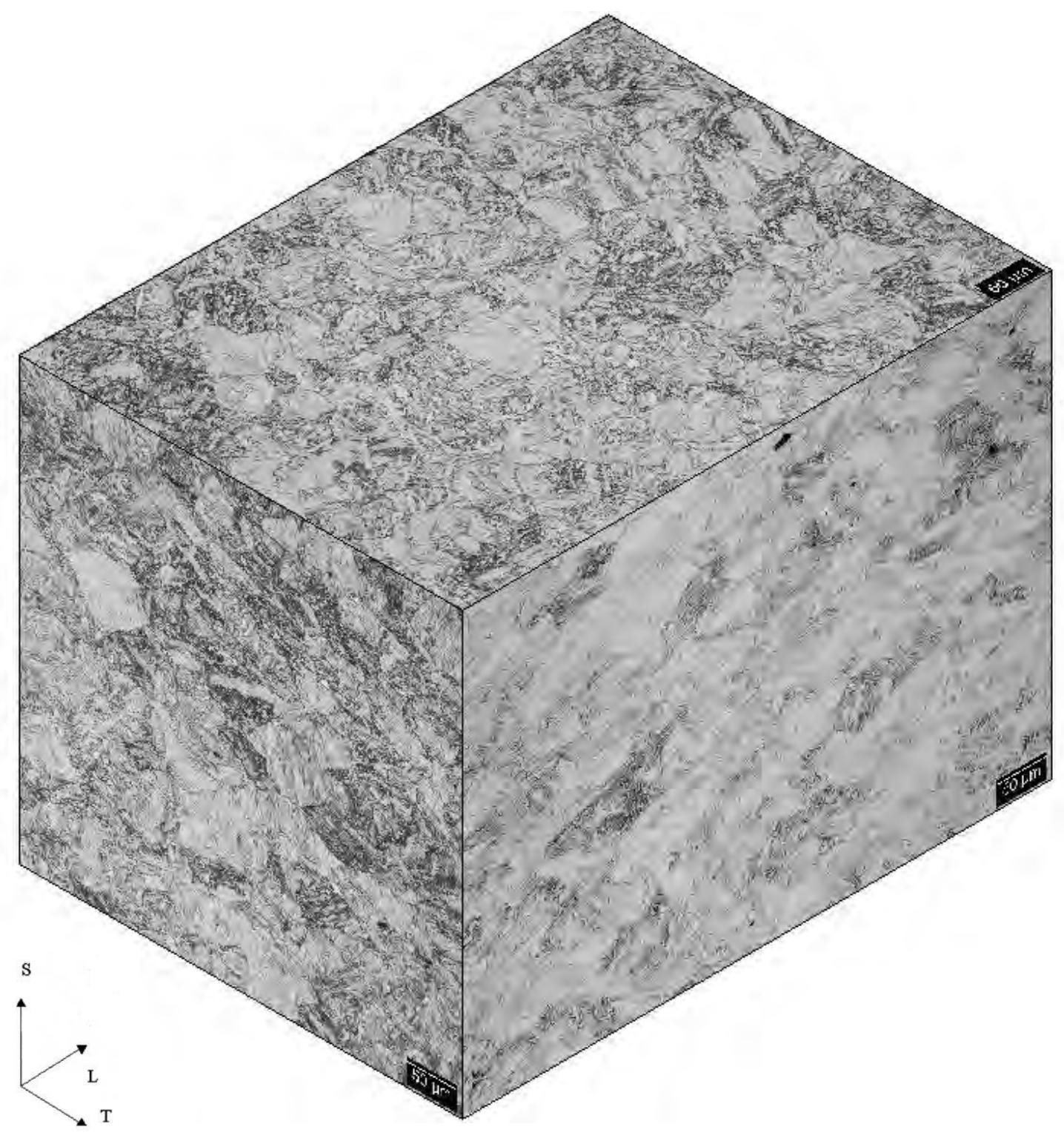

Figure 15: Sample 1 - Summary Composite Photo - At Burst 


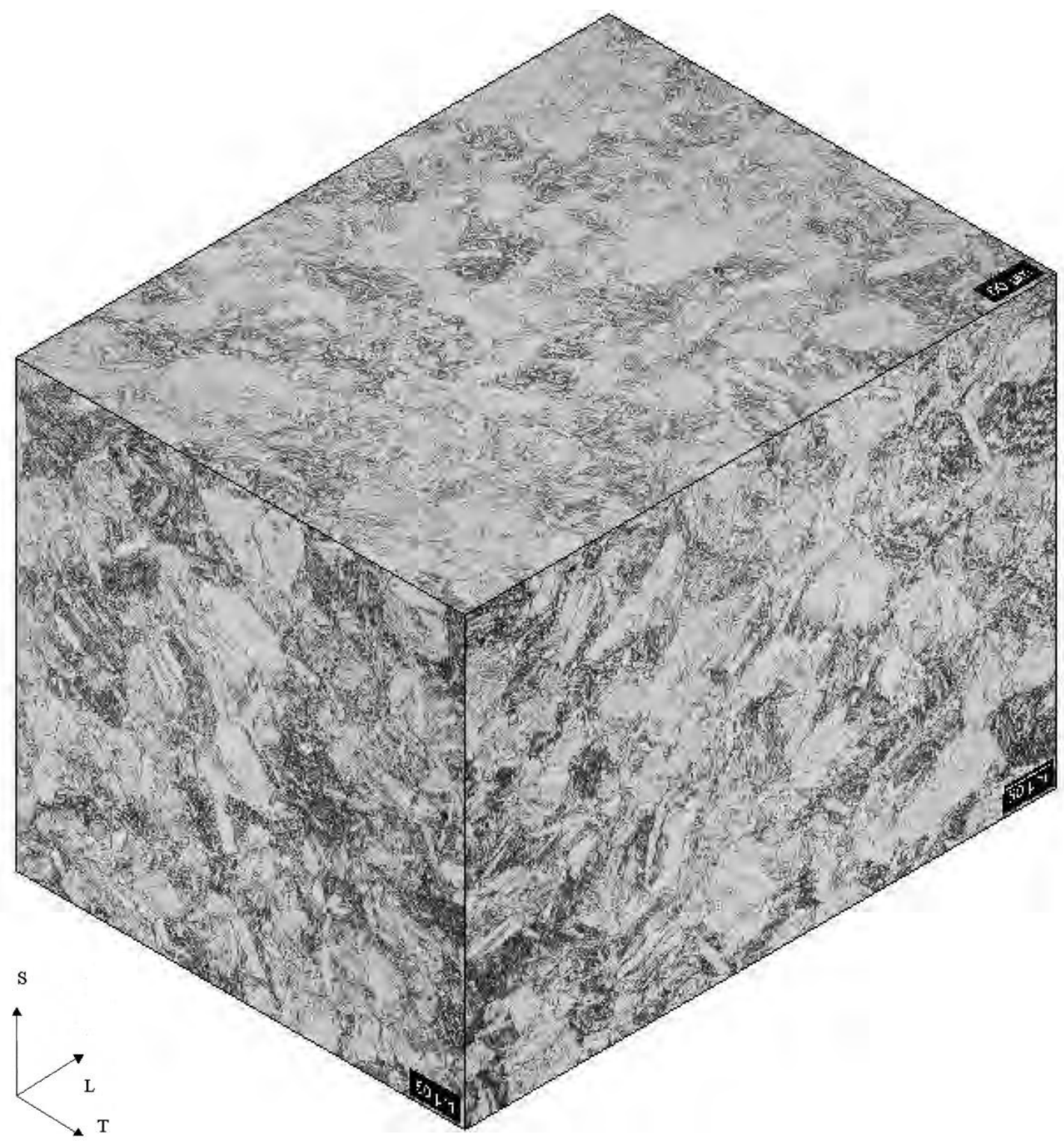

Figure 16: Sample 1 - Summary Composite Photo - 180 


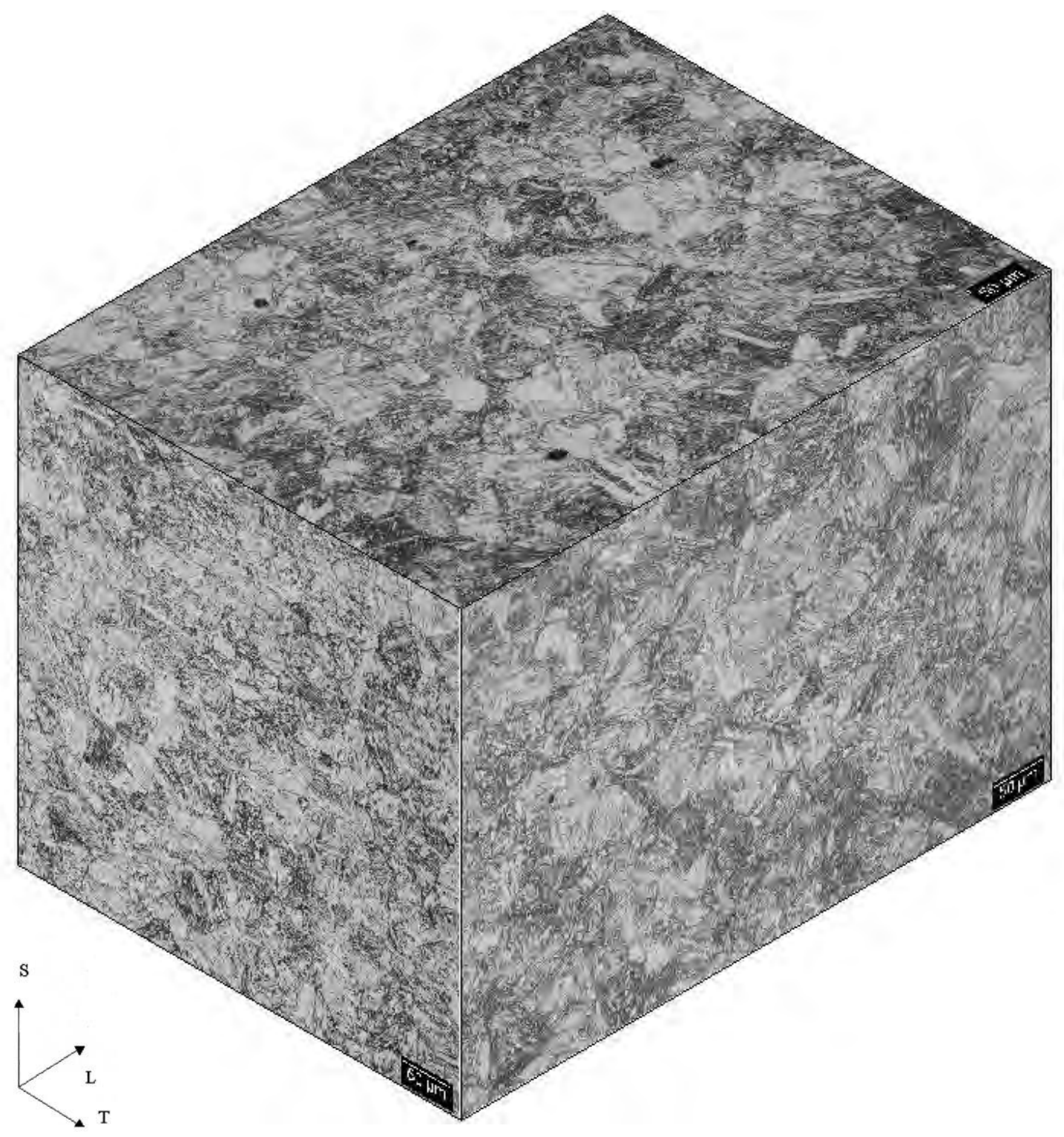

Figure 17: Sample 1 - Summary Composite Photo - $180^{\circ}$ from Burst at End 
Reference No: 602731

Issue: 01
Aiken Engineering Company

51 Pages

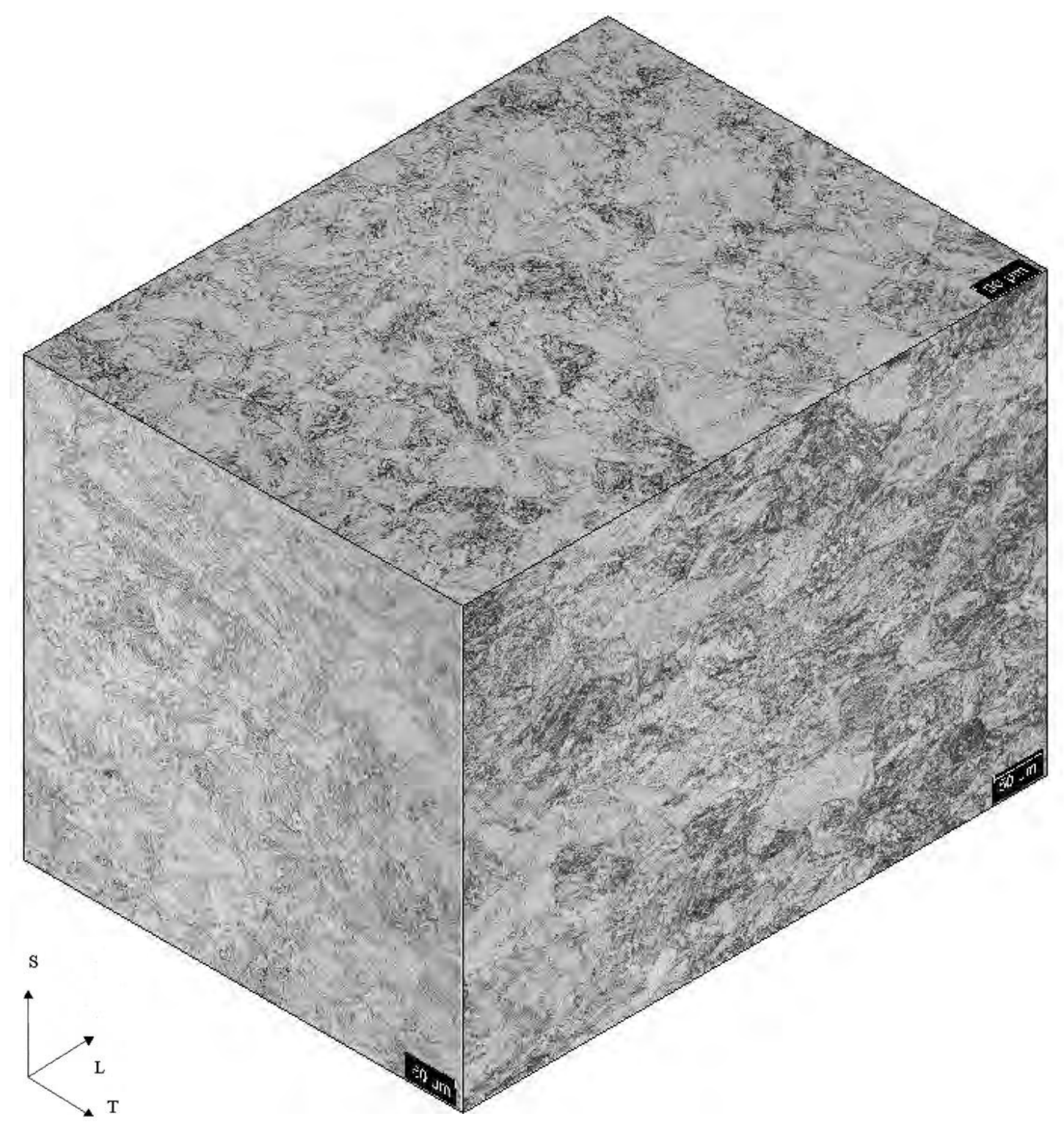

Figure 18: Sample 2 - Summary Composite Photo - At Burst 


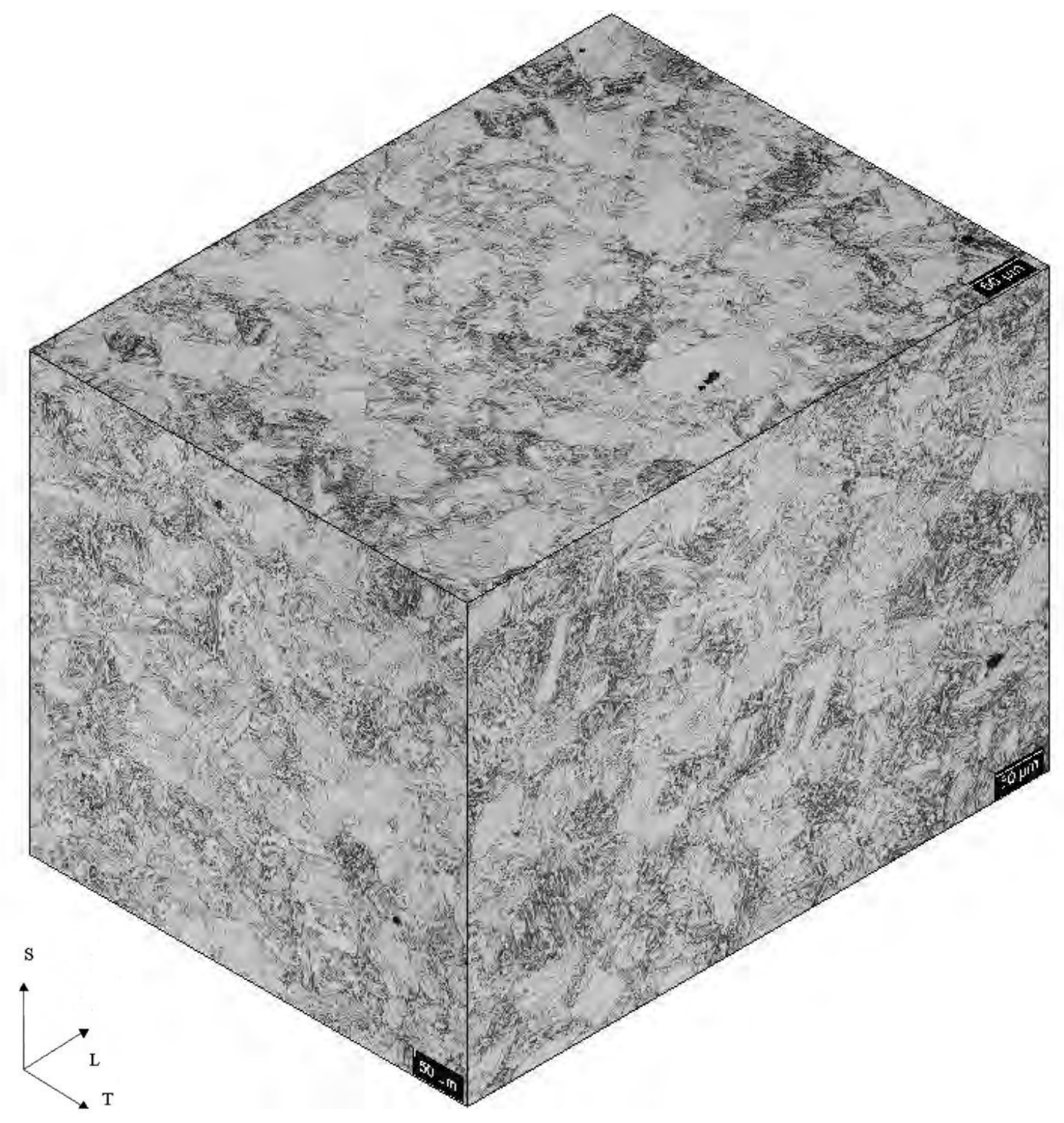

Figure 19: Sample 2 - Summary Composite Photo - 180 $^{\circ}$ 


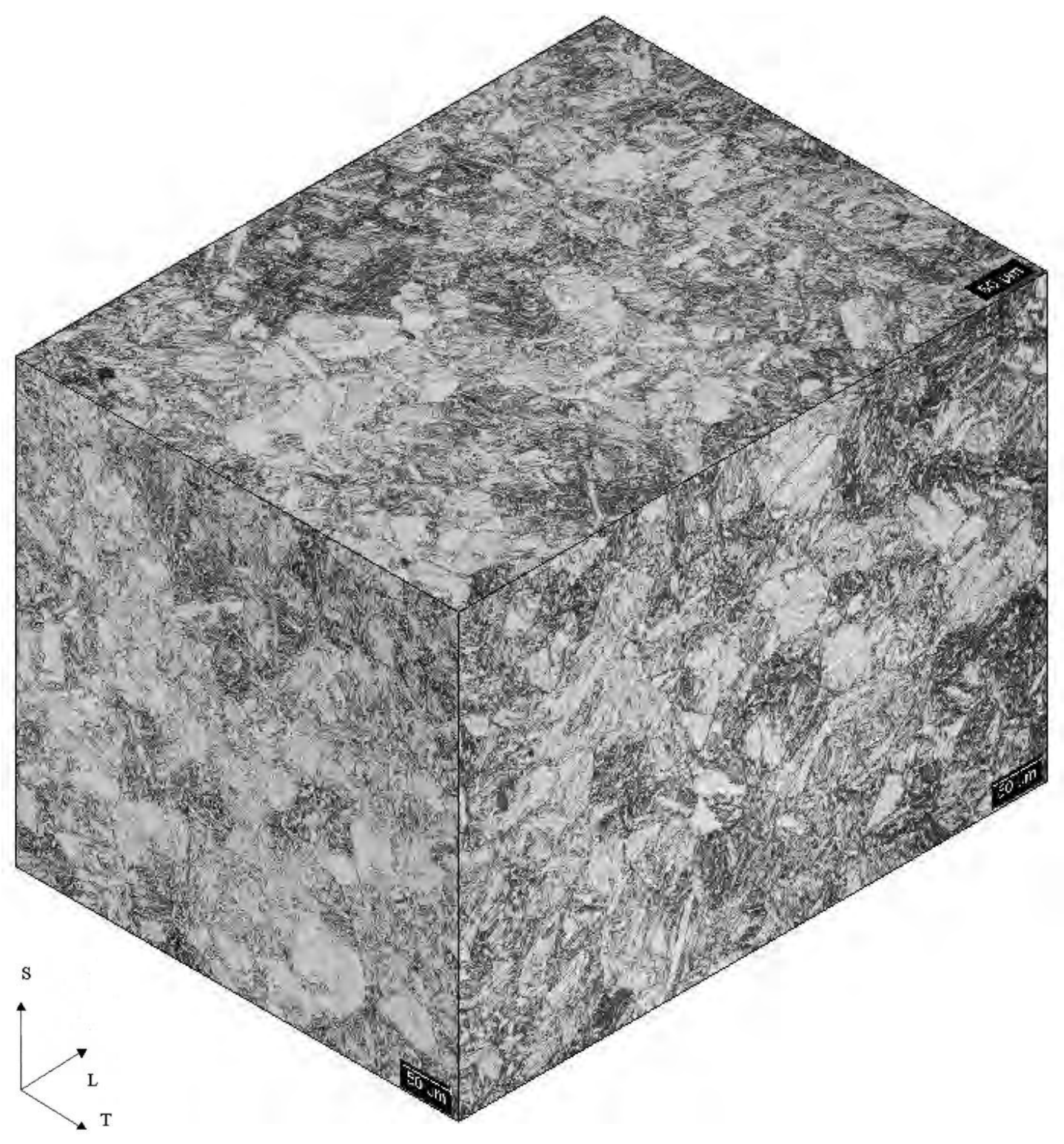

Figure 20: Sample 2 - Summary Composite Photo $-180^{\circ}$ from Burst at End 


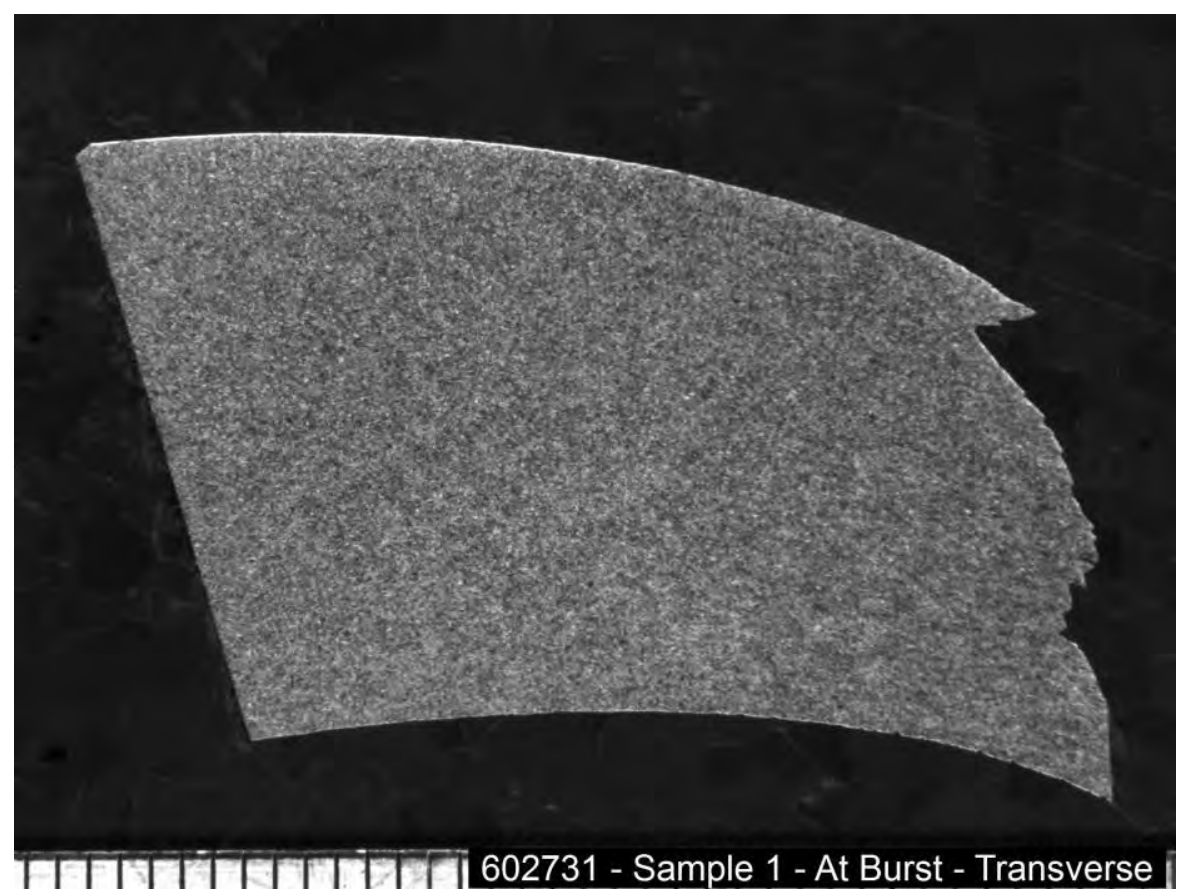

Figure 21: Sample 1 - Macrophotograph of Transverse cross-section at Burst (scale in mm)

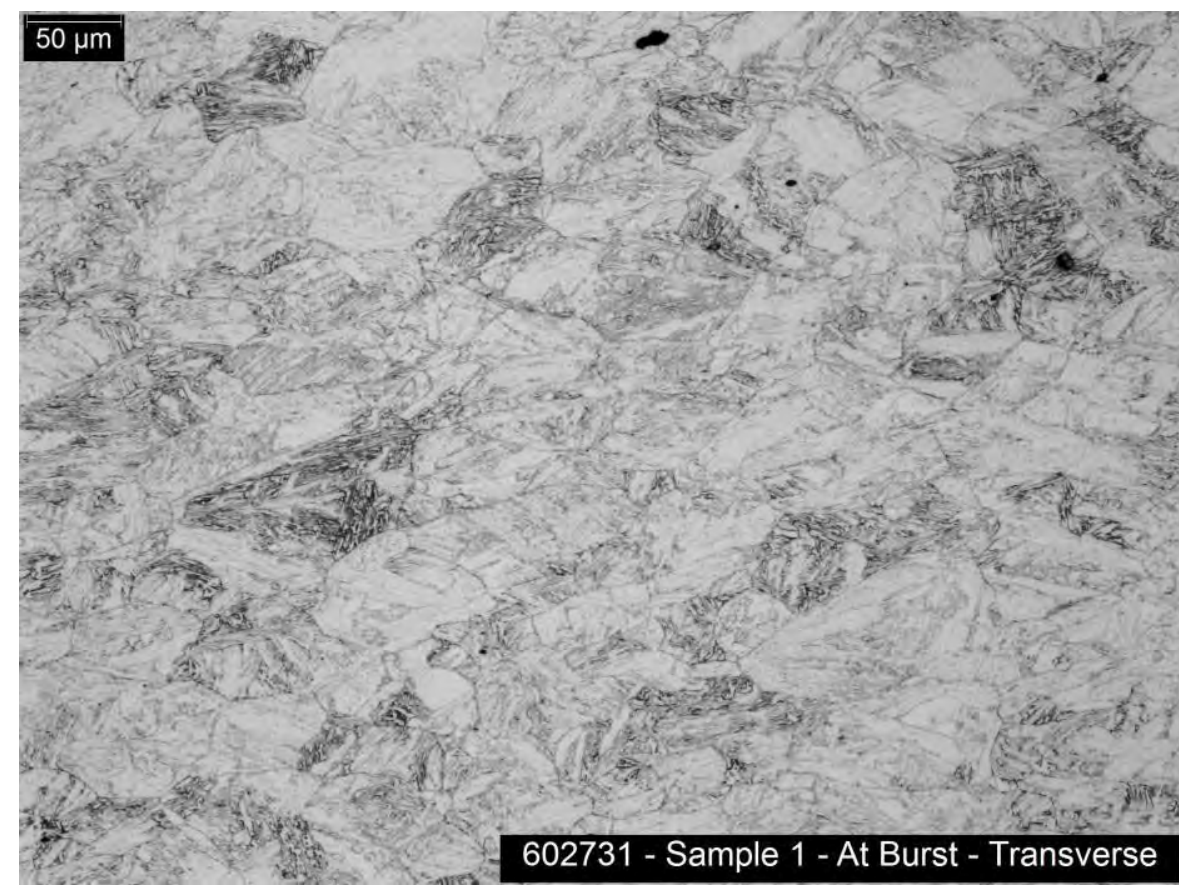

Figure 22: Sample 1 - Microphotograph of Transverse cross-section at Burst, Grain Size No. 7 


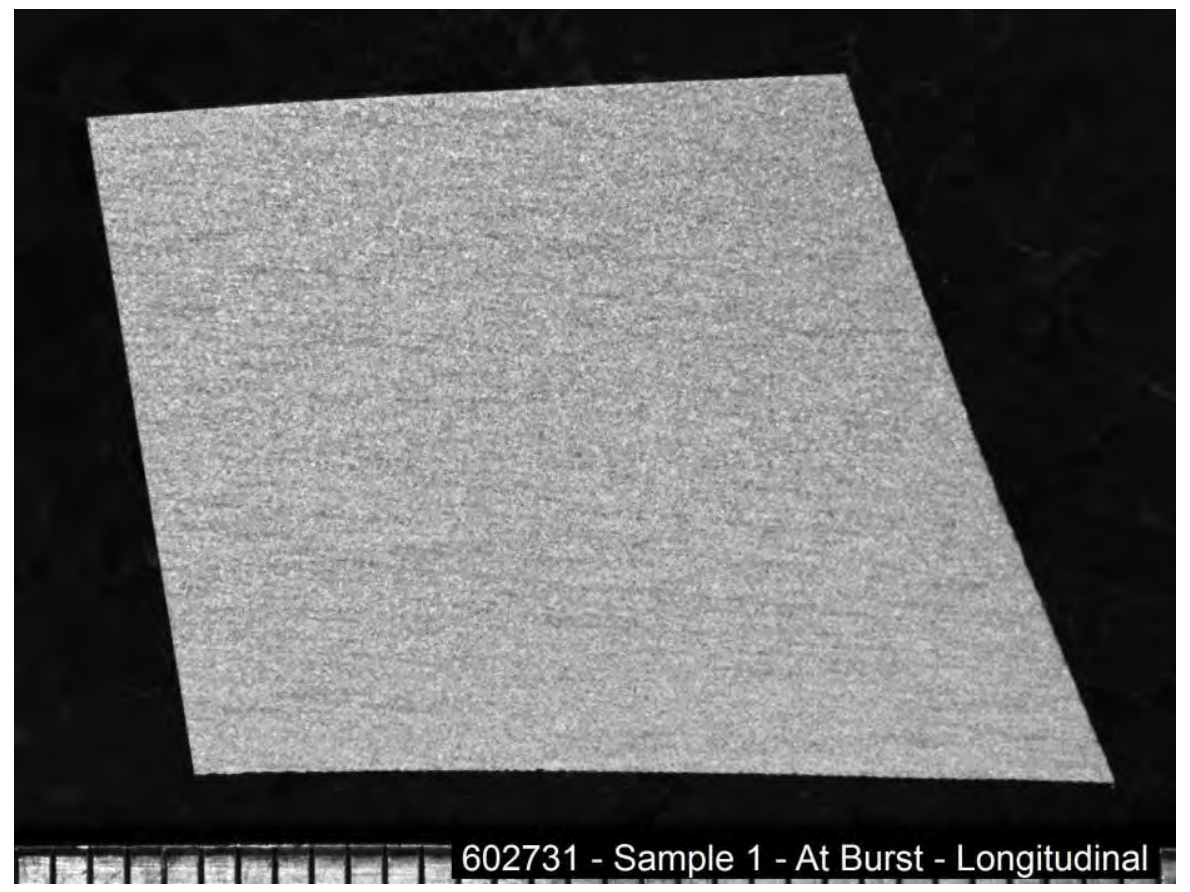

Figure 23: Sample 1 - Macrophotograph of Longitudinal cross-section at Burst (scale in mm)

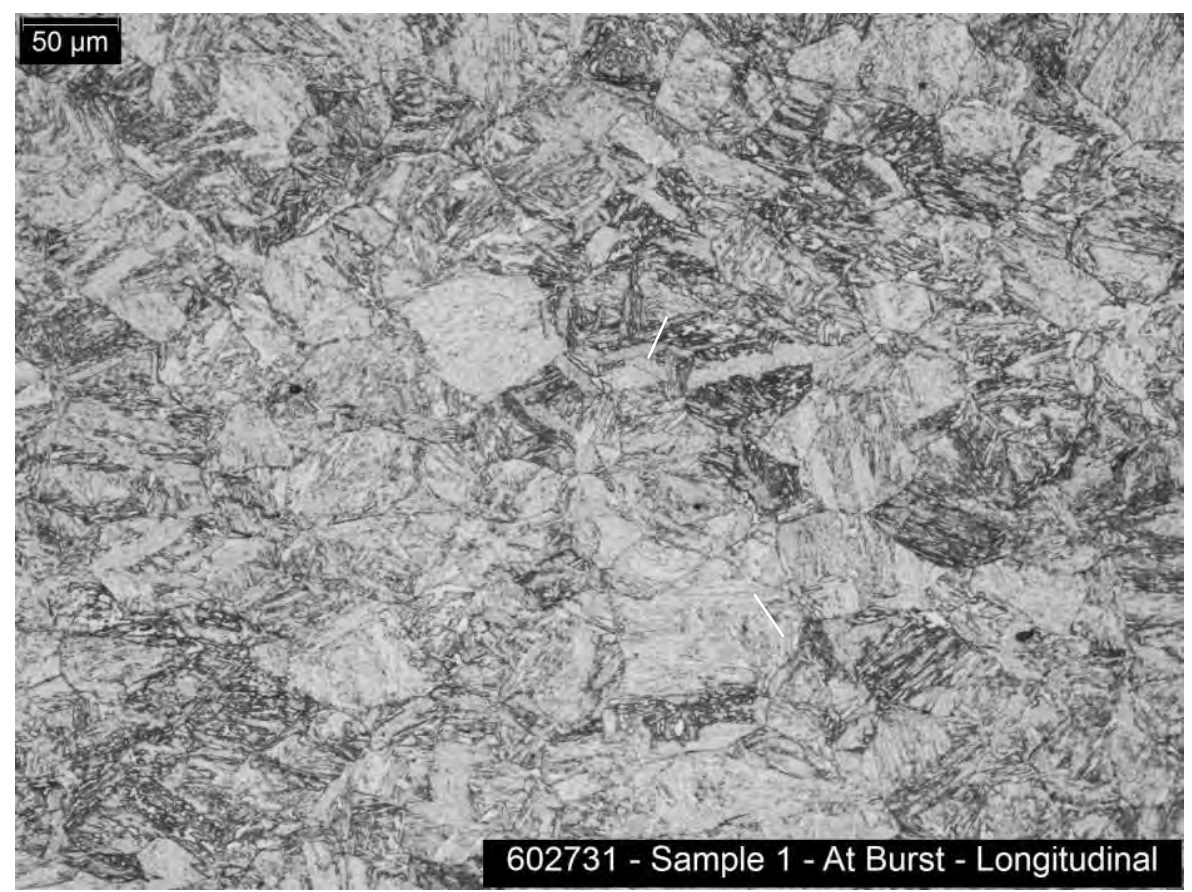

Figure 24: Sample 1 - Microphotograph of Longitudinal cross-section at Burst, Grain Size No.6 


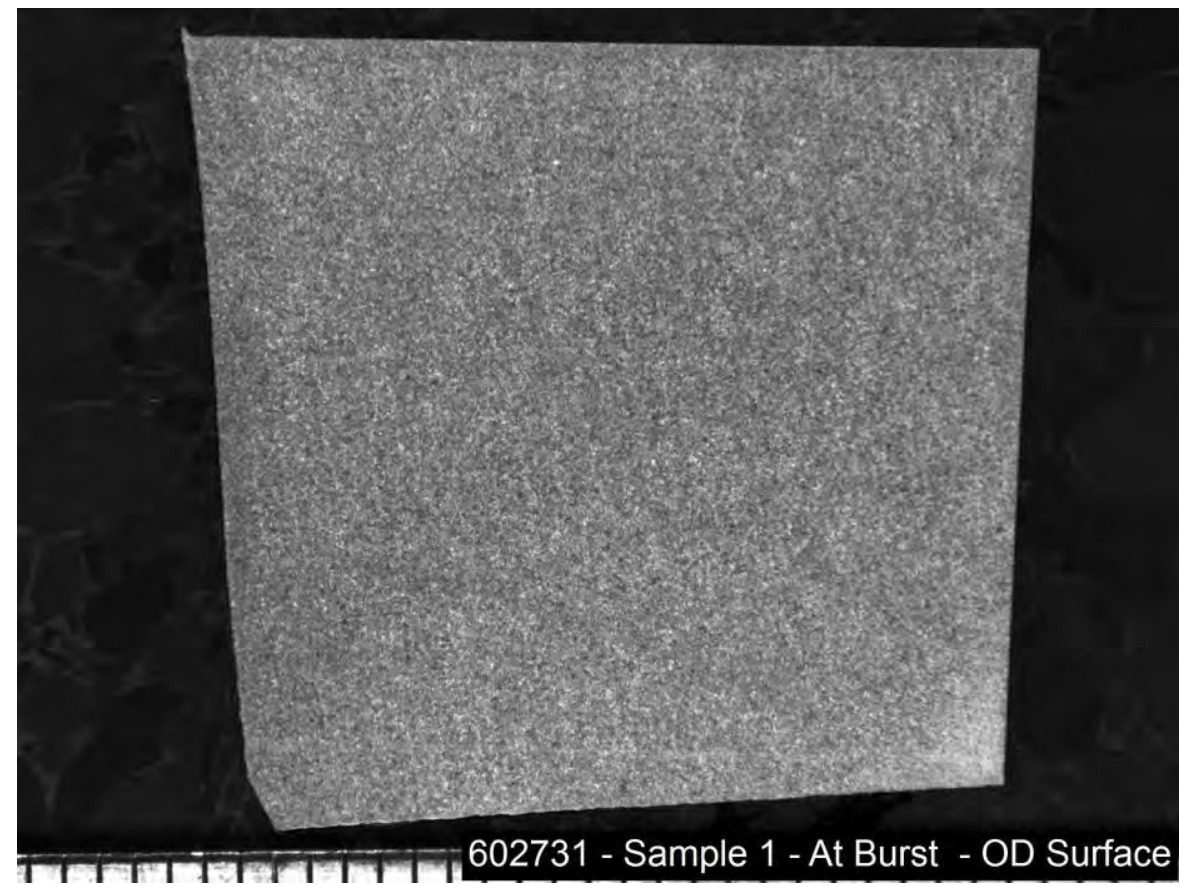

Figure 25: Sample 1 - Macrophotograph of OD Surface cross-section at Burst (scale in mm)

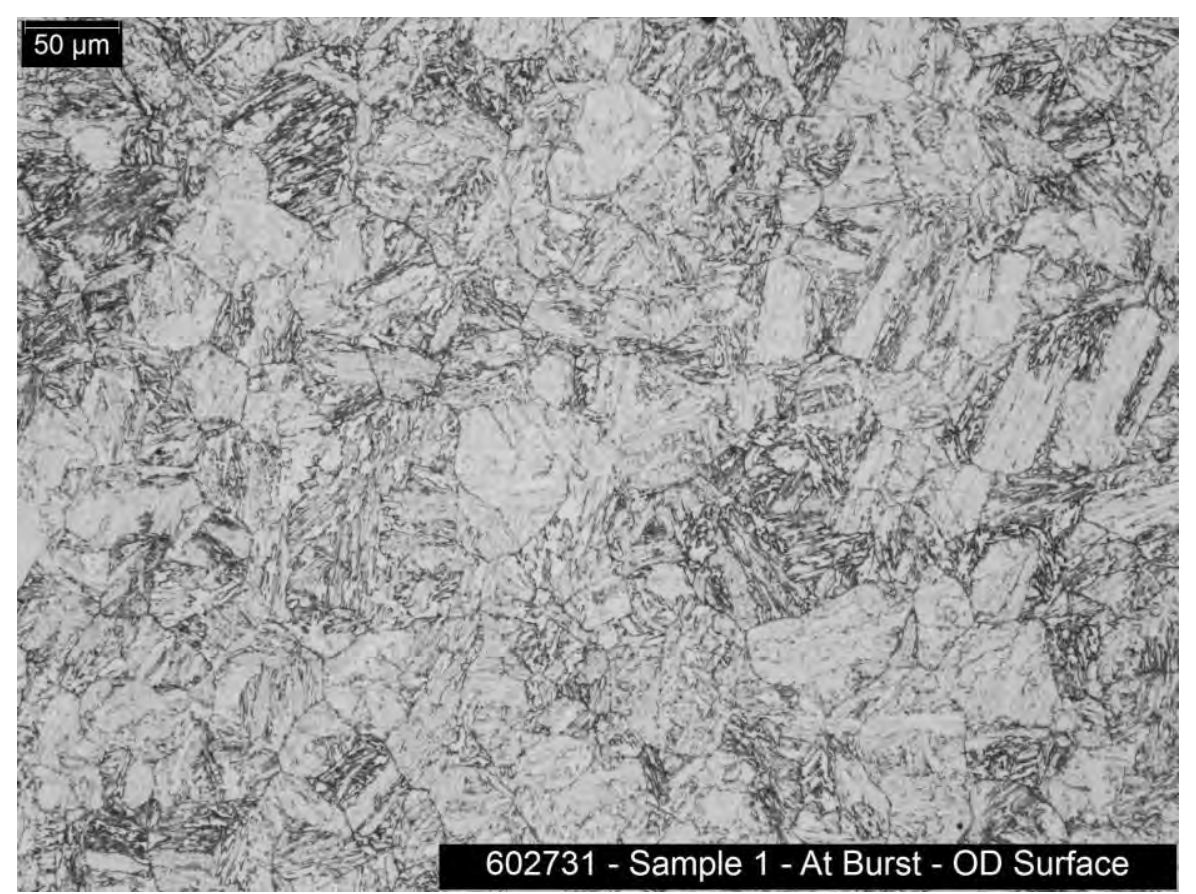

Figure 26: Sample 1 - Microphotograph of OD Surface cross-section at Burst, Grain Size No. 6 


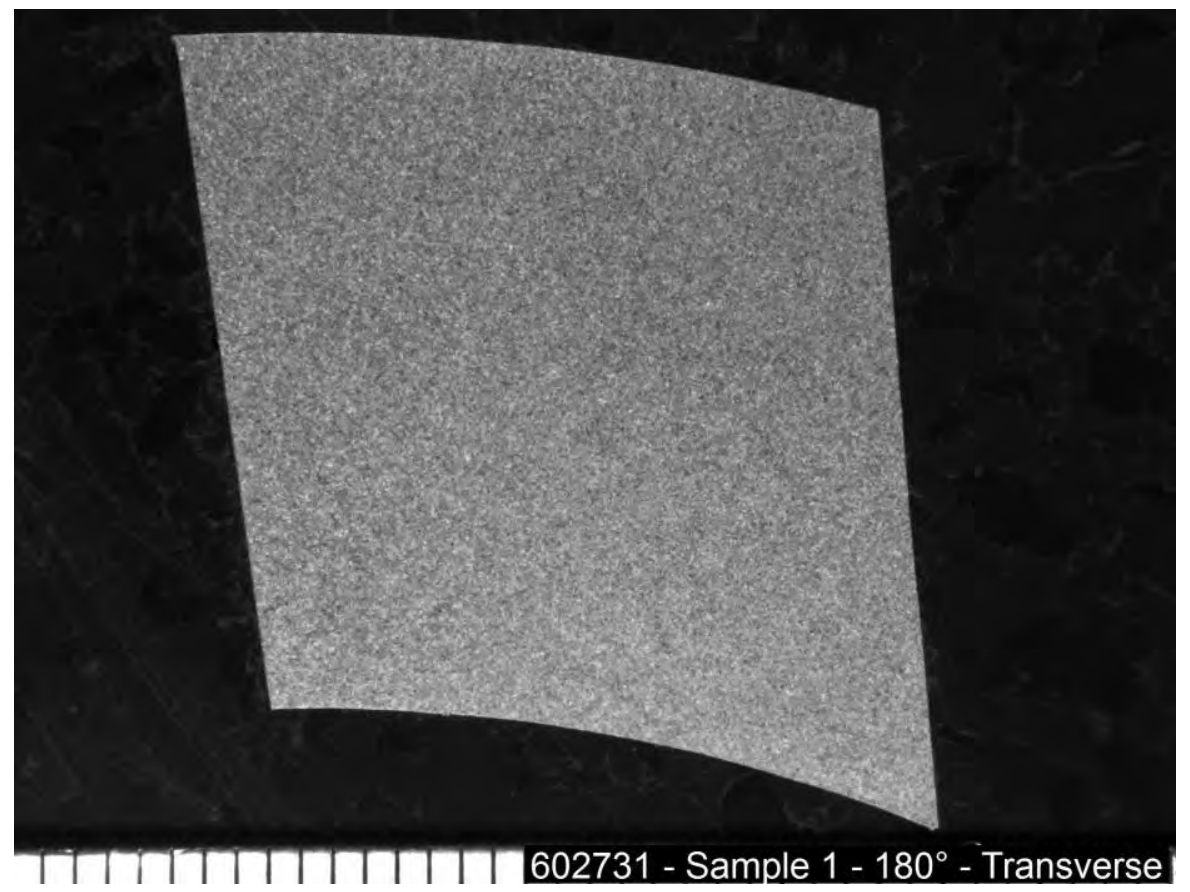

Figure 27: Sample 1 - Macrophotograph of Transverse cross-section at $180^{\circ}$ from Burst (scale in mm)

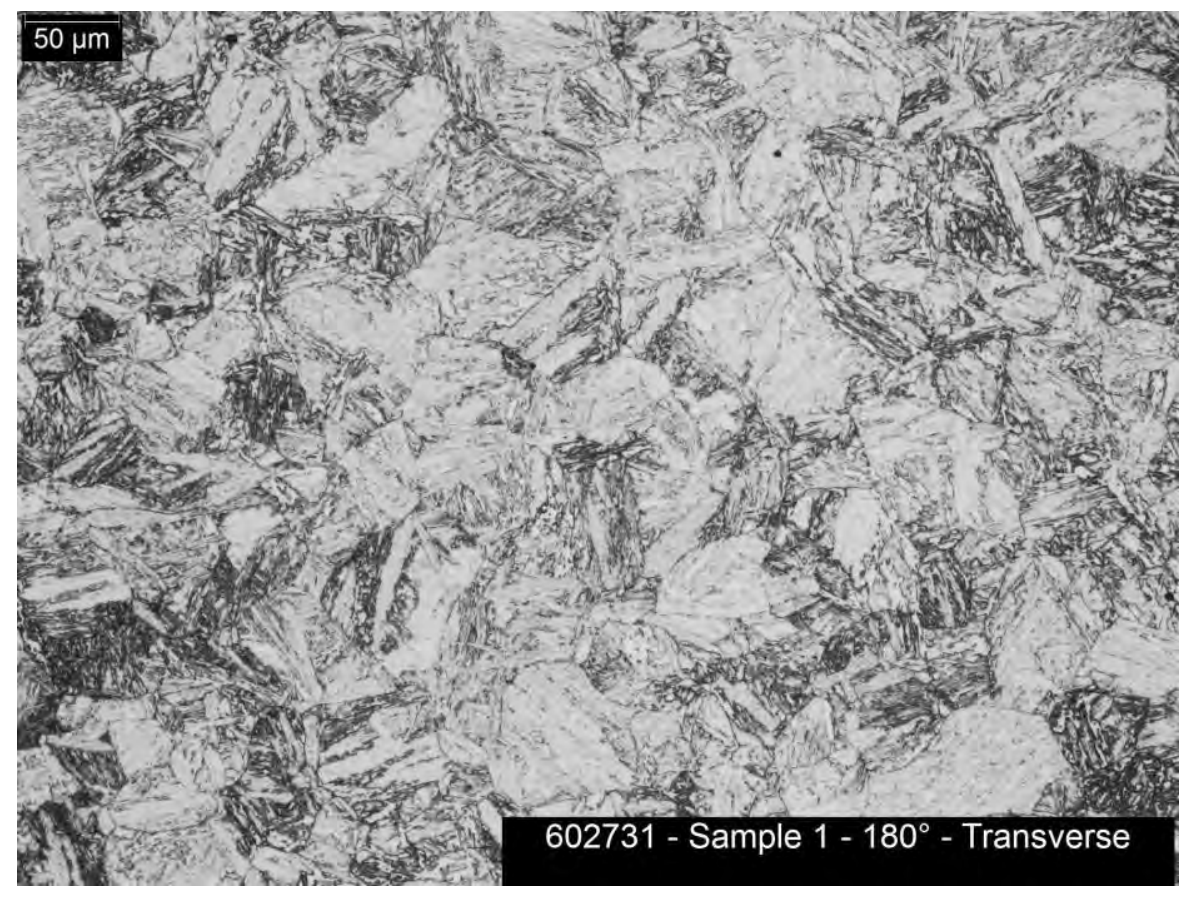

Figure 28: Sample 1 - Microphotograph of Transverse cross-section at $180^{\circ}$ from Burst, Grain Size No. 6 


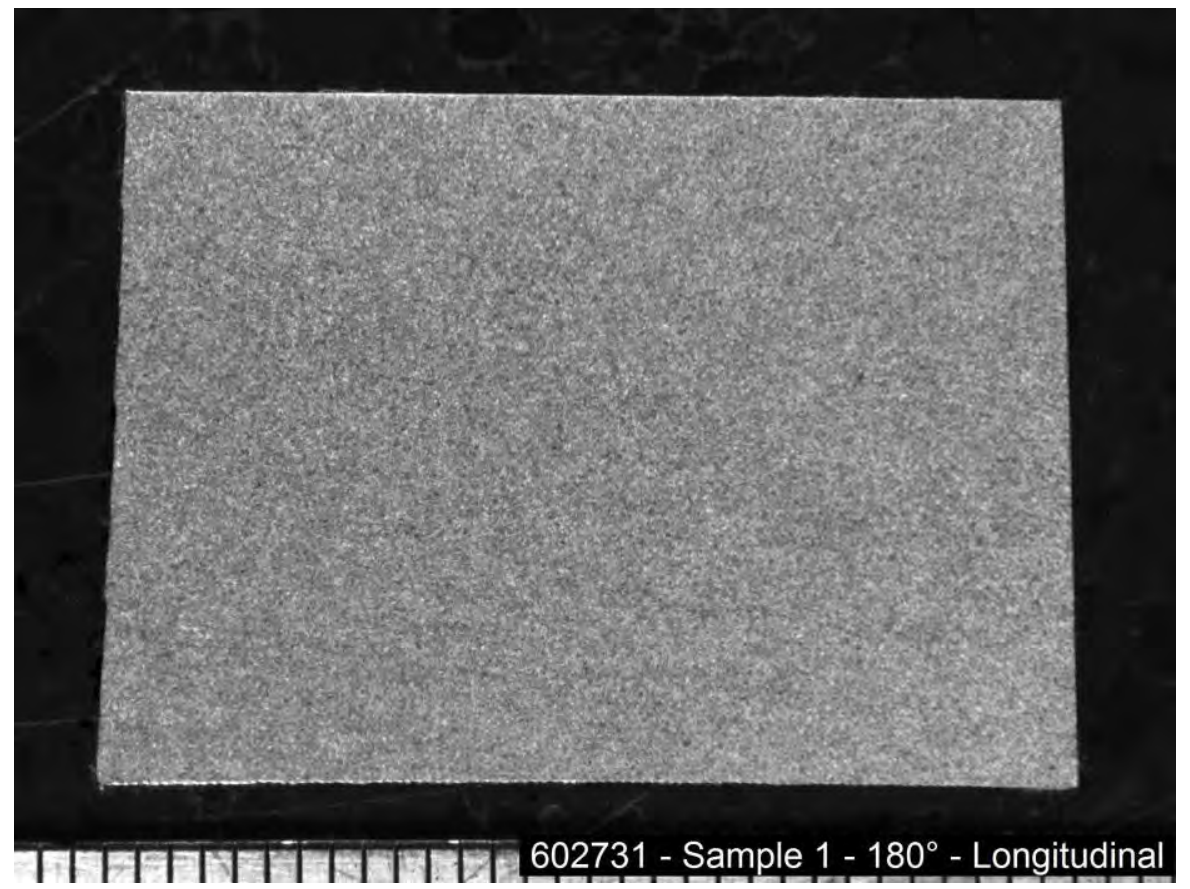

Figure 29: Sample 1 - Macrophotograph of Longitudinal cross-section at $180^{\circ}$ from Burst (scale in mm)

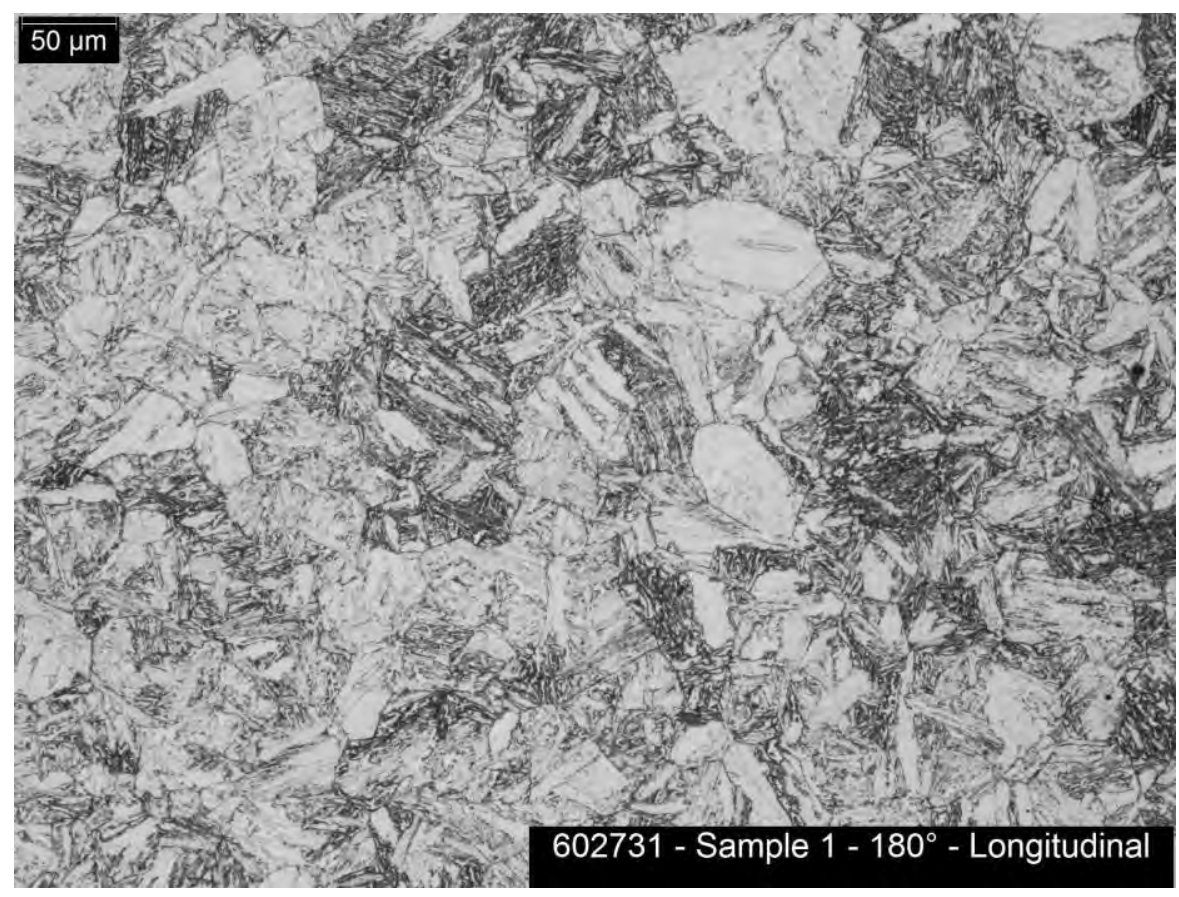

Figure 30: Sample 1 - Microphotograph of Longitudinal cross-section at $180^{\circ}$ from Burst, Grain Size No. 6 


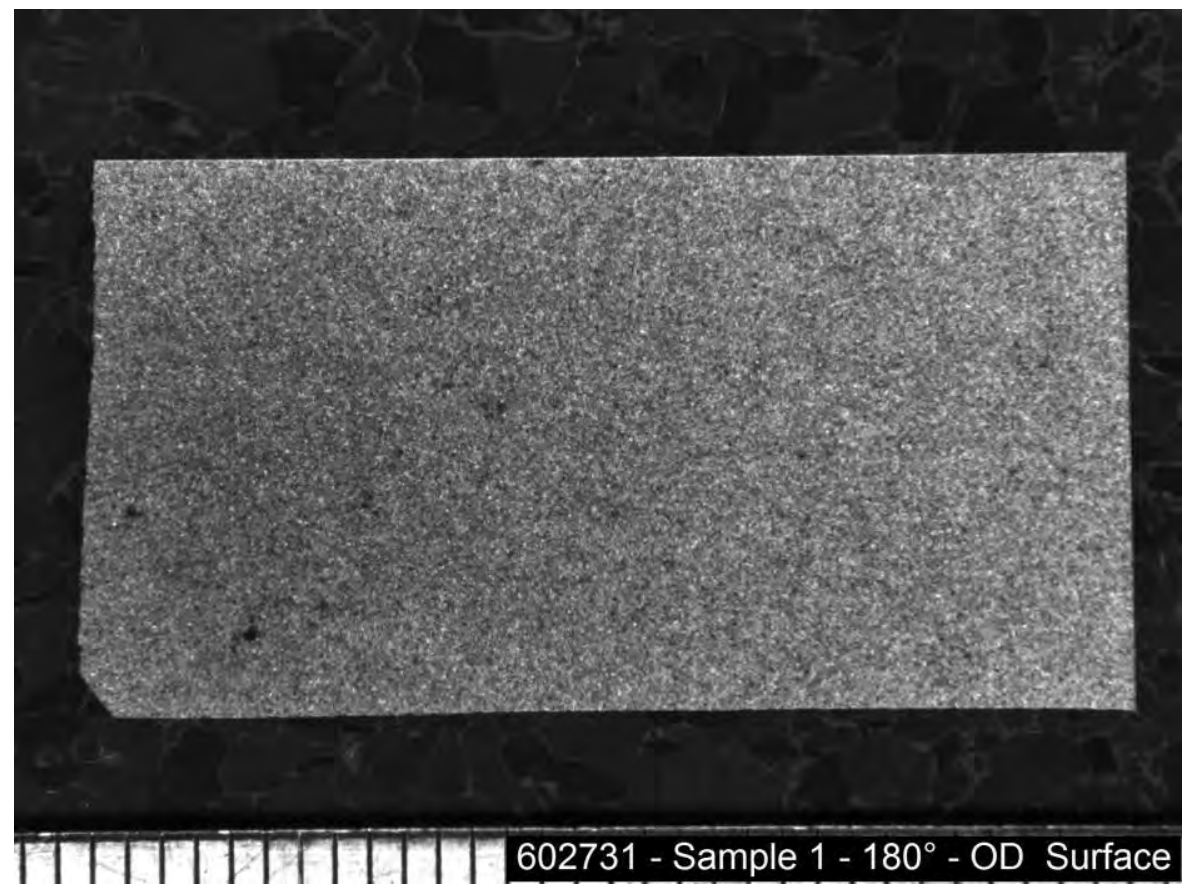

Figure 31: Sample 1 - Macrophotograph of OD Surface cross-section at $180^{\circ}$ from Burst (scale in mm)

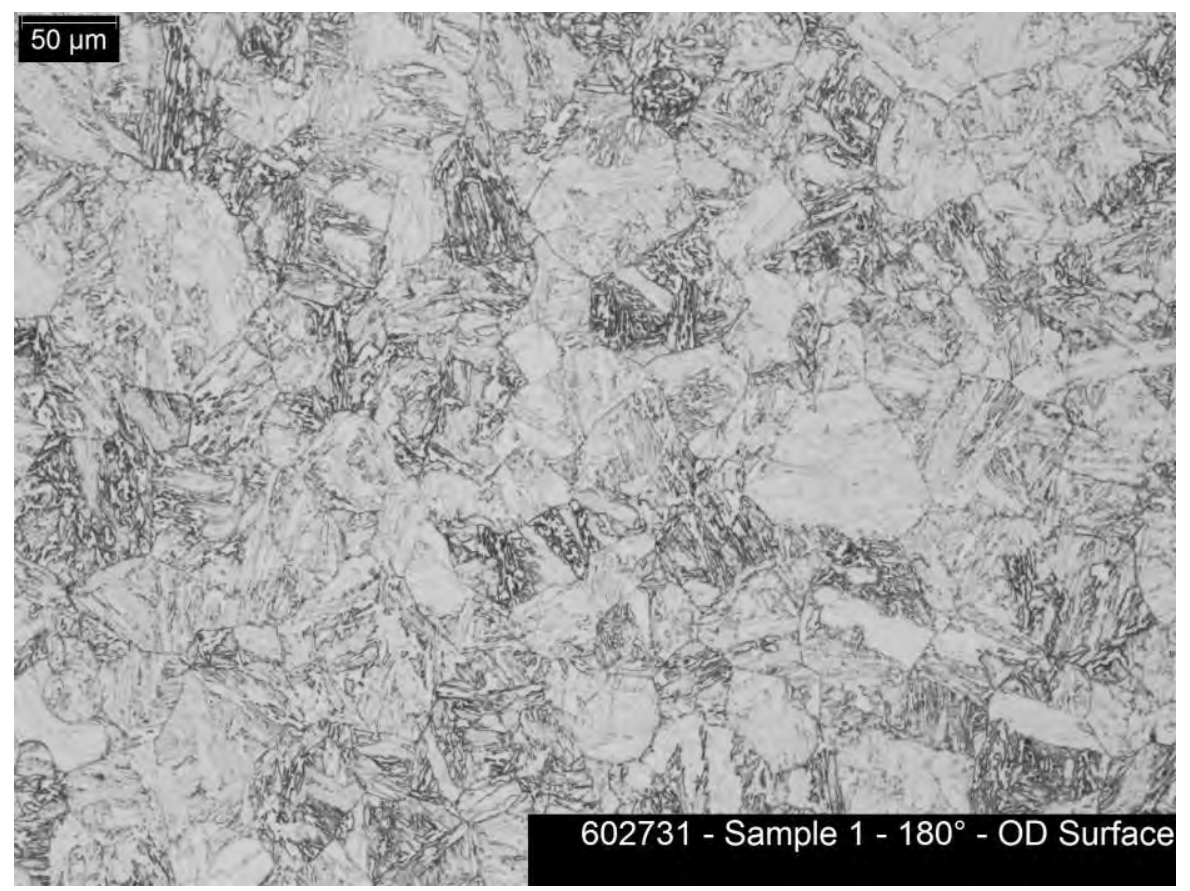

Figure 32: Sample 1 - Microphotograph of OD Surface cross-section at $180^{\circ}$ from Burst, Grain Size No. 6 


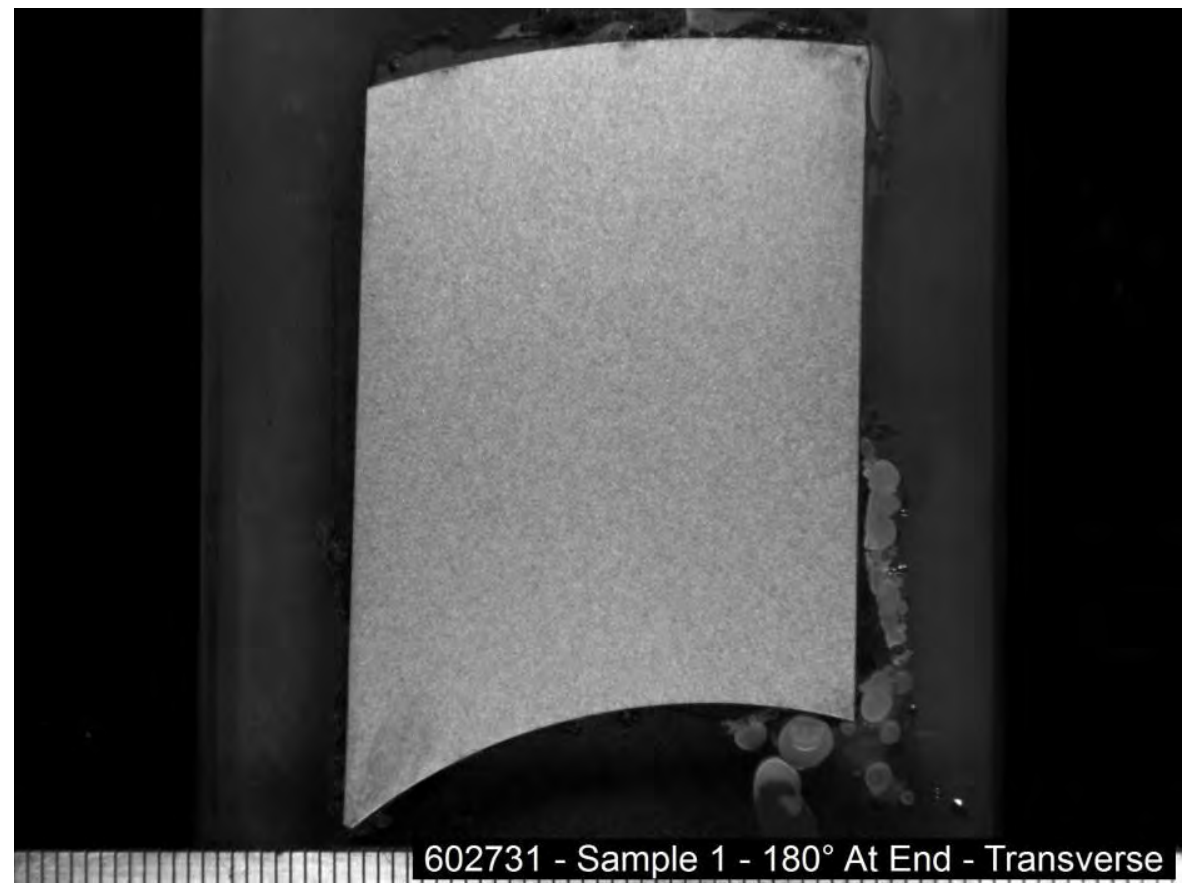

Figure 33: Sample 1 - Macrophotograph of Transverse cross-section at $180^{\circ}$ from Burst at End (scale in mm)

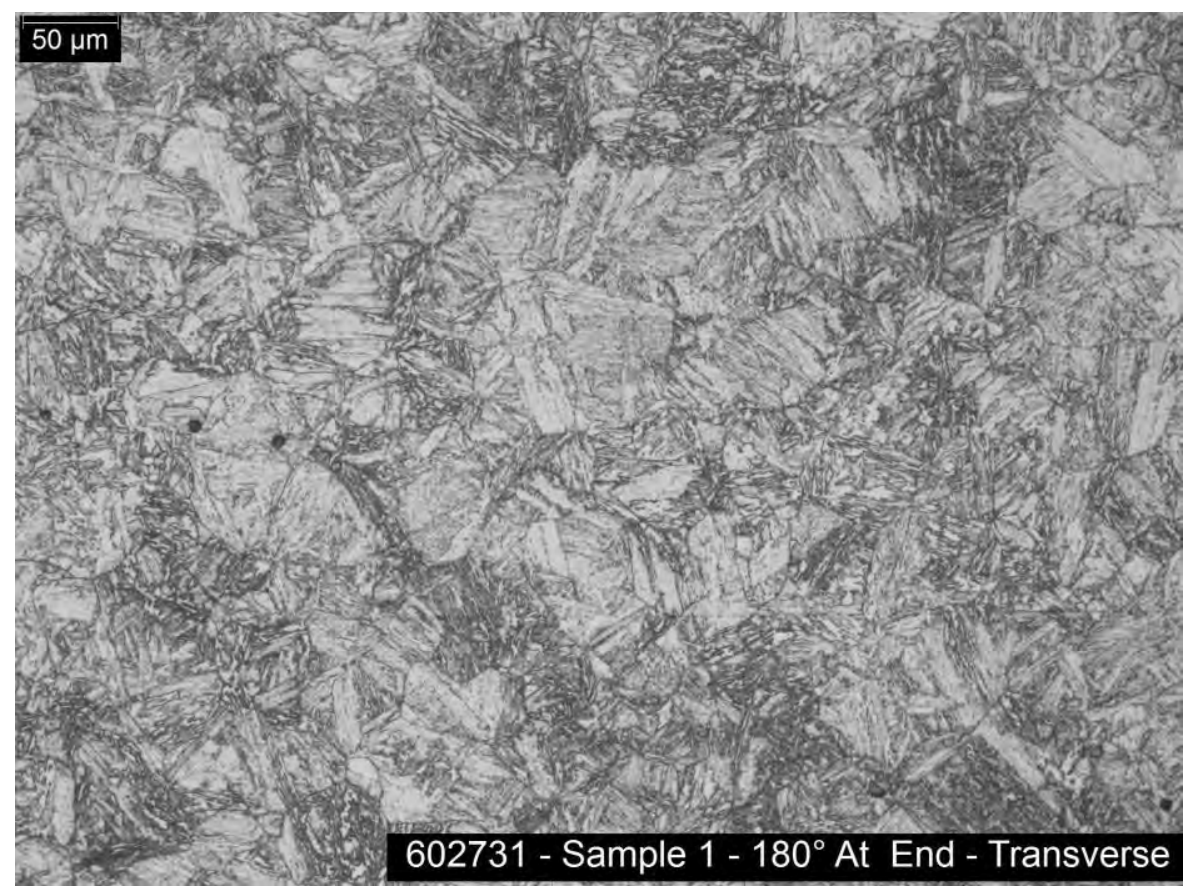

Figure 34: Sample 1 - Microphotograph of Transverse cross-section at $180^{\circ}$ from Burst at End, Grain Size No. 6 


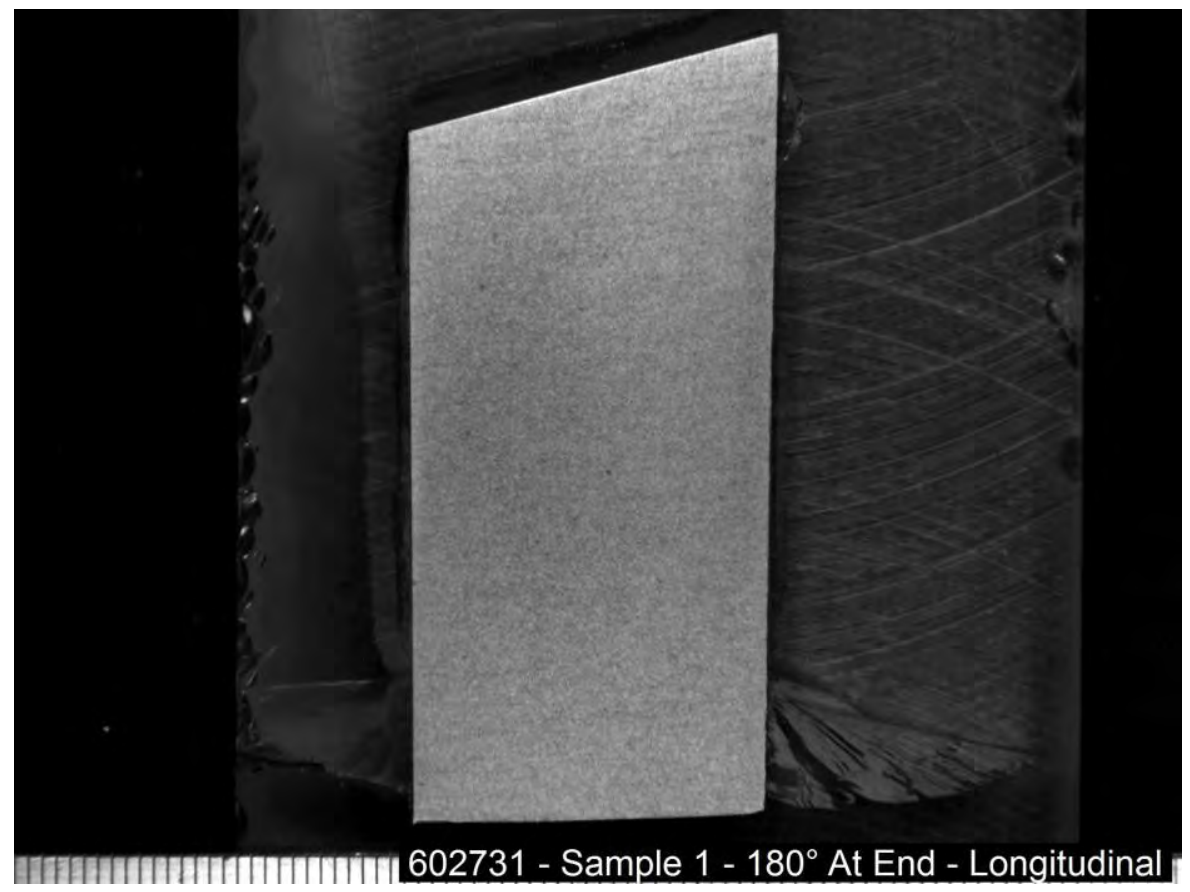

Figure 35: Sample 1 - Macrophotograph of Longitudinal cross-section at $180^{\circ}$ from Burst at End (scale in mm)

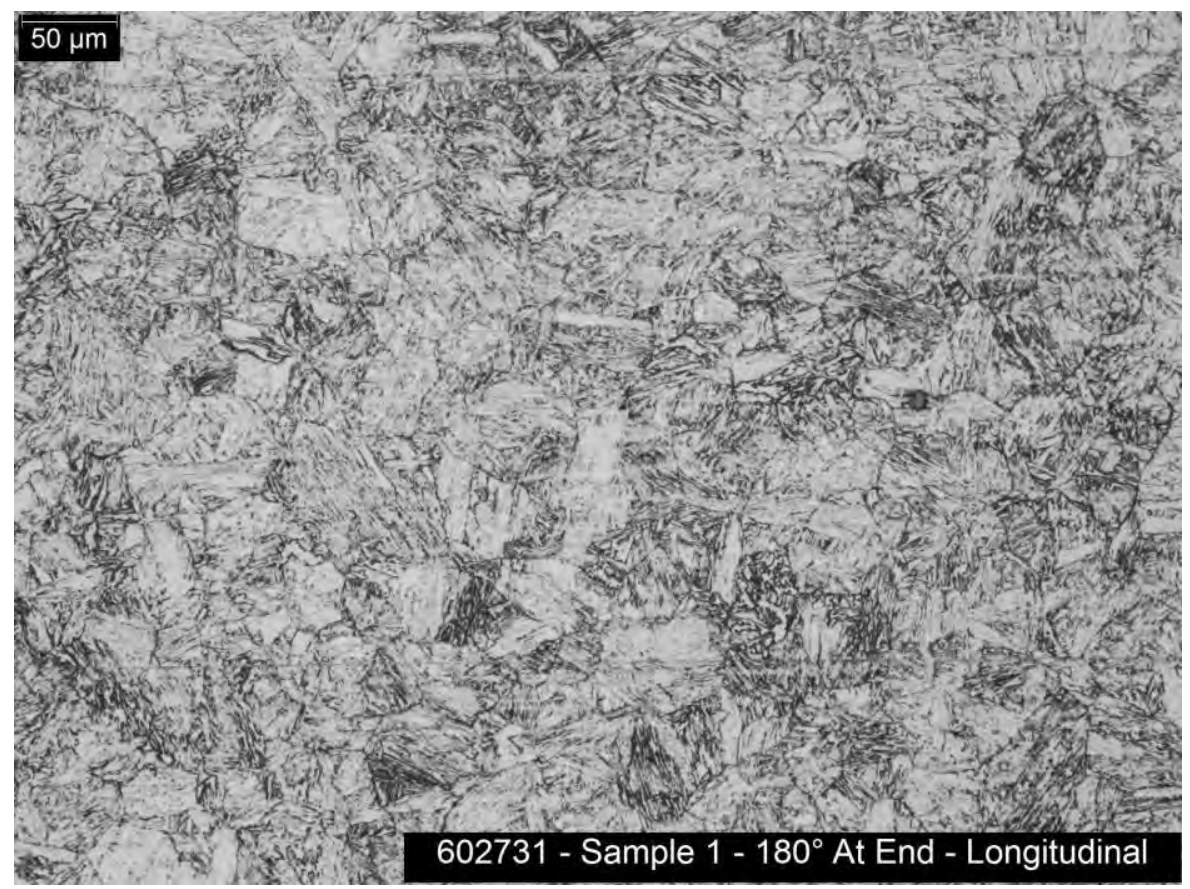

Figure 36: Sample 1 - Microphotograph of Longitudinal cross-section at $180^{\circ}$ from Burst at End, Grain Size No. 6 


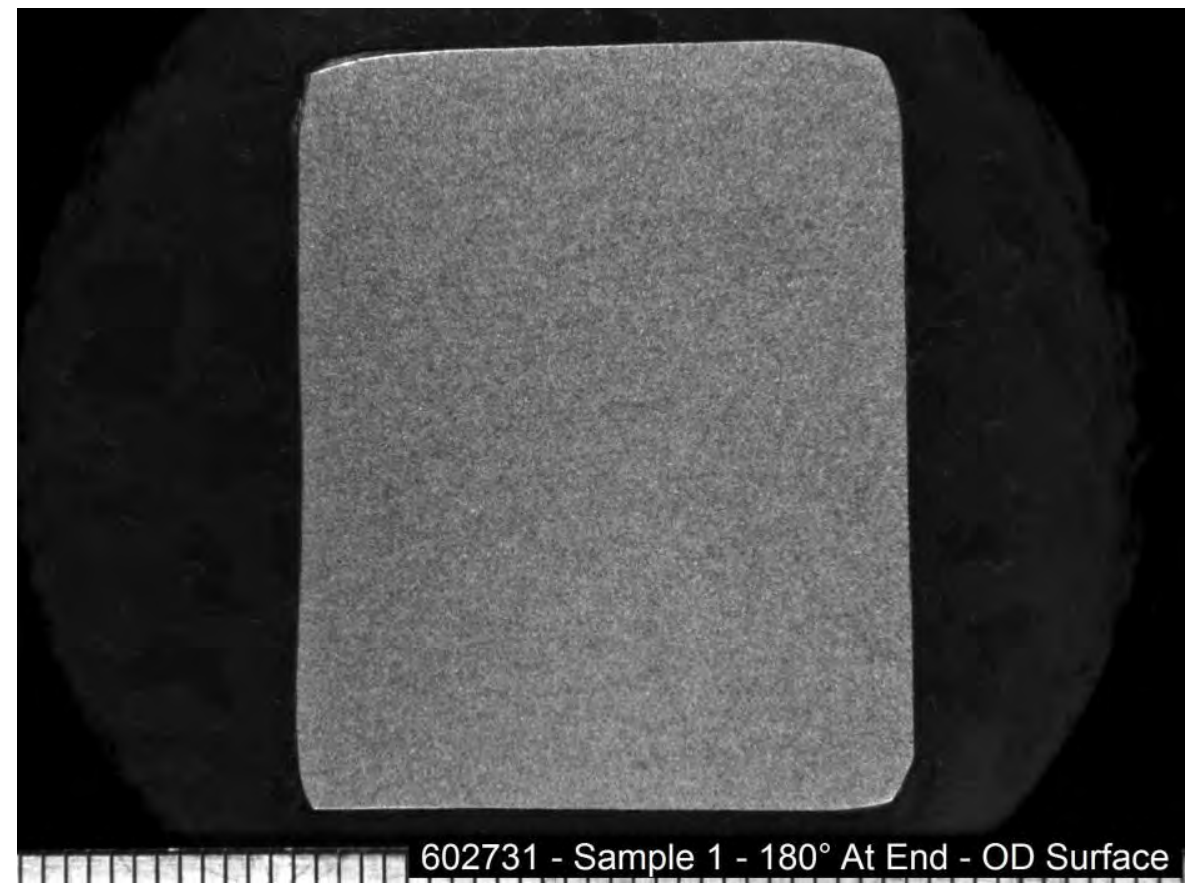

Figure 37: Sample 1 - Macrophotograph of OD Surface cross-section at $180^{\circ}$ from Burst at End (scale in mm)

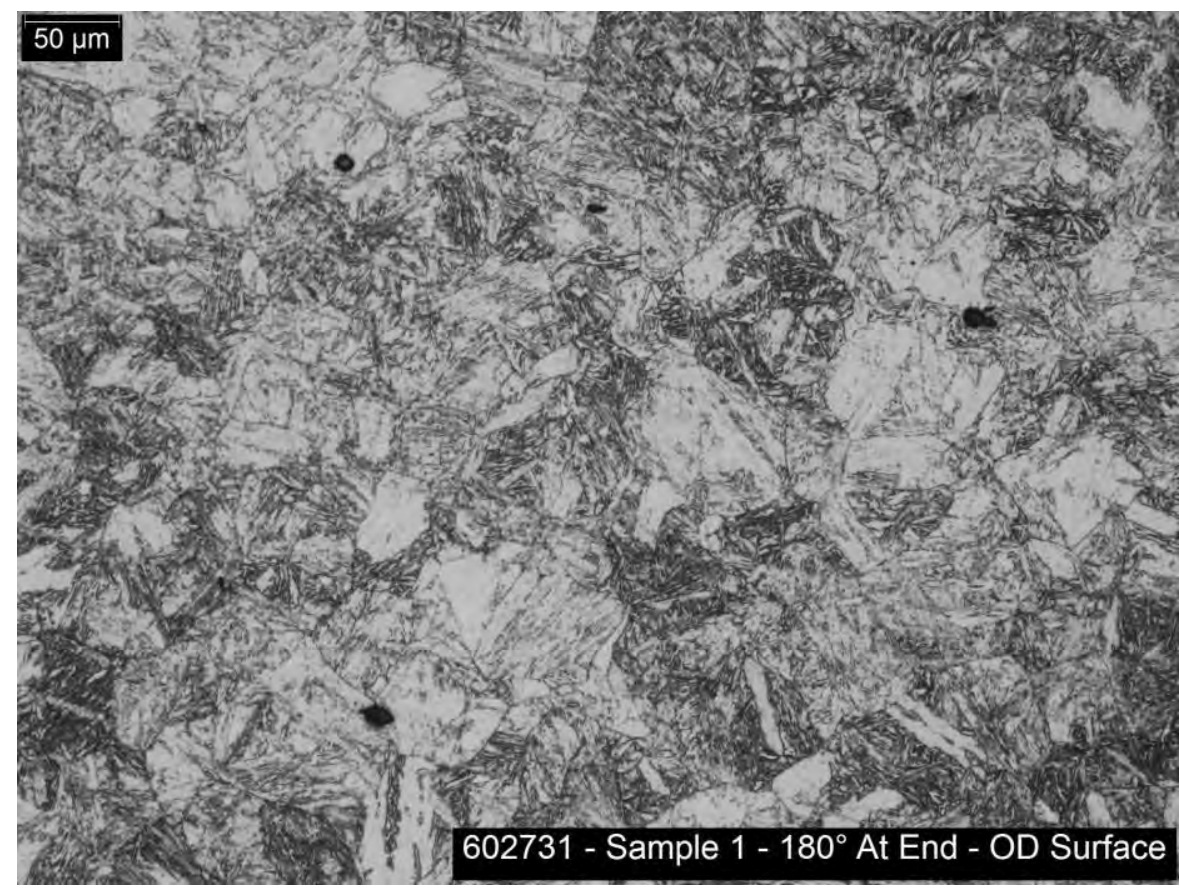

Figure 38: Sample 1 - Microphotograph of OD Surface cross-section at $180^{\circ}$ from Burst at End, Grain Size No. 7 


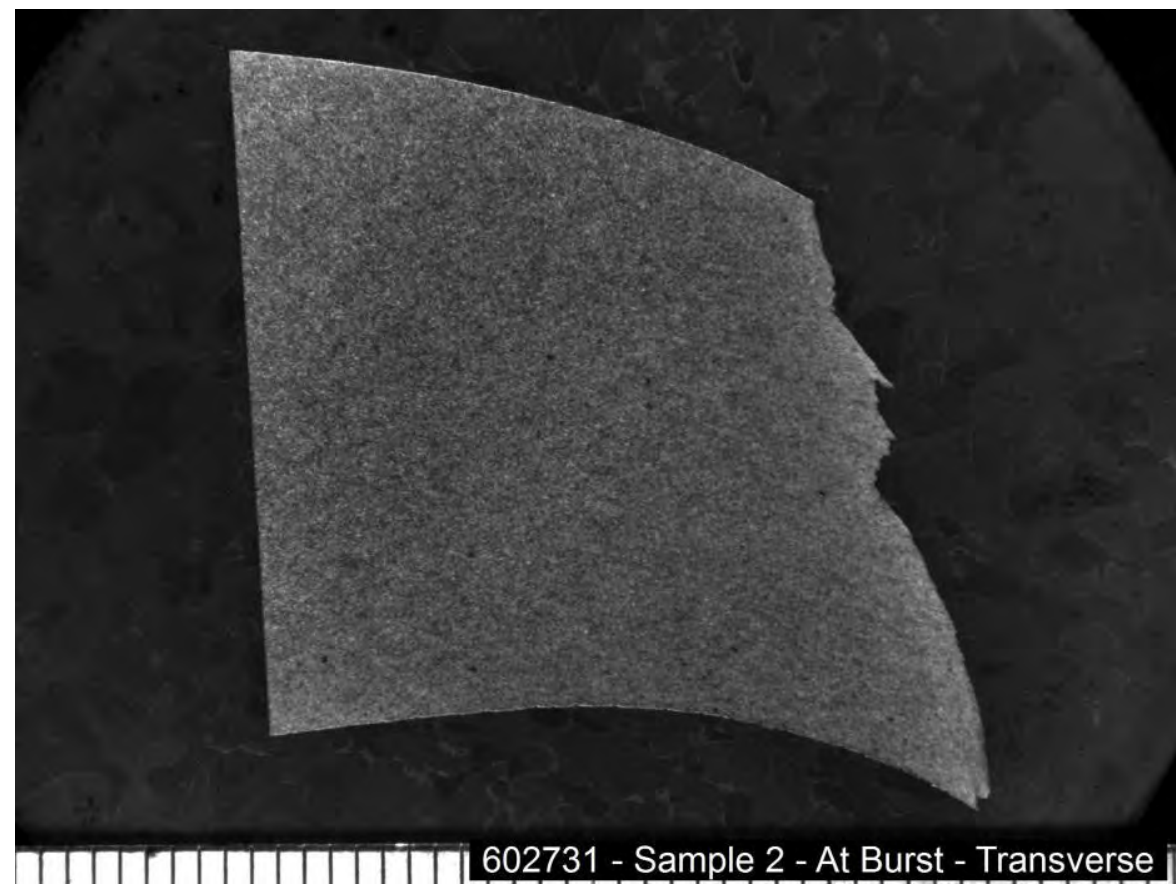

Figure 39: Sample 2 - Macrophotograph of Transverse cross-section at Burst (scale in mm)

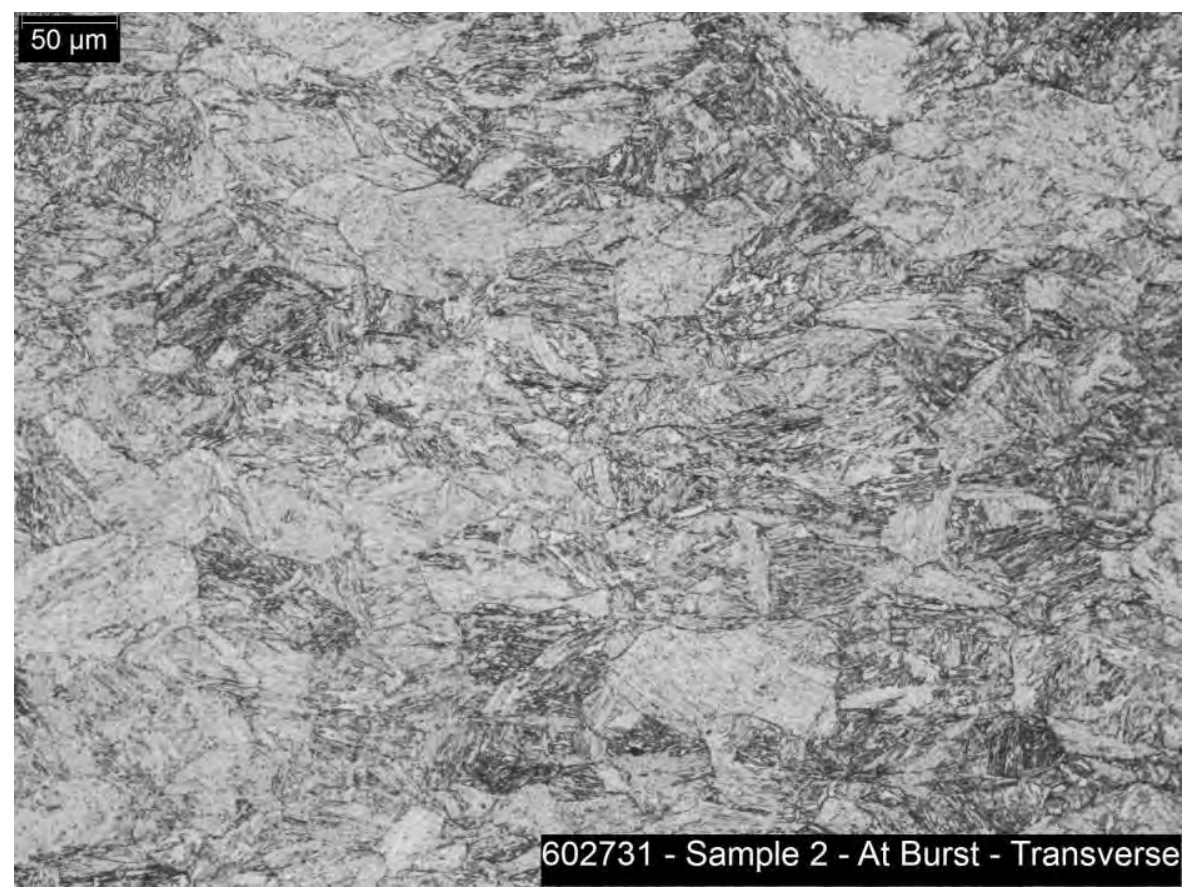

Figure 40: Sample 2 - Microphotograph of Transverse cross-section at Burst, Grain Size No. 7 


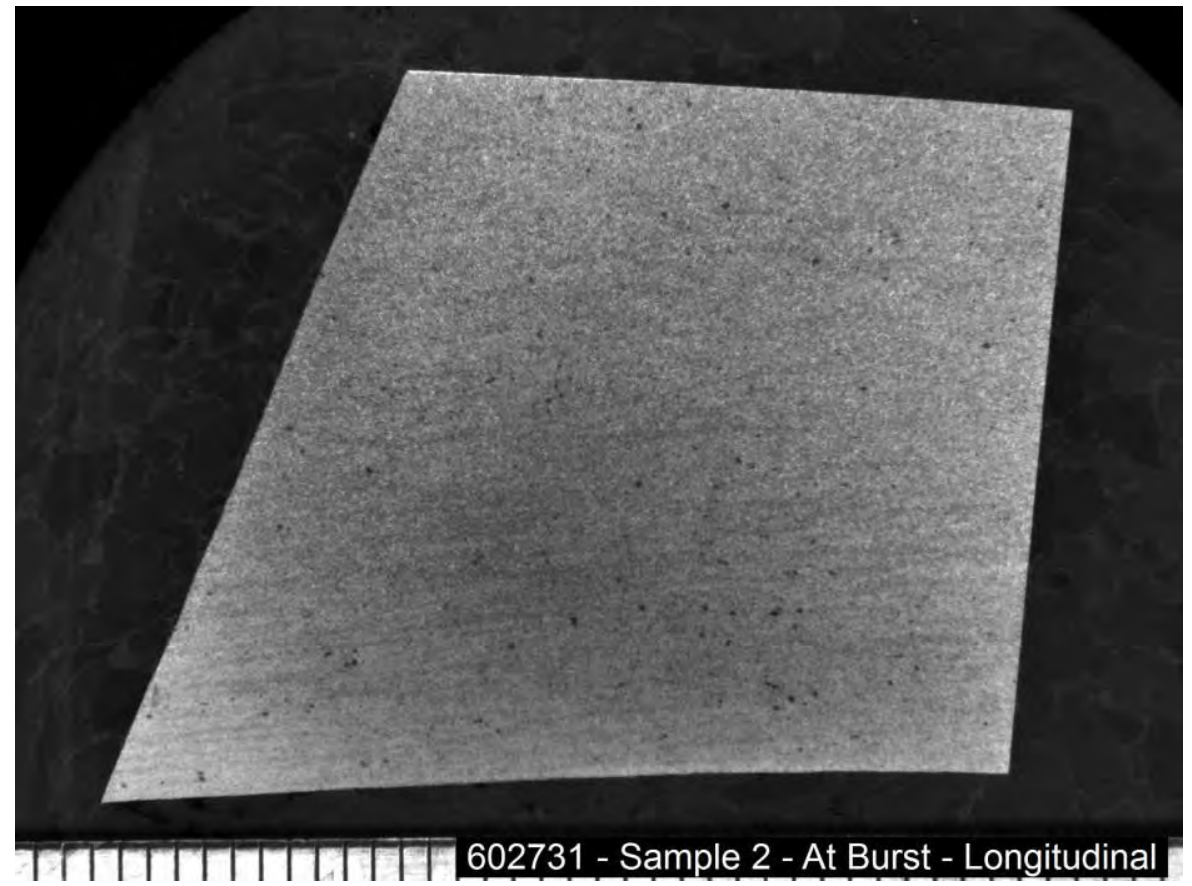

Figure 41: Sample 2 - Macrophotograph of Longitudinal cross-section at Burst (scale in mm)

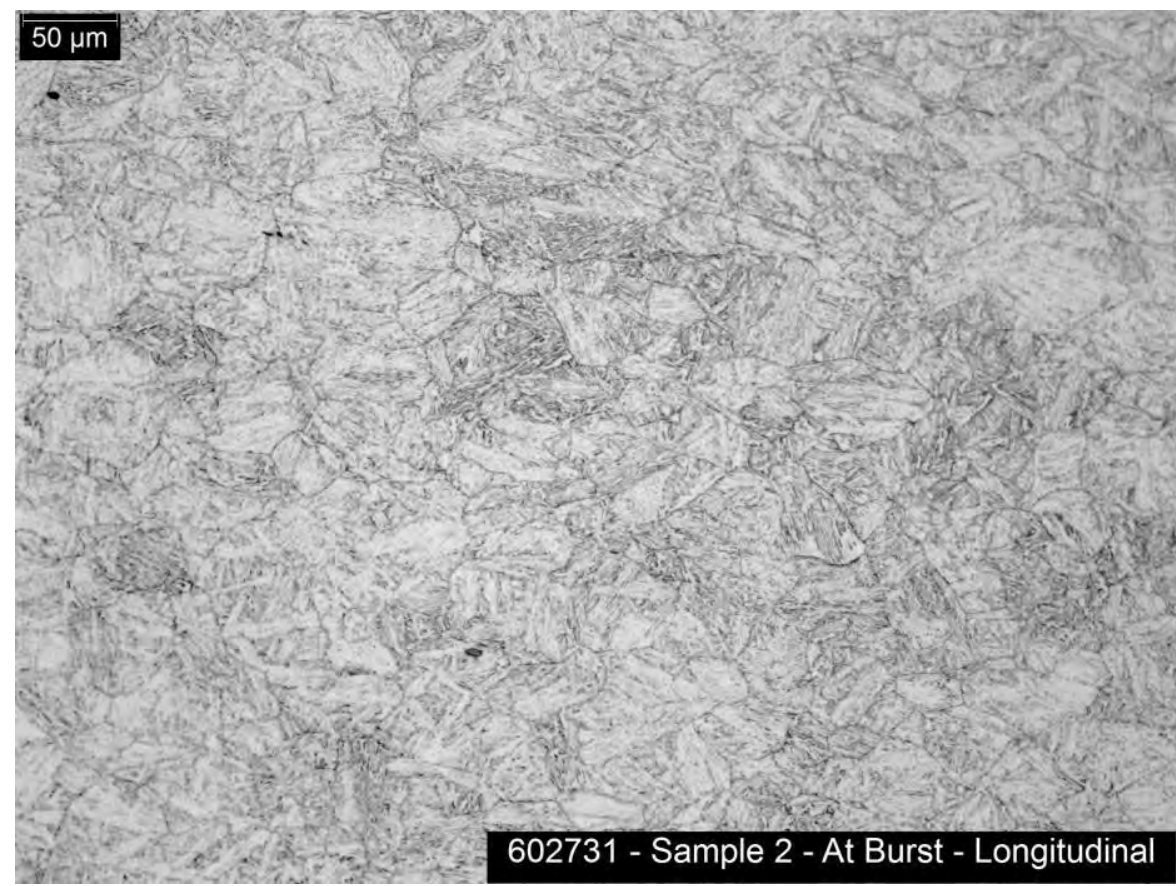

Figure 42: Sample 2 - Microphotograph of Longitudinal cross-section at Burst, Grain Size No. 7 


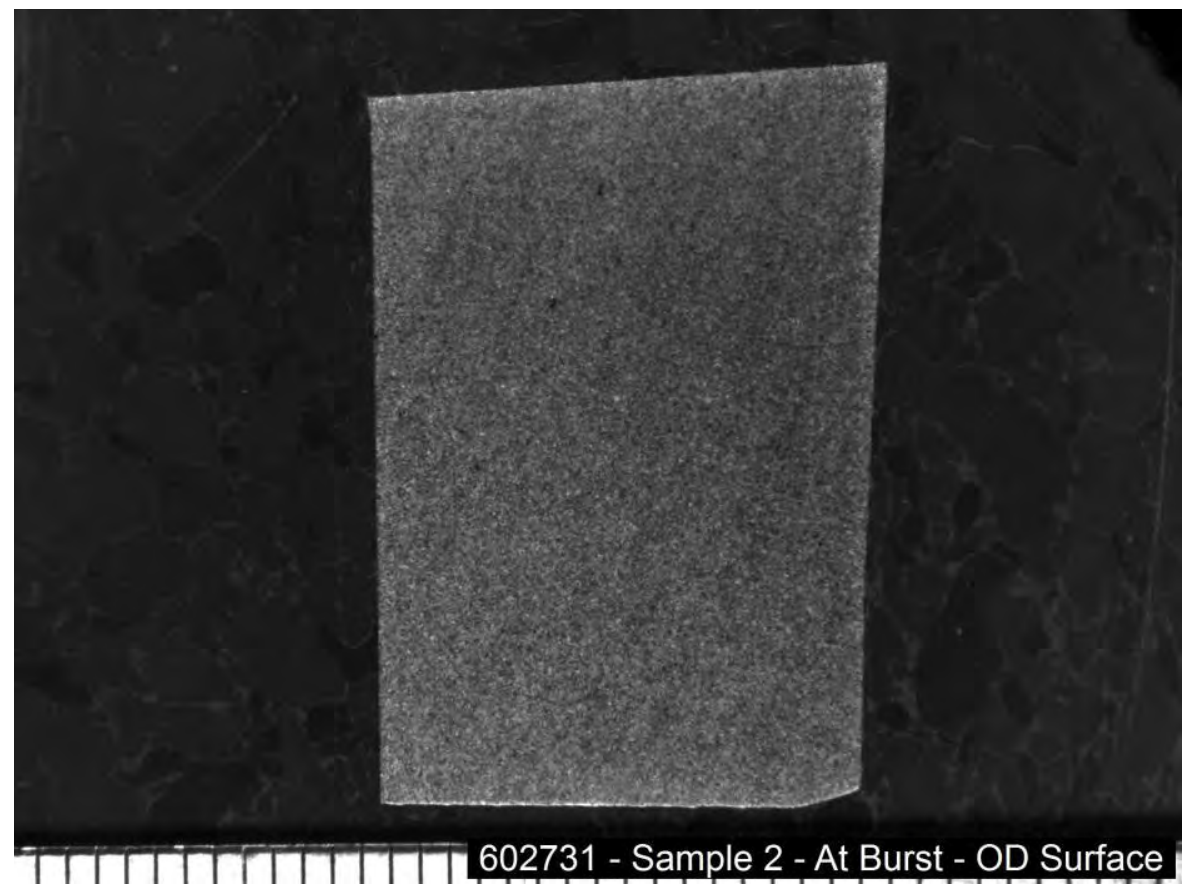

Figure 43: Sample 2 - Macrophotograph of OD Surface cross-section at Burst (scale in mm)

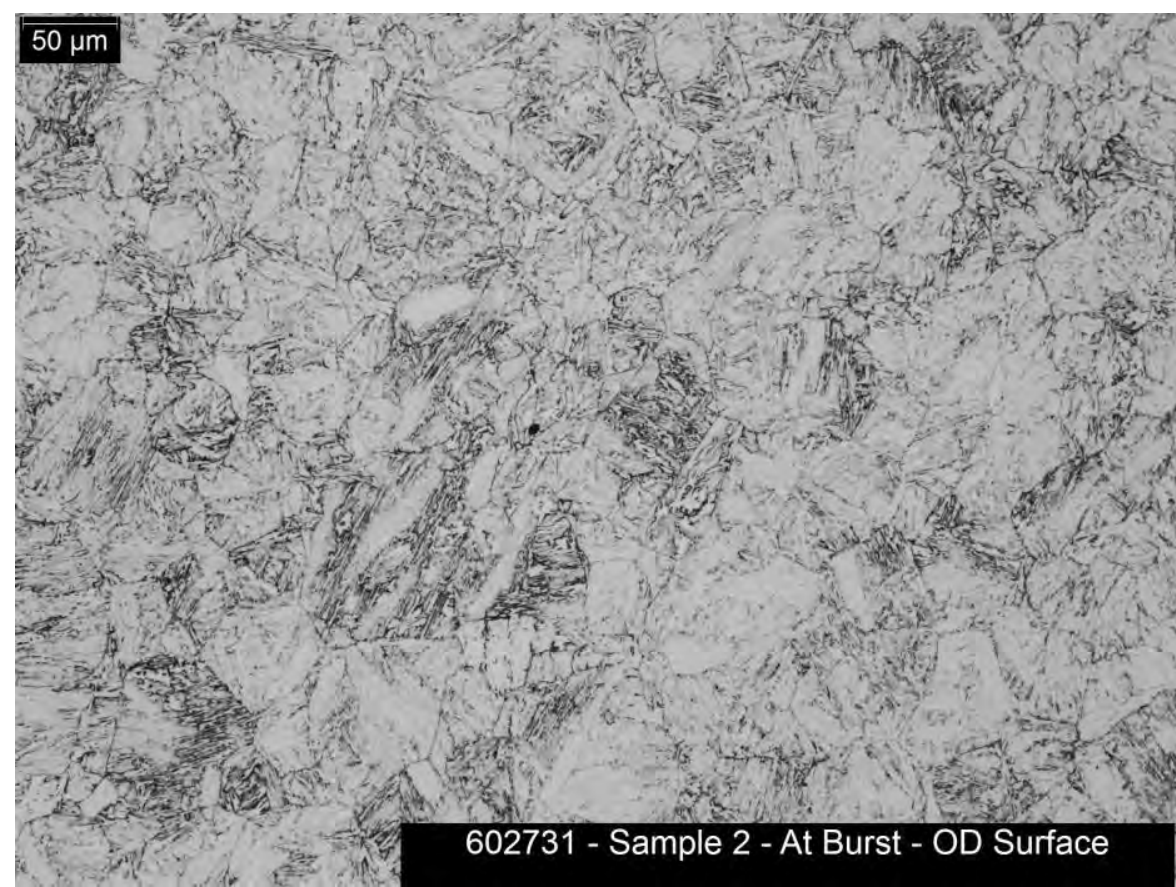

Figure 44: Sample 2 - Microphotograph of OD Surface cross-section at Burst, Grain Size No. 6 


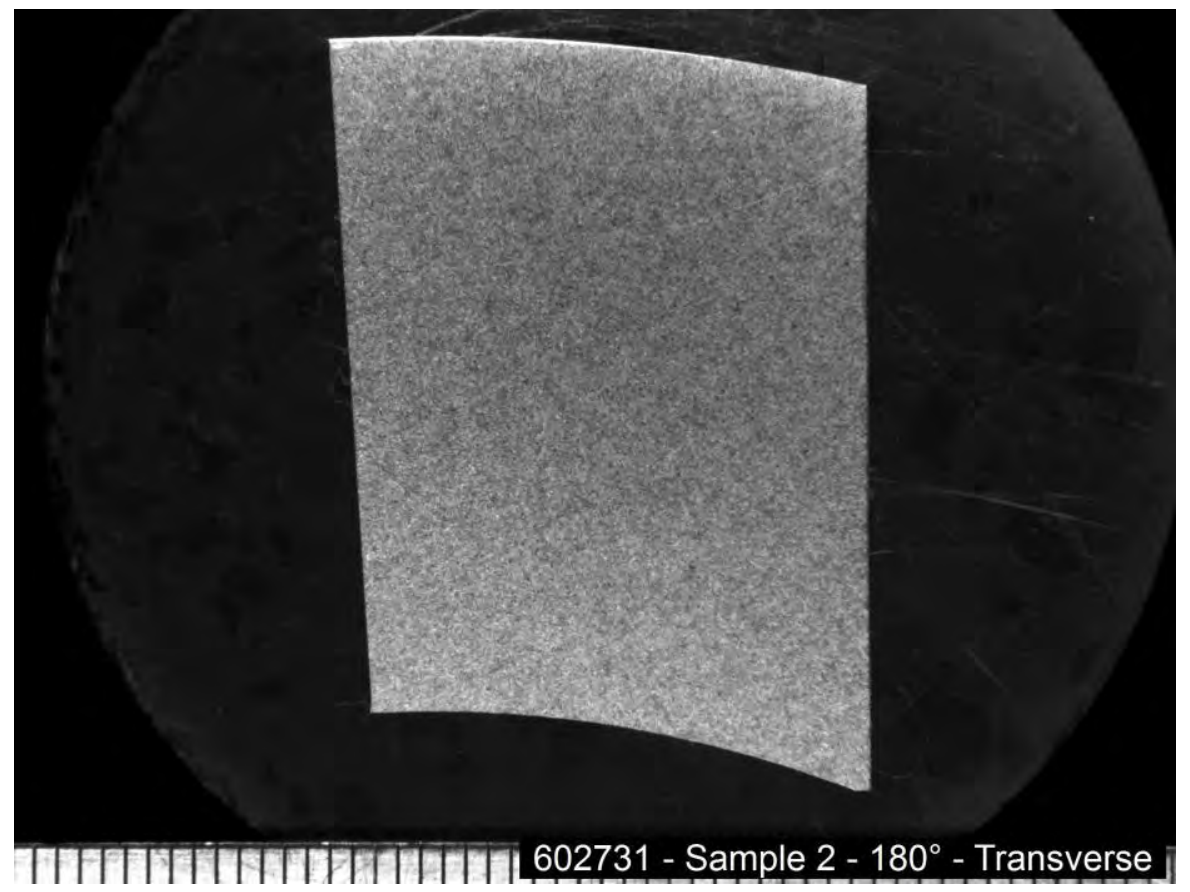

Figure 45: Sample 2 - Macrophotograph of Transverse cross-section at $180^{\circ}$ from Burst (scale in mm)

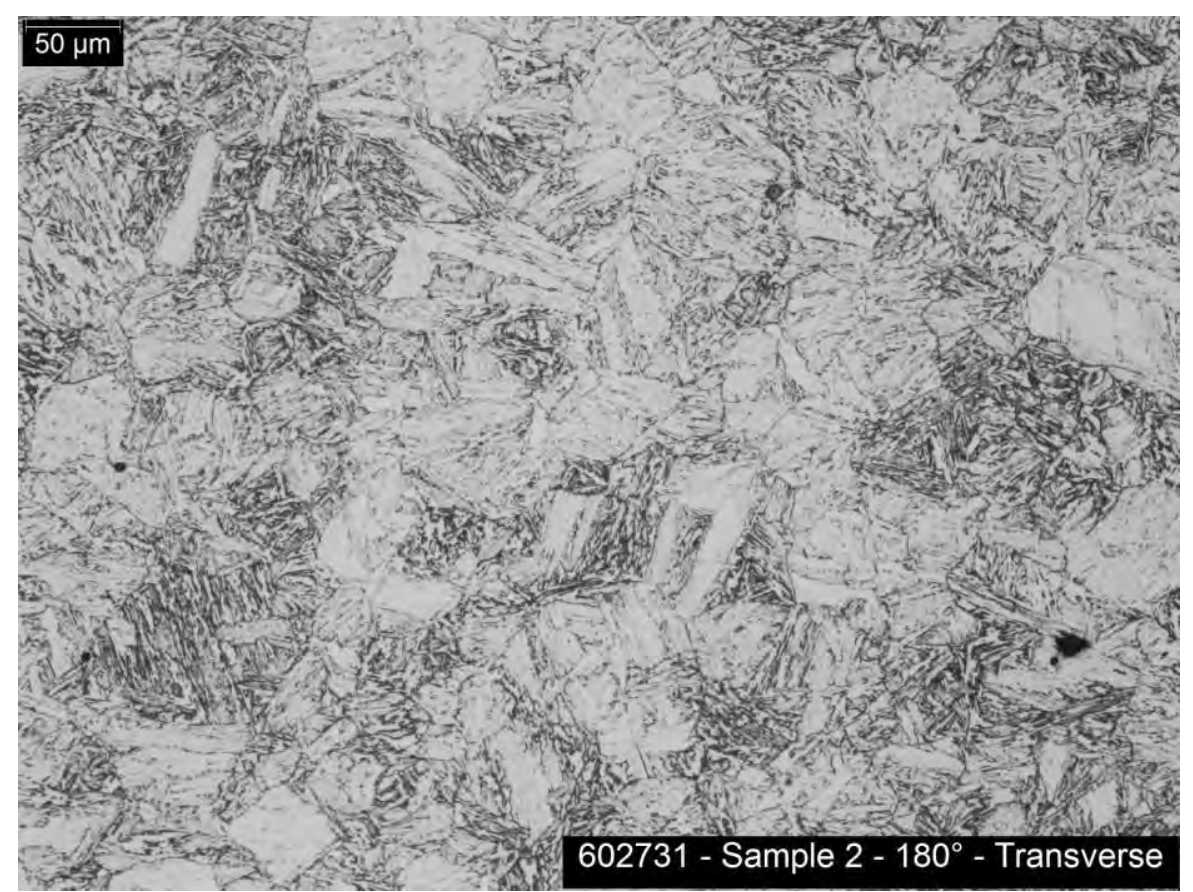

Figure 46: Sample 2 - Microphotograph of Transverse cross-section at $180^{\circ}$ from Burst, Grain Size No. 6 


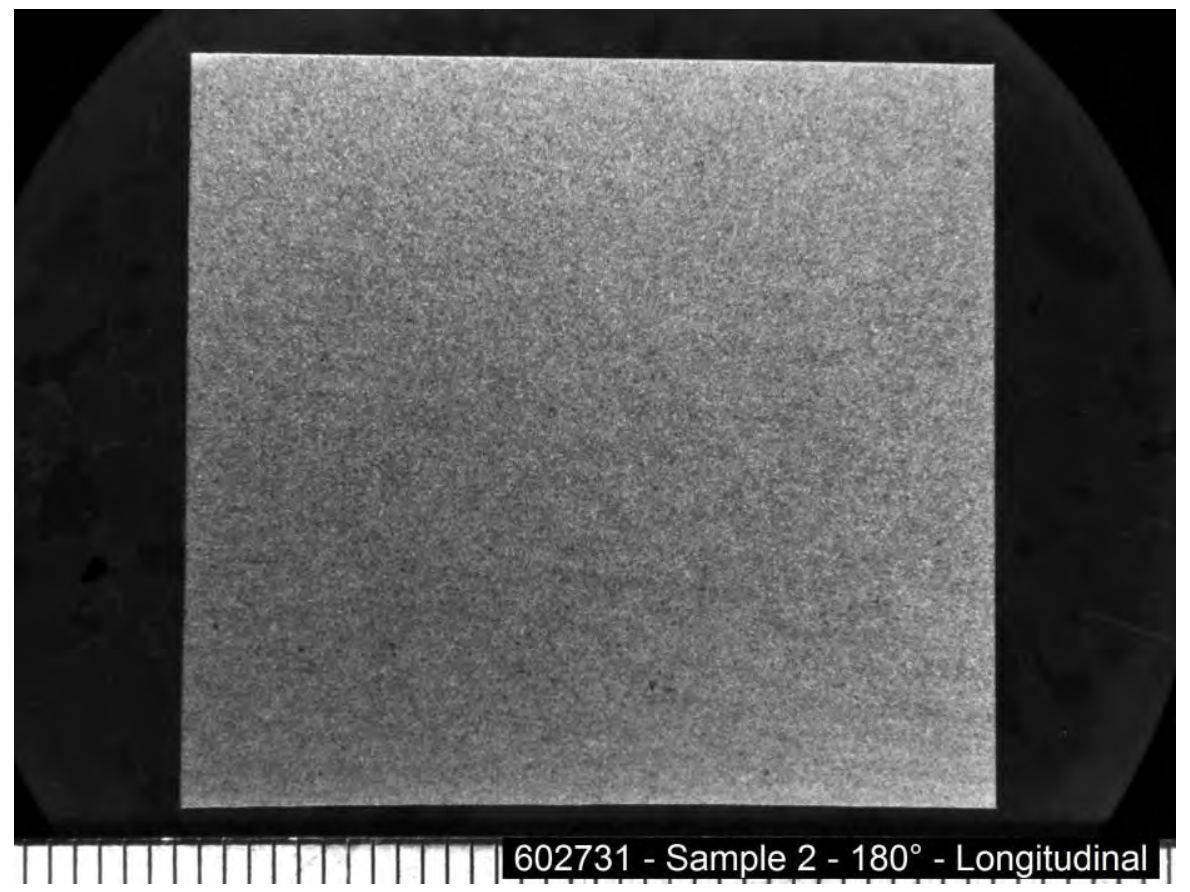

Figure 47: Sample 2 - Microphotograph of Transverse cross-section at $180^{\circ}$ from Burst (scale in mm)

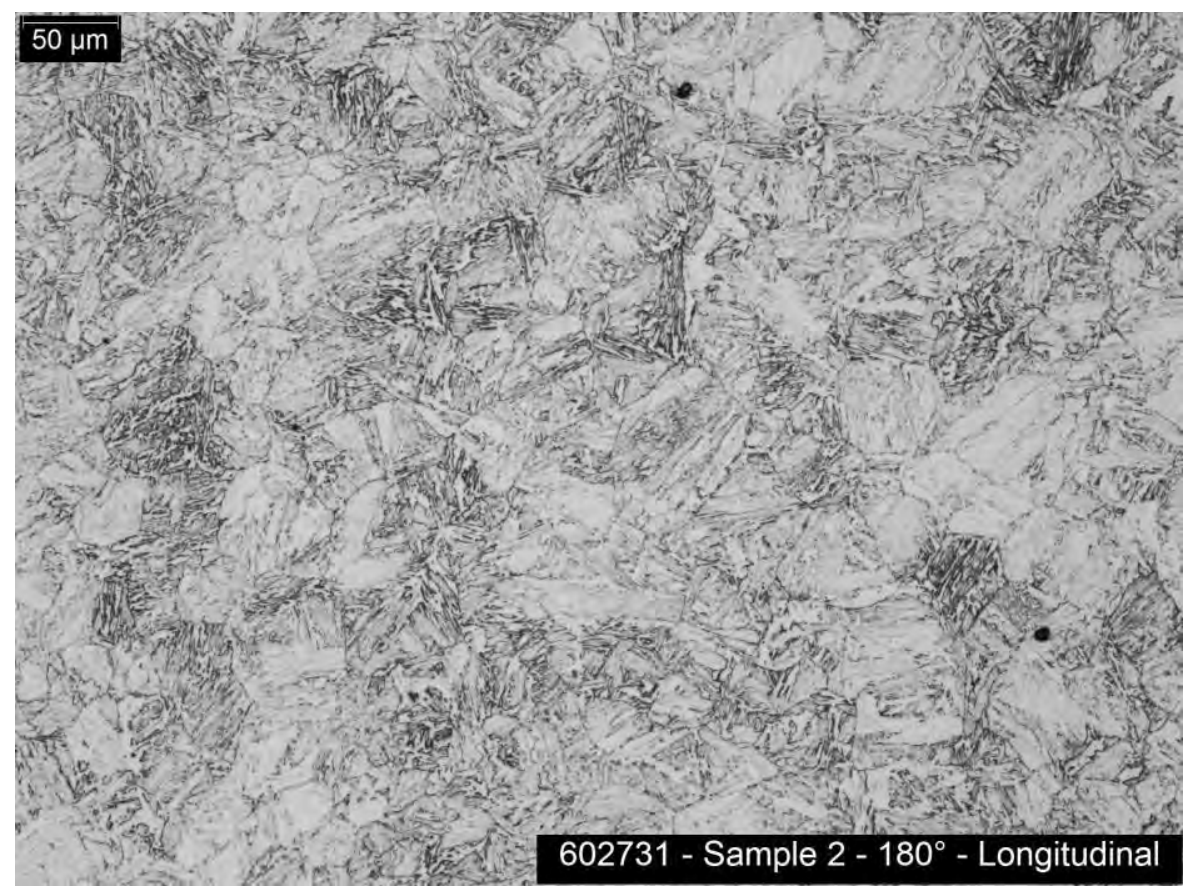

Figure 48: Sample 2 - Microphotograph of Longitudinal cross-section at $180^{\circ}$ from Burst, Grain Size No. 7 


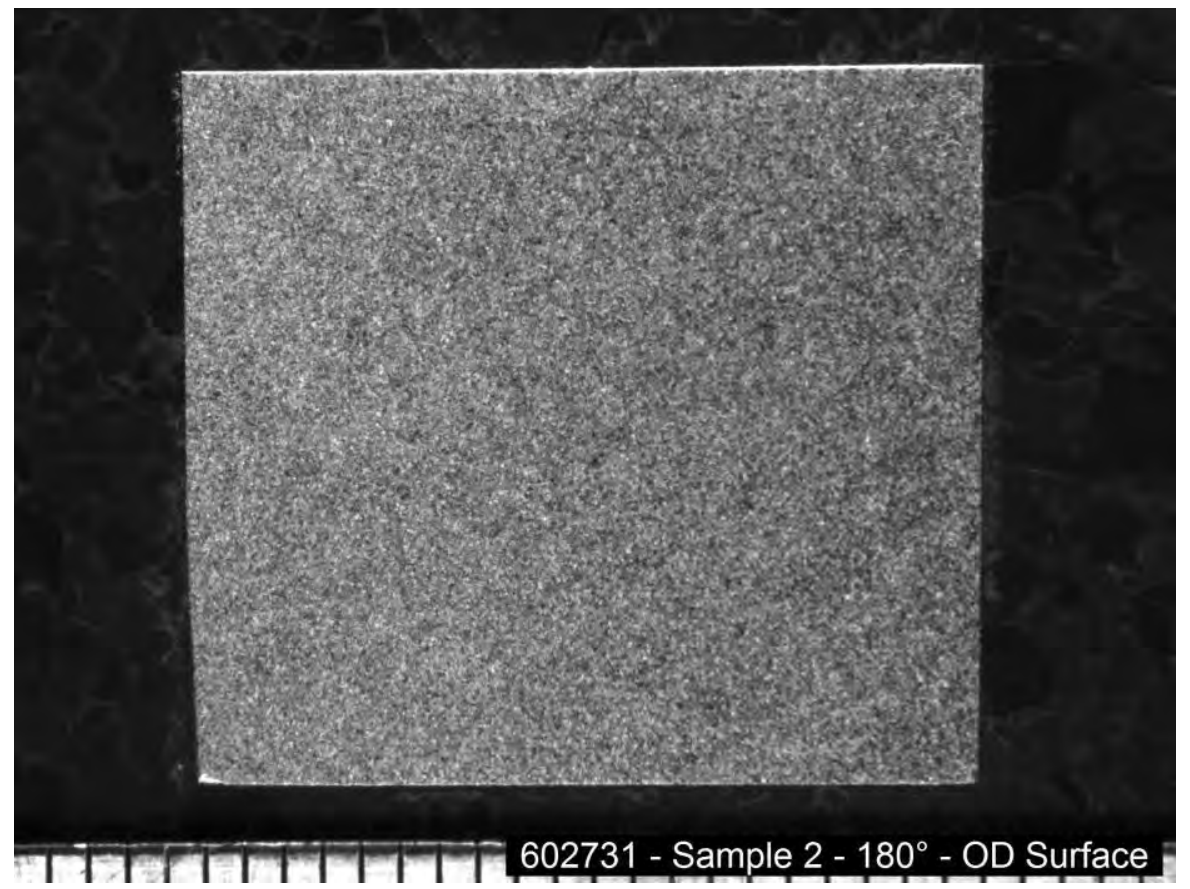

Figure 49: Sample 2 - Macrophotograph of OD Surface cross-section at $180^{\circ}$ from Burst (scale in mm)

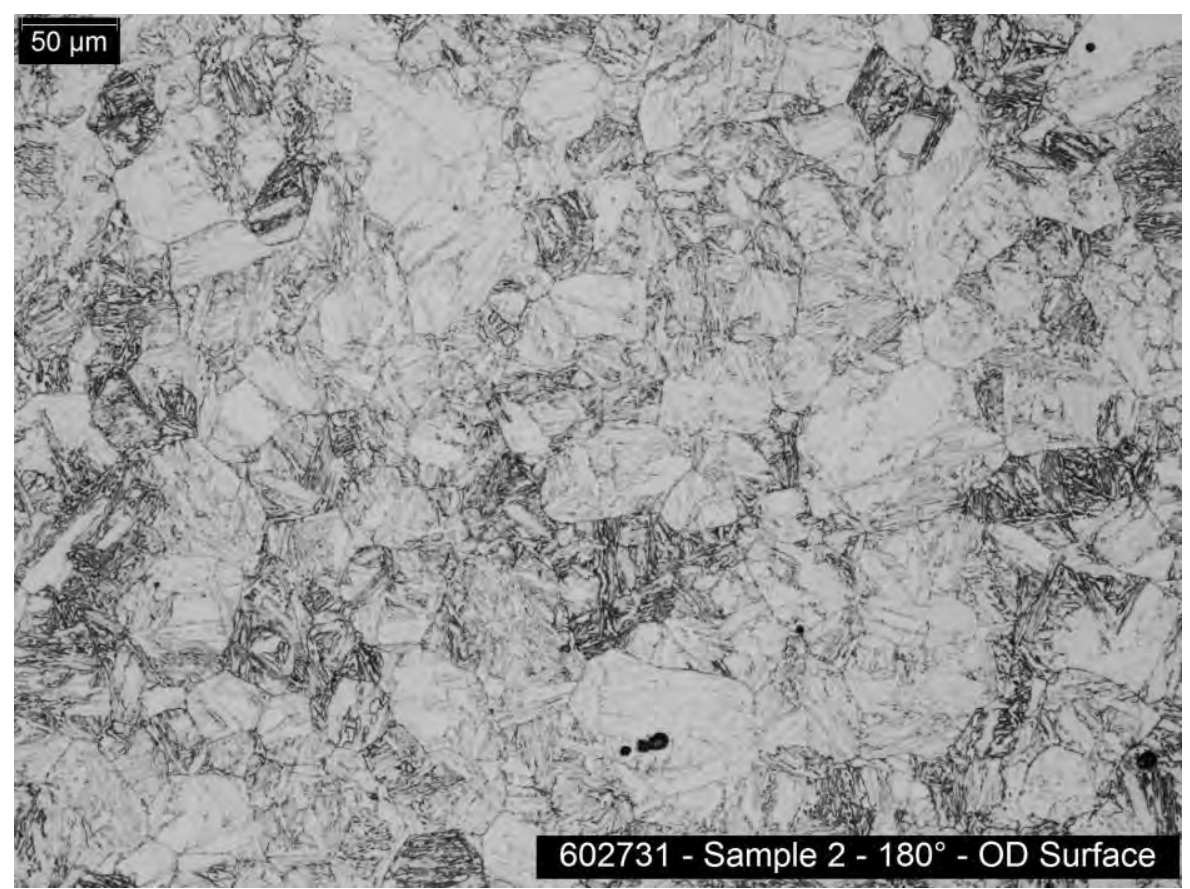

Figure 50: Sample 2 - Microphotograph of OD Surface cross-section at $180^{\circ}$ from Burst, Grain Size No. 7 


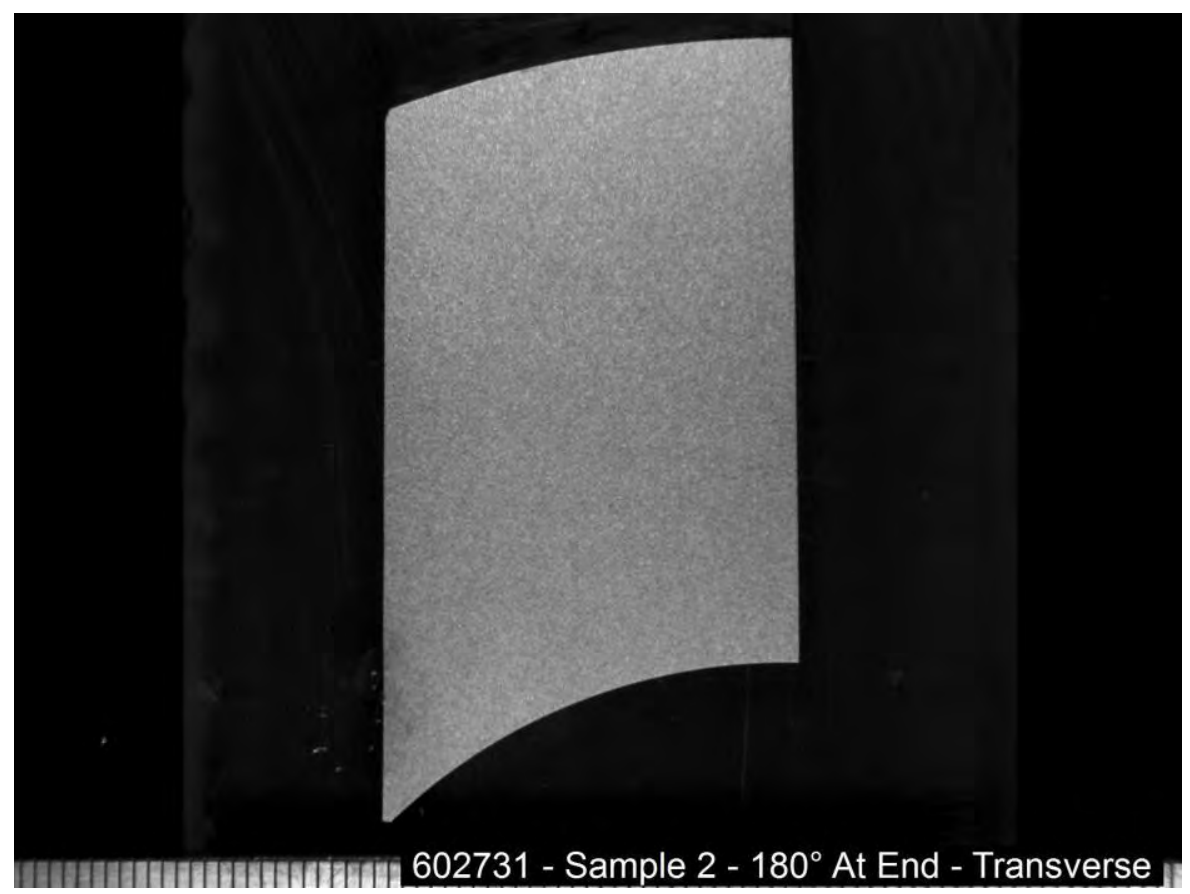

Figure 51: Sample 2 - Macrophotograph of Transverse cross-section at $180^{\circ}$ from Burst at End (scale in mm)

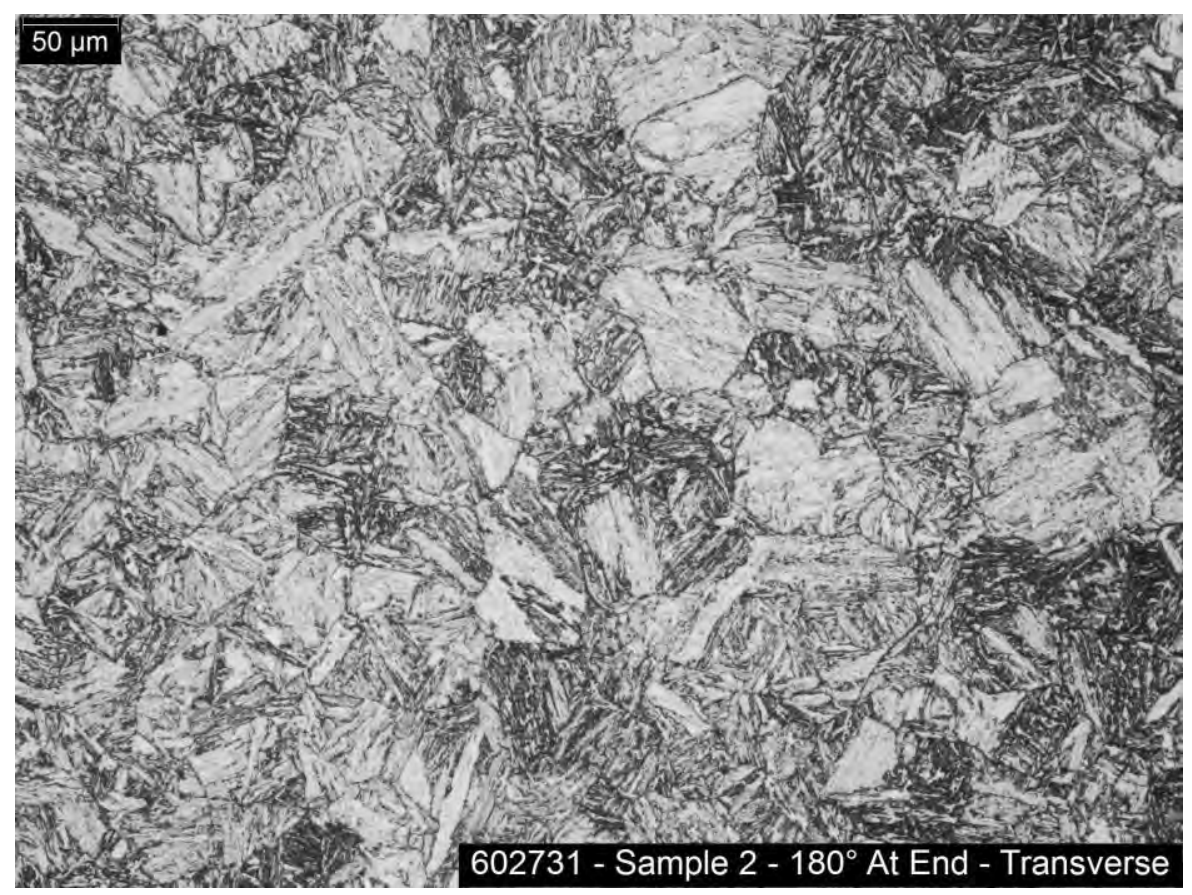

Figure 52: Sample 2 - Microphotograph of Transverse cross-section at $180^{\circ}$ from Burst at End, Grain Size No. 7 


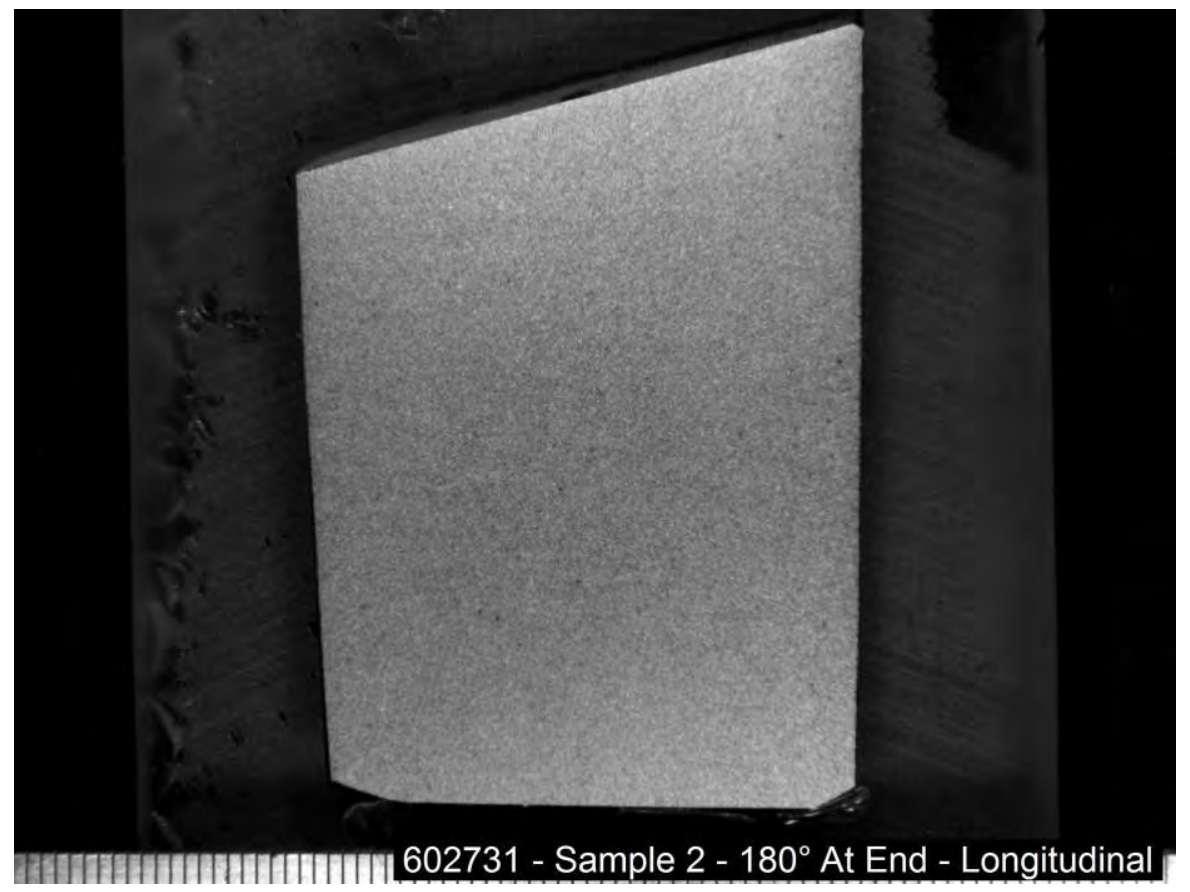

Figure 53: Sample 2 - Macrophotograph of Longitudinal cross-section at $180^{\circ}$ from Burst at End (scale in mm)

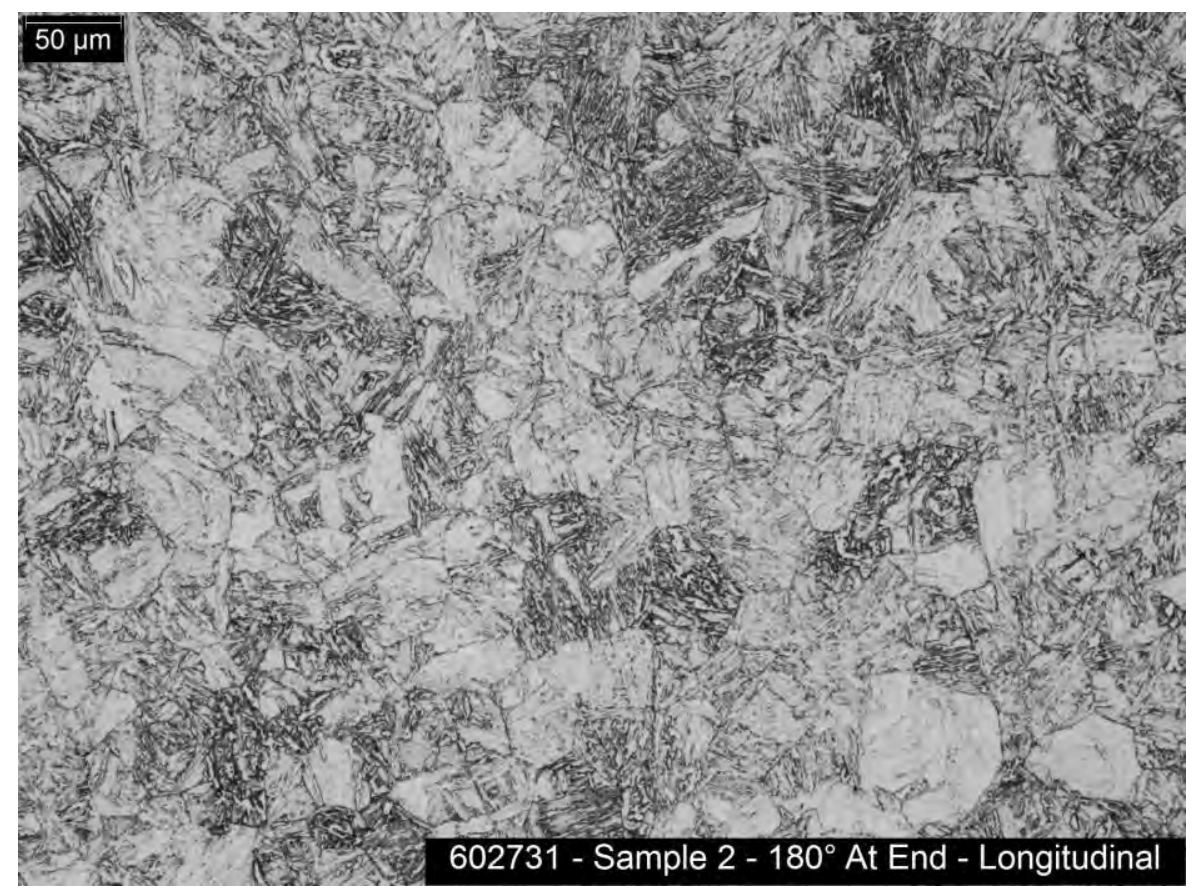

Figure 54: Sample 2 - Microphotograph of Longitudinal cross-section at $180^{\circ}$ from Burst at End, Grain Size No. 7 


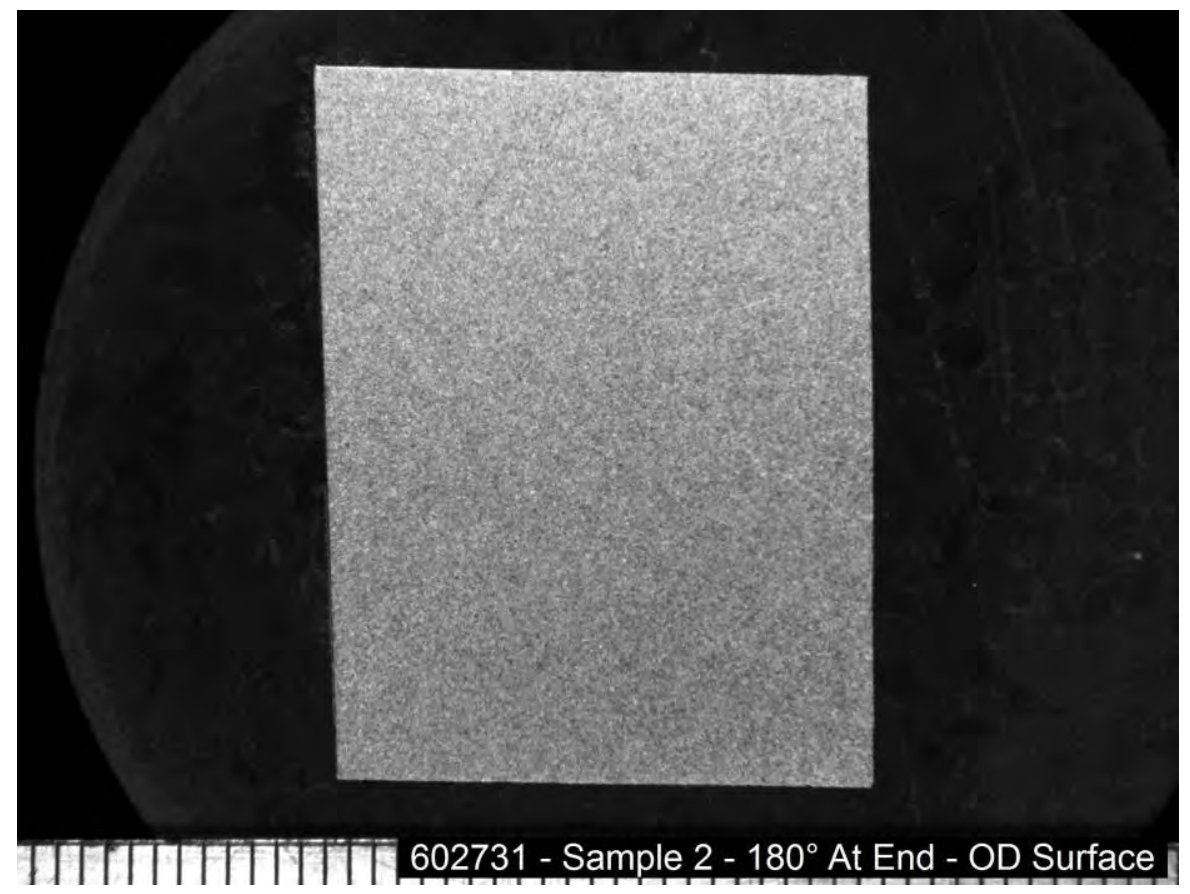

Figure 55: Sample 2 - Macrophotograph of OD Surface cross-section at $180^{\circ}$ from Burst at End (scale in mm)

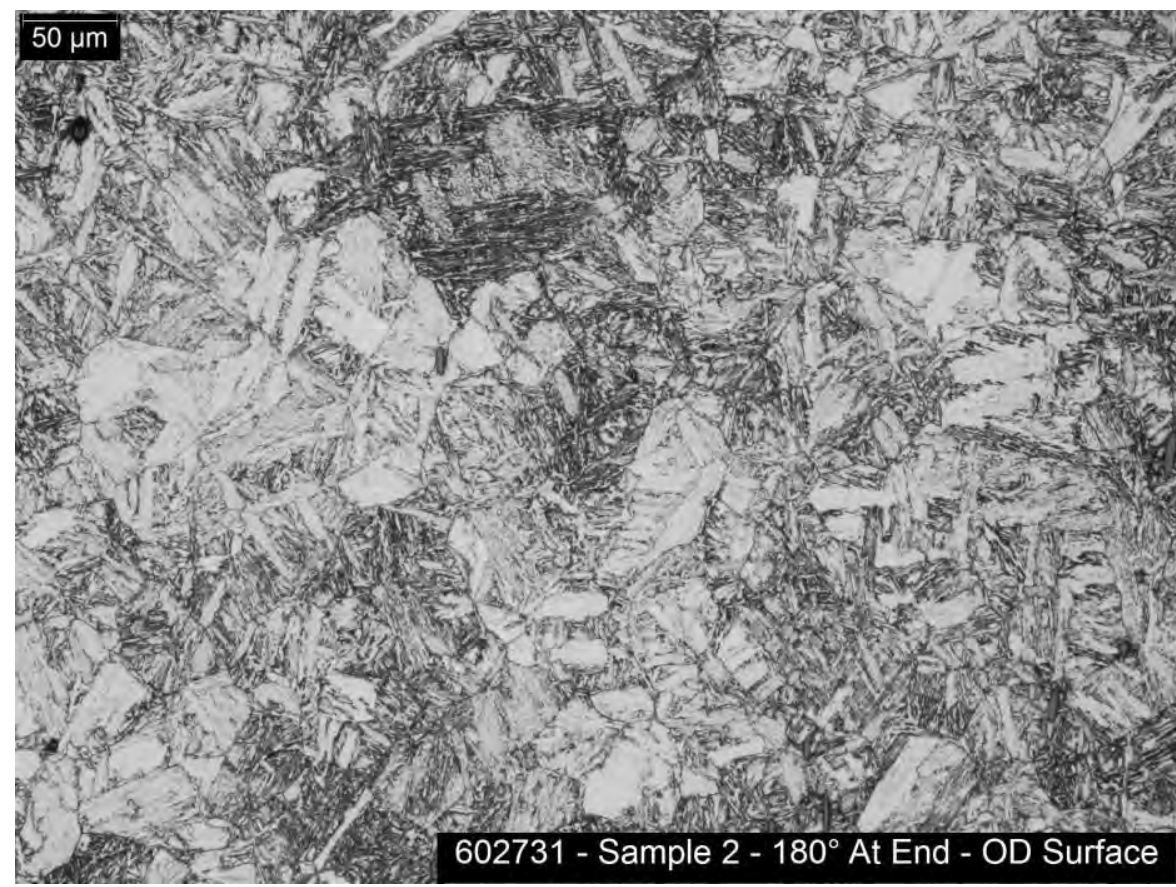

Figure 56: Sample 2 - Microphotograph of OD Surface cross-section at $180^{\circ}$ from Burst at End, Grain Size No. 7 
Issue: 01

\subsection{HARDNESS TESTS}

The six transverse samples from Sample 1 \& 2 were used to perform Vickers Hardness as shown in Figures 57-62. The tests were performed with a load of $10 \mathrm{kgf}$ per the current revision of ASTM E384. As requested by the client, indentations were mapped across the majority of each cross-section surface.

Tables 3 \& 4 shows the difference in overall hardness values between locations in each sample. The microhardness average at the Burst Locations for each sample is nearly the same; Sample 1 Vickers Hardness Average is 272, while Sample 2 is 279.

\begin{tabular}{|l|l|c|c|c|l|}
\hline \multicolumn{7}{|l|}{ Vickers Hardness Comparison-Sample 1 } \\
\hline Location & Minimum & Maximum & Range & Average & \multicolumn{1}{c|}{ Comments } \\
\hline \multicolumn{1}{|c|}{ AtBurst } & $* 252$ & 300 & 48 & 272 & $\begin{array}{c}\text { *Hardness value of 229 resultedas an invalidindent, excluded from } \\
\text { data; next lowest is 252. Highhardness near ID and fracture. High } \\
\text { hardness at fracture is due to strain hardening. }\end{array}$ \\
\hline $180^{\circ}$ from Burst & 246 & 279 & 33 & 260 & Higherhardness valuesnear ID \\
\hline $180^{\circ}$ fromBurstat End & 226 & 250 & 24 & 237 & $\begin{array}{l}\text { Hardness valuesmorehomogenousacross sample.Lowerhardness } \\
\text { valuescompared to AtBurstand } 180^{\circ} \text { fromBurstLocations. }\end{array}$ \\
\hline
\end{tabular}

Table 3: Sample 1 - Comparison of Hardness Results at Three Locations

\begin{tabular}{|l|l|c|c|l|l|}
\hline \multicolumn{7}{|l|}{ Vickers Hardness Comparison-Sample 2 } \\
\hline Location & Minimum & Maximum & Range & Average & Comments \\
\hline \multicolumn{1}{|c|}{ AtBurst } & 252 & 300 & 48 & 279 & $\begin{array}{c}\text { Highhardness near ID and at fracture. Highhardness at fracture is due } \\
\text { to strainhardening. }\end{array}$ \\
\hline $180^{\circ}$ from Burst & 244 & 276 & 32 & 256 & Higherhardness valuesnear ID. \\
\hline $180^{\circ}$ fromBurstat End & 228 & 256 & 28 & 239 & $\begin{array}{c}\text { Higherhardness valuesnear ID. Lowerhardness values compared to } \\
\text { AtBurstand } 180^{\circ} \text { fromBurst Locations. }\end{array}$ \\
\hline
\end{tabular}

Table 4: Sample 2 - Comparison of Hardness Results at Three Locations 


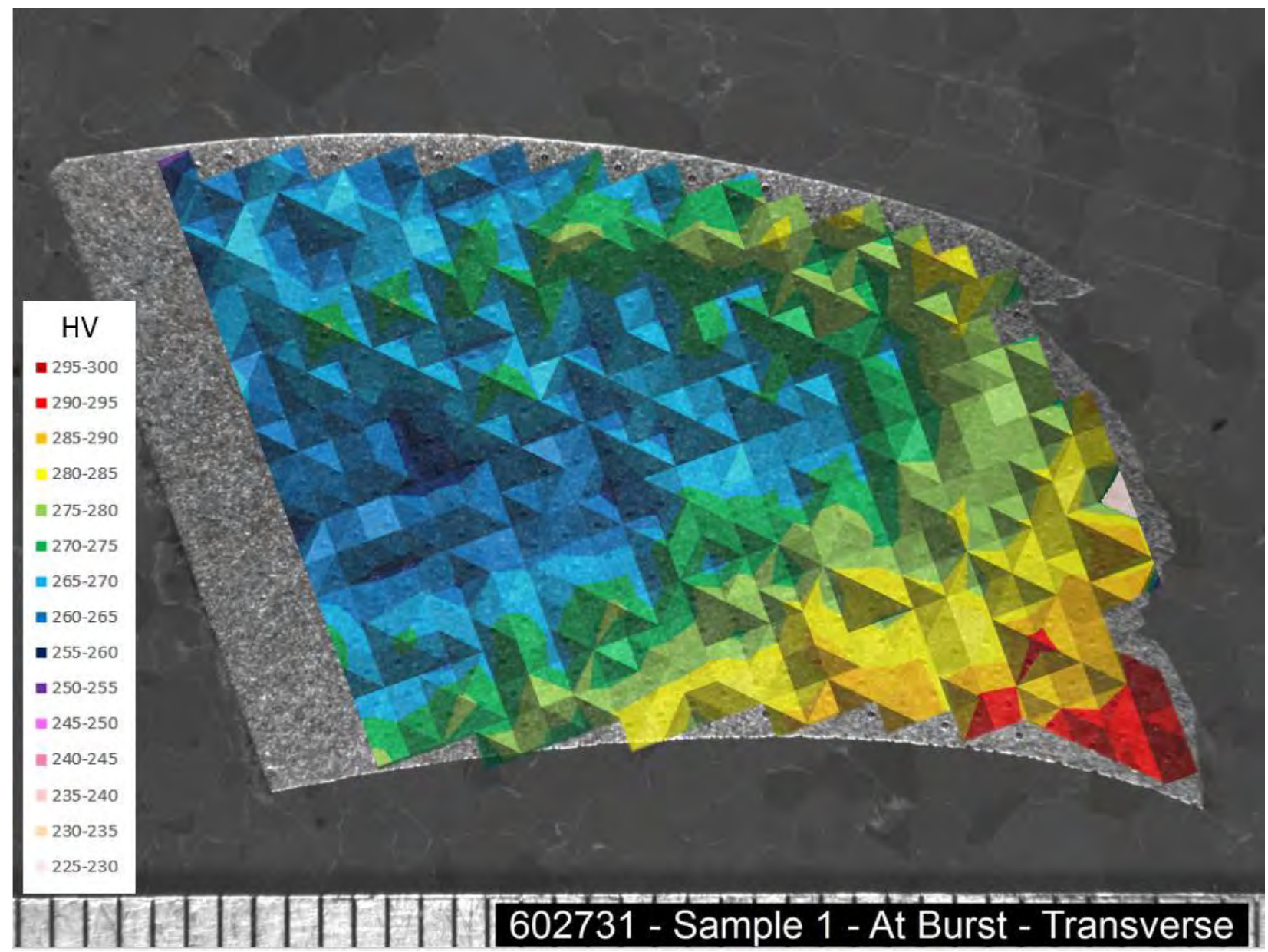

Figure 57: Sample 1 - Hardness Map of At Burst - Transverse Area (scale in mm) 


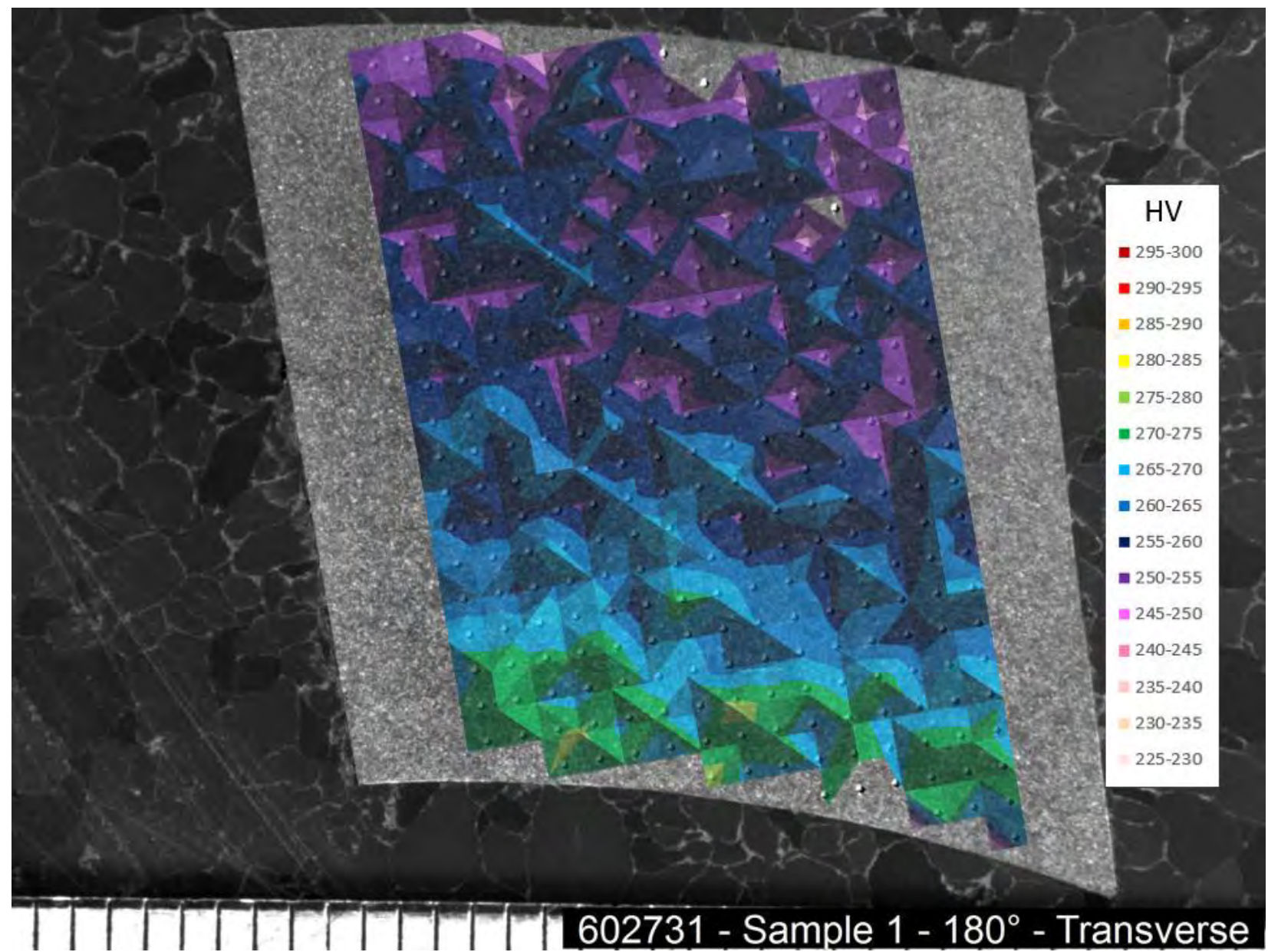

Figure 58: Sample 1 - Hardness Map of $180^{\circ}$ - Transverse Area (scale in mm) 


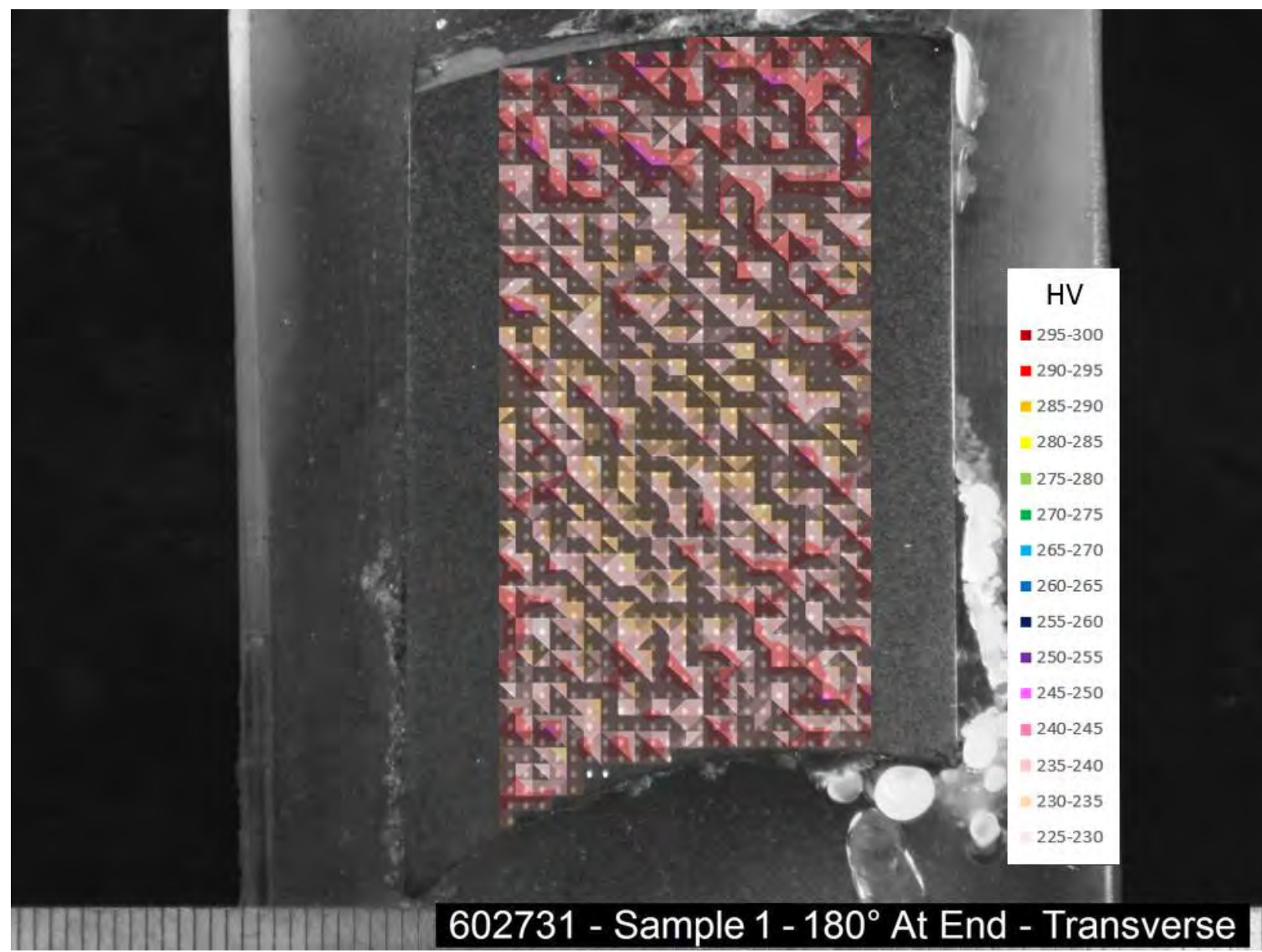

Figure 59: Sample 1 - Hardness Map of $180^{\circ}$ At End - Transverse Area (scale in mm) 


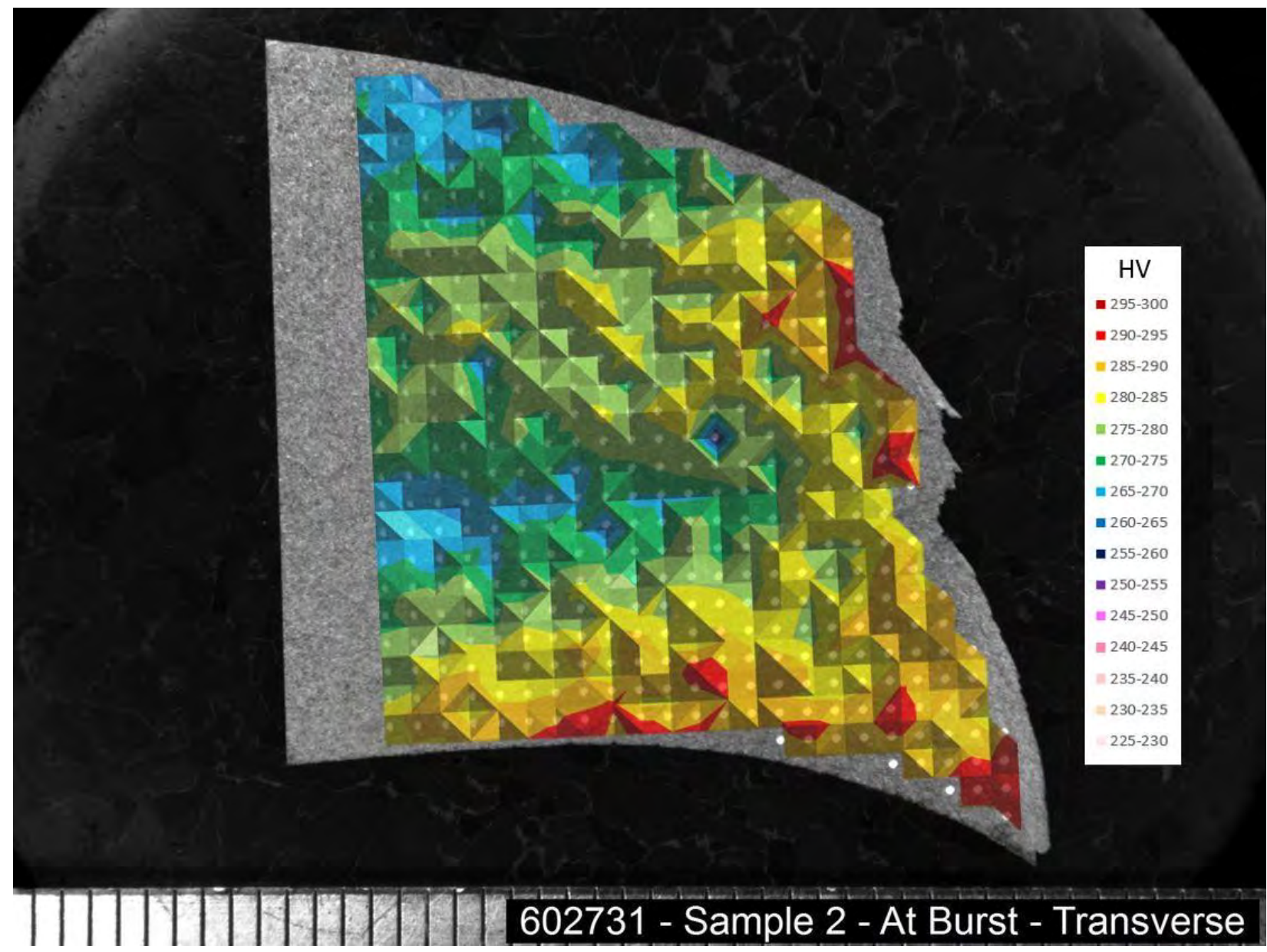

Figure 60: Sample 2 - Hardness Map of At Burst - Transverse Area (scale in mm) 


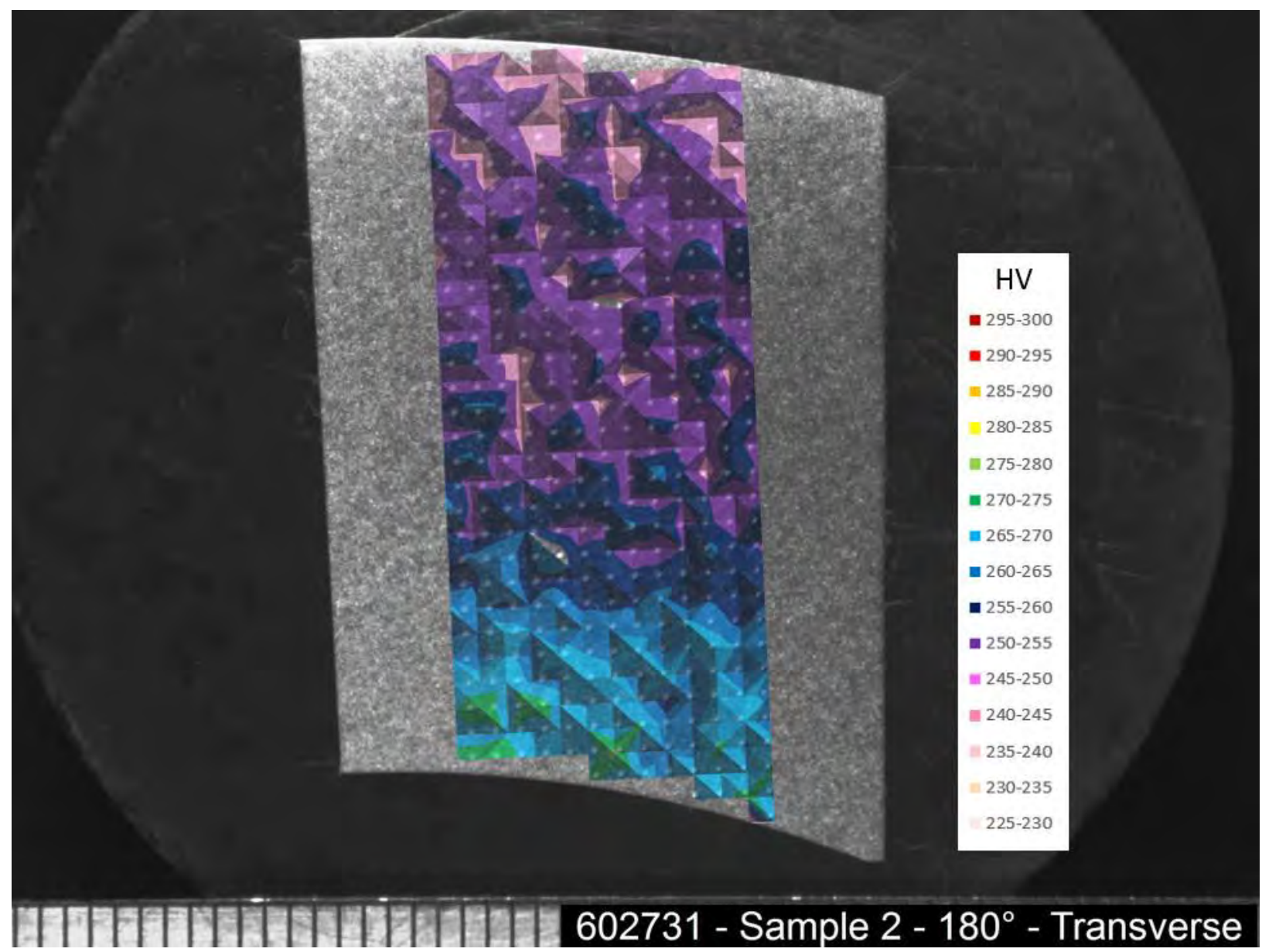

Figure 61: Sample 2 - Hardness Map of $180^{\circ}$ - Transverse Area (scale in $\mathbf{m m}$ ) 


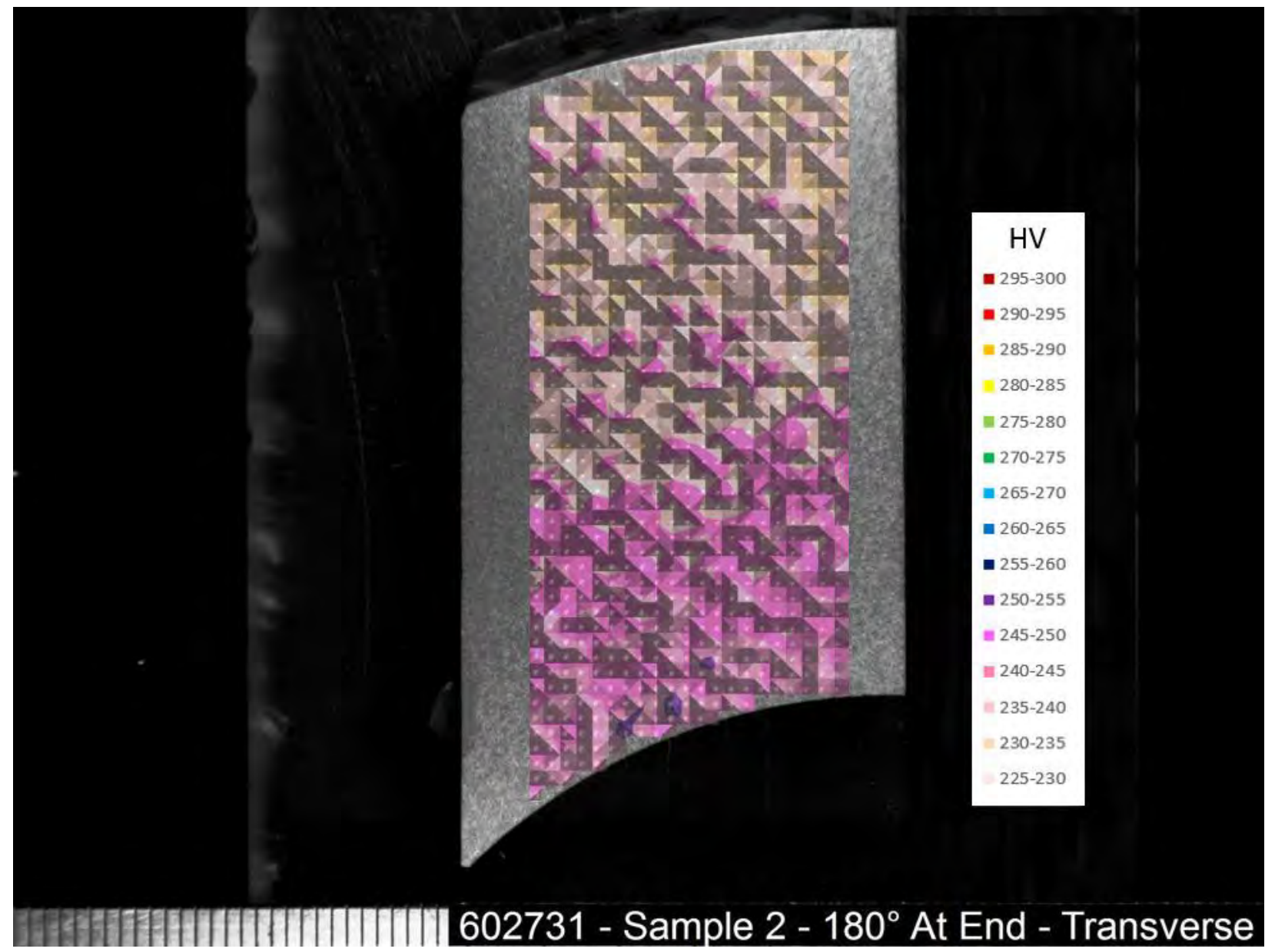

Figure 62: Sample 2 - Hardness Map of $180^{\circ}$ At End - Transverse Area (scale in mm) 


\subsection{SCANNING ELECTRON MICROSCOPY}

In order to identify the nature of the fracture at the OD, MW, and ID, the fracture surfaces were prepared for examination using scanning electron microscopy (SEM). Figure 63 is the fracture face of Sample 1 and shows where the SEM images are located. The SEM images for Sample 1 are shown in Figures 64-69. Figure 70 is the fracture face of Sample 2 and shows where the SEM images are located. The SEM images for Sample 2 are shown in Figures 71-76.

The SEM examination for both samples revealed numerous cuplike depressions consistent with dimple rupture. Elongated dimples were observed near the OD and ID. No evidence of machining or material defects were found during the SEM examination.

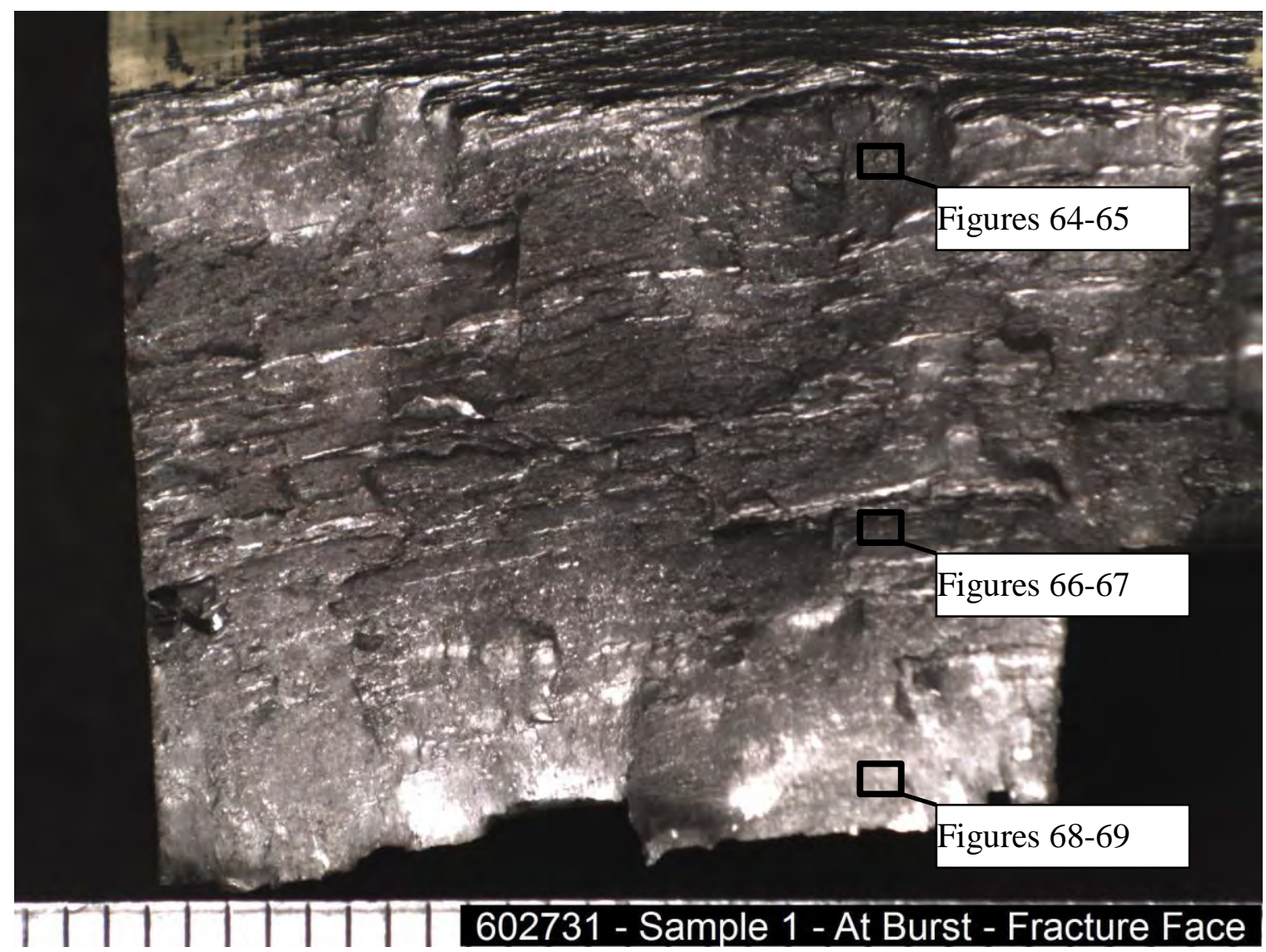

Figure 63: Sample 1 - Fracture Face and SEM Locations (scale in mm) 
Reference No: 602731

Issue: 01

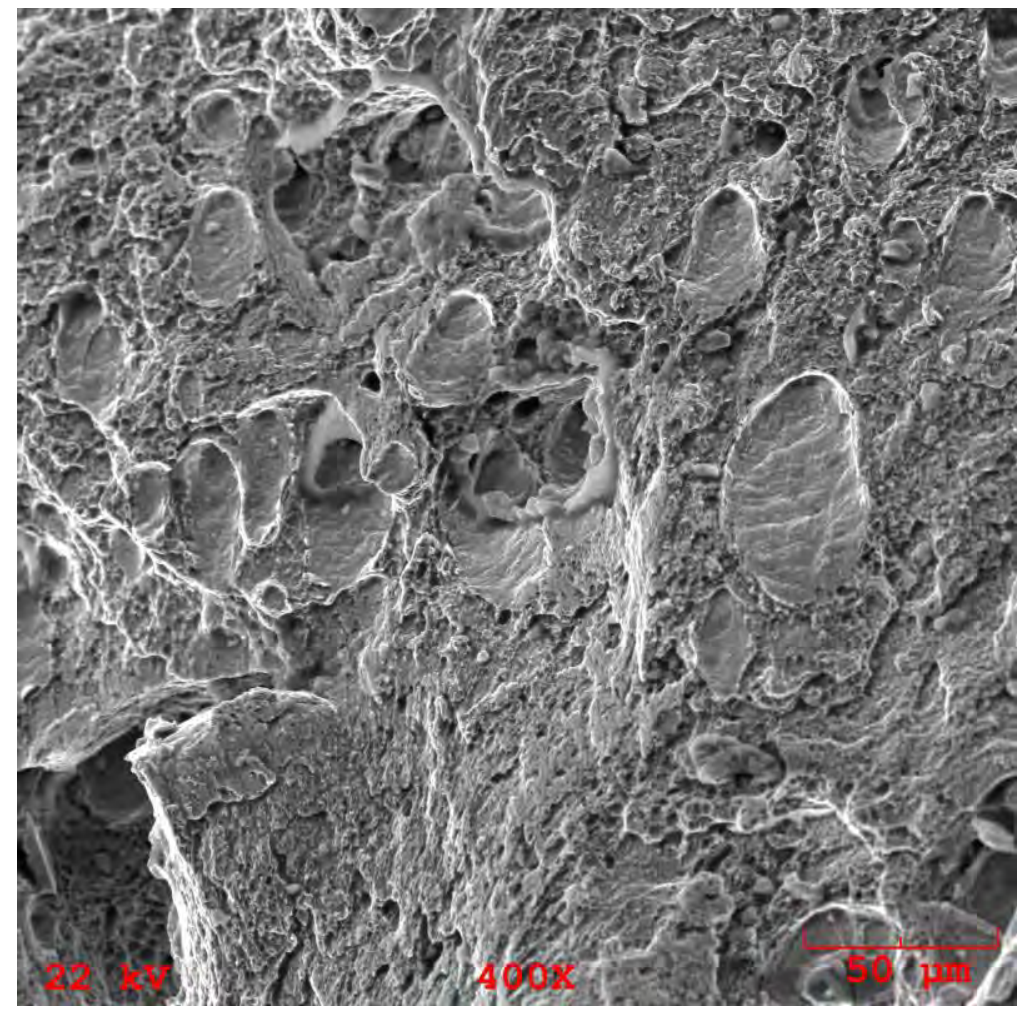

Figure 64: Sample 1 - SEM Image of Fracture Face near OD
Aiken Engineering Company

51 Pages

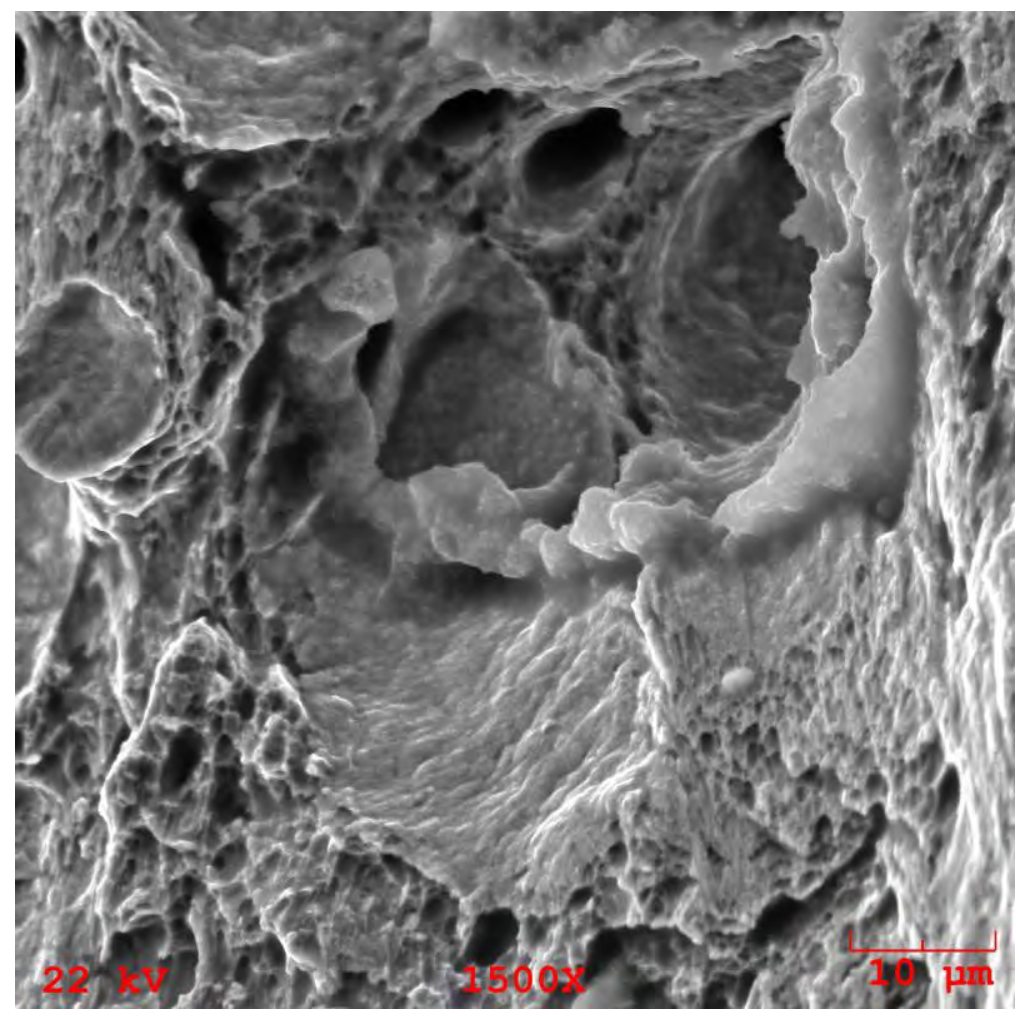

Figure 65: Sample 1 - SEM Image of Fracture Face near OD 
Reference No: 602731

Issue: 01
Aiken Engineering Company

51 Pages

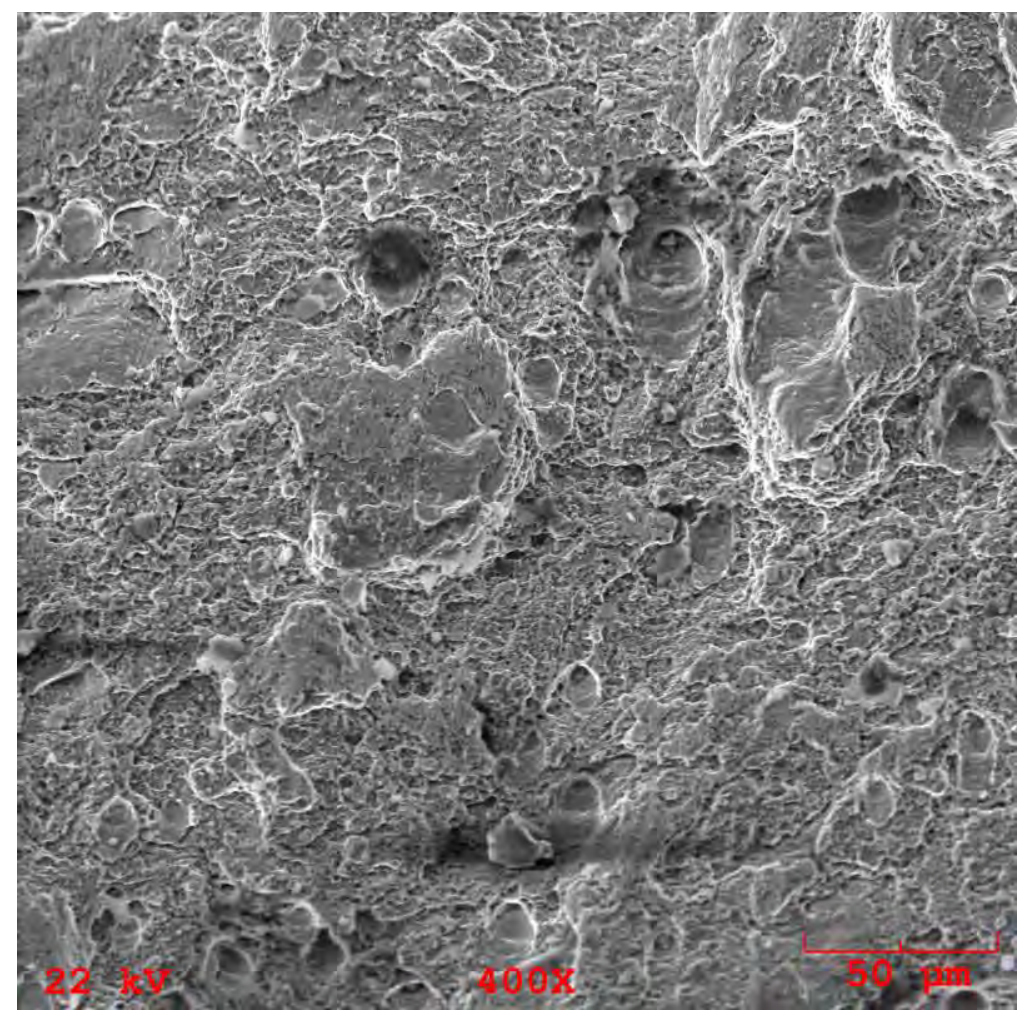

Figure 66: Sample 1 - SEM Image of Fracture Face near MW

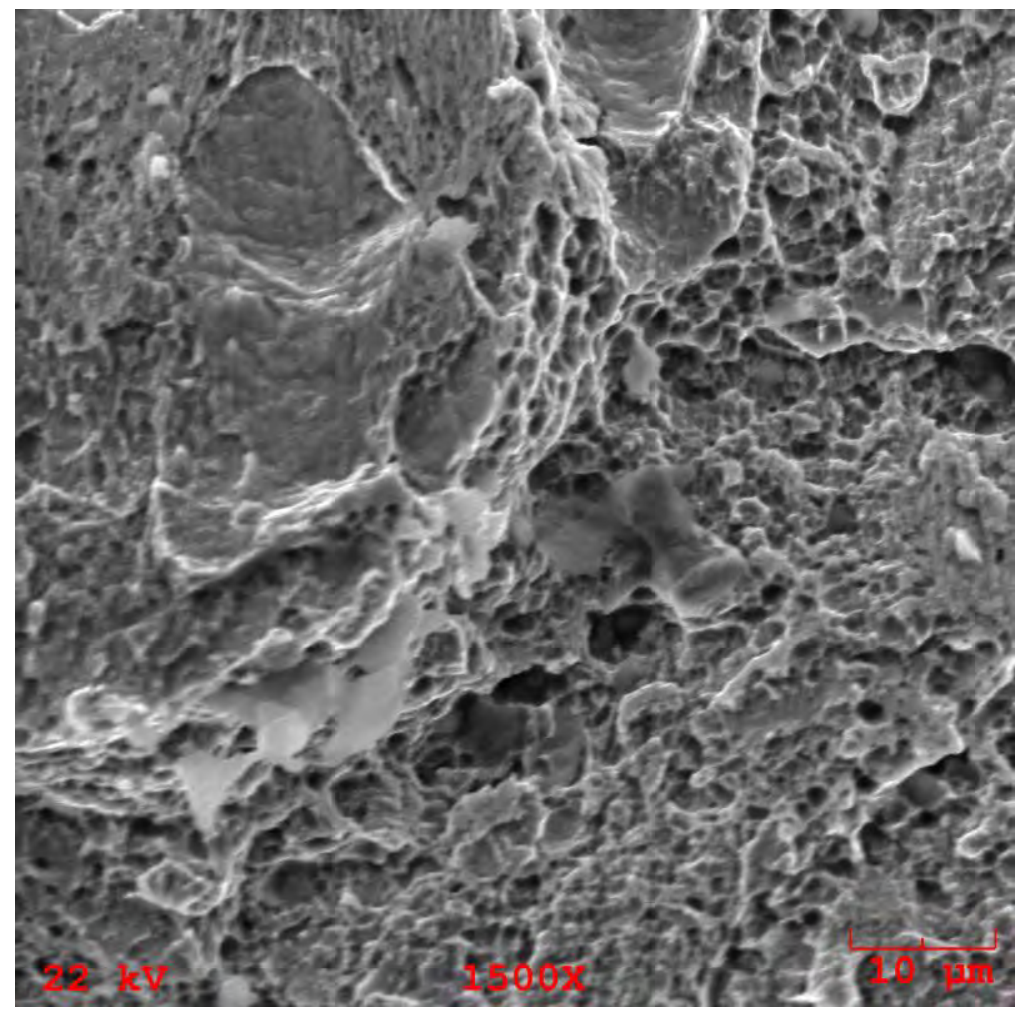

Figure 67: Sample 2 - SEM Image of Fracture Face near MW 
Reference No: 602731

Issue: 01

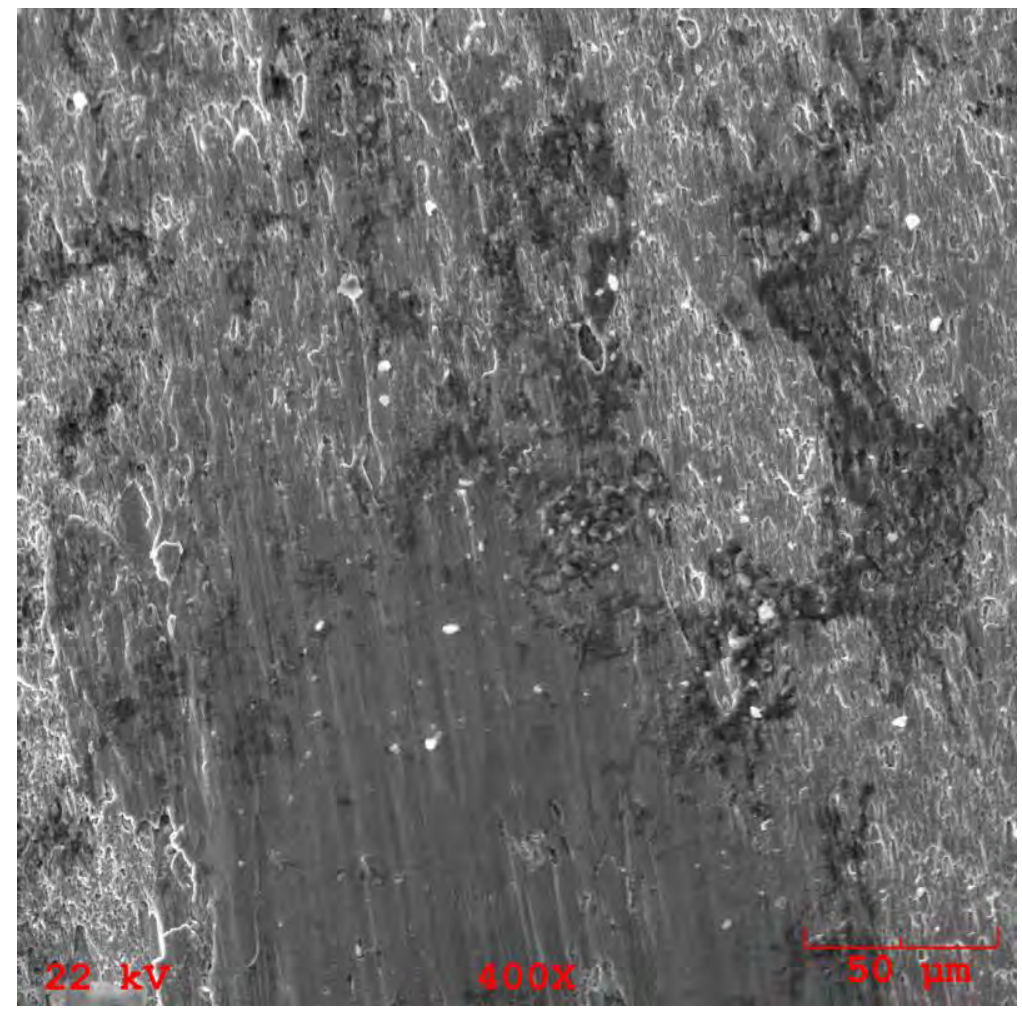

Figure 68: Sample 1 - SEM Image of Fracture Face near ID
Aiken Engineering Company

51 Pages

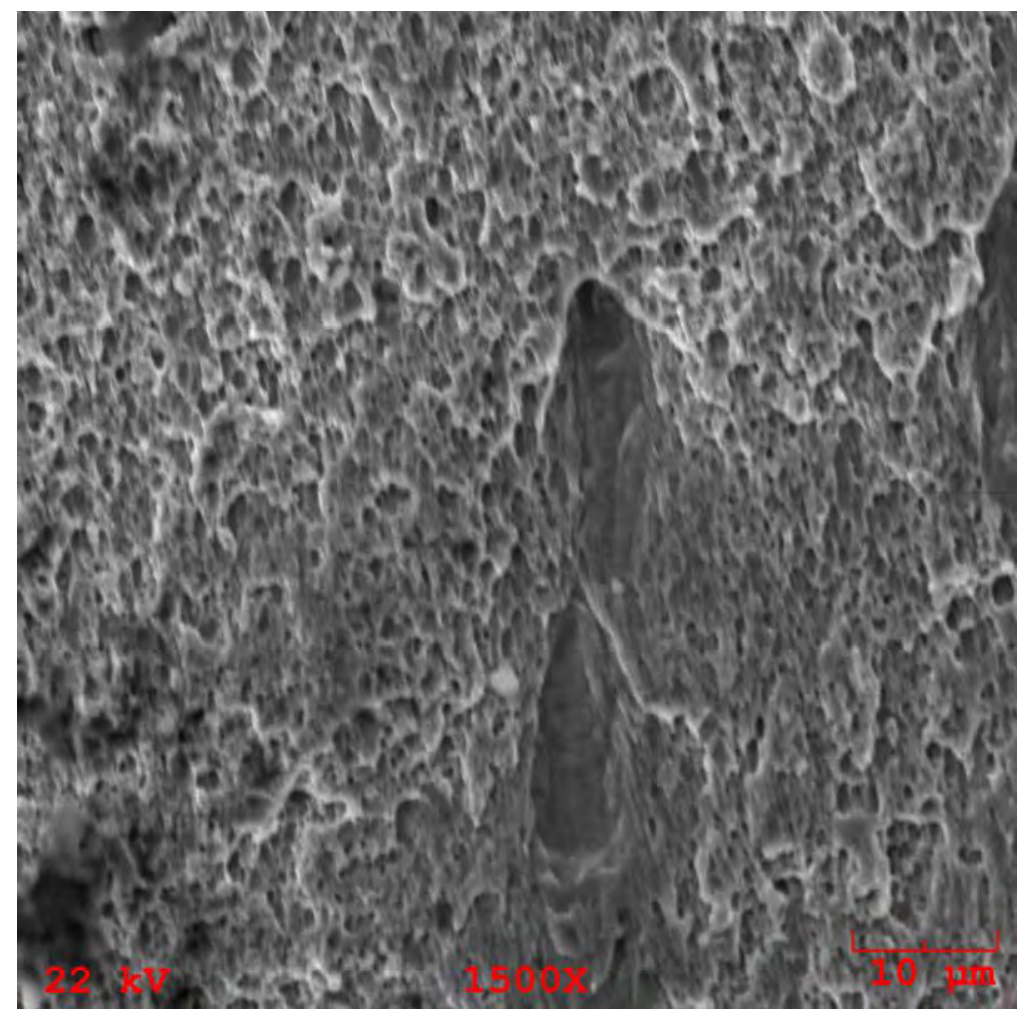

Figure 69: Sample 1 - SEM Image of Fracture Face near ID 


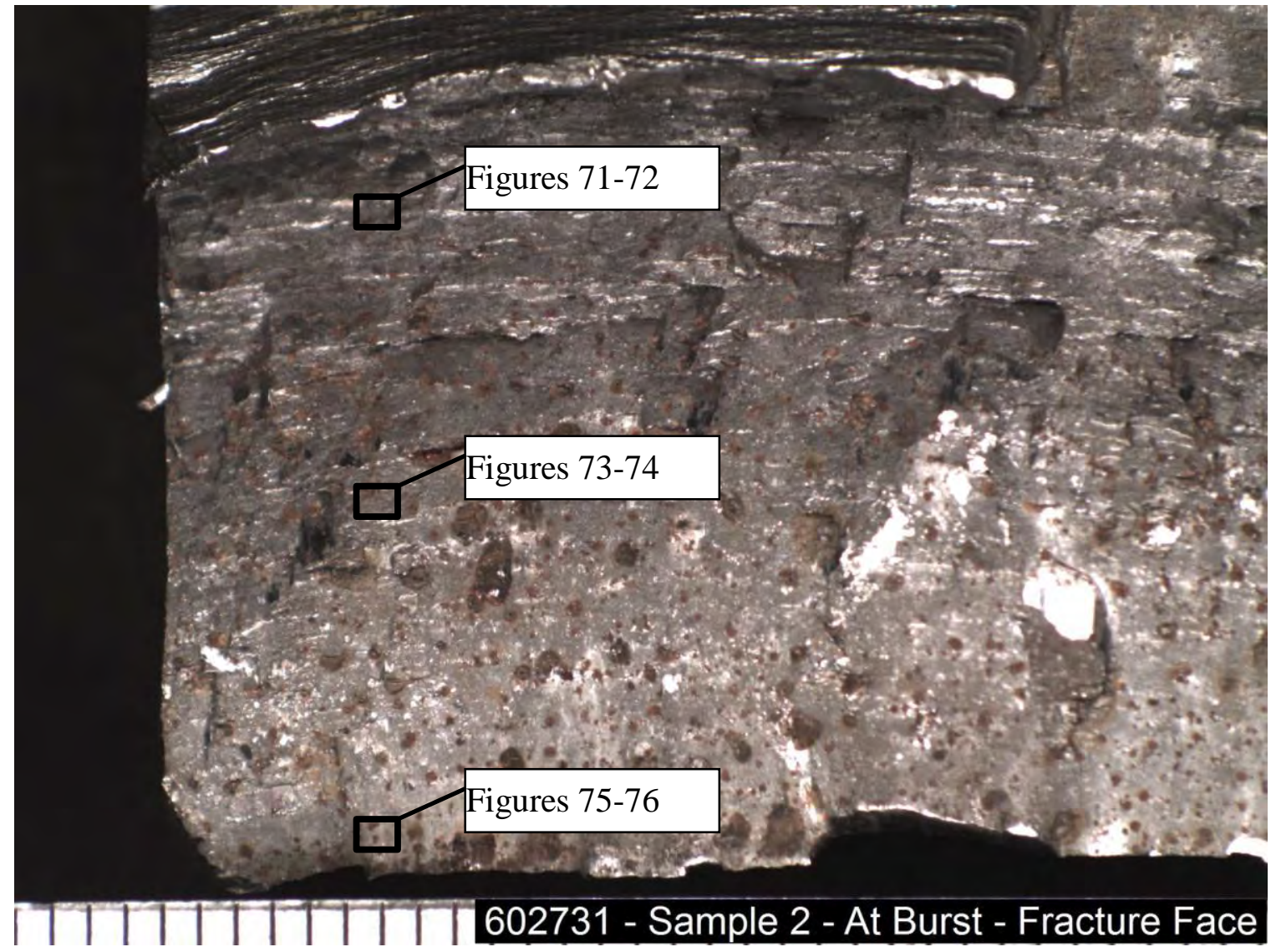

Figure 70: Sample 2 - Fracture Face and SEM Locations (scale in mm) 
Reference No: 602731

Issue: 01

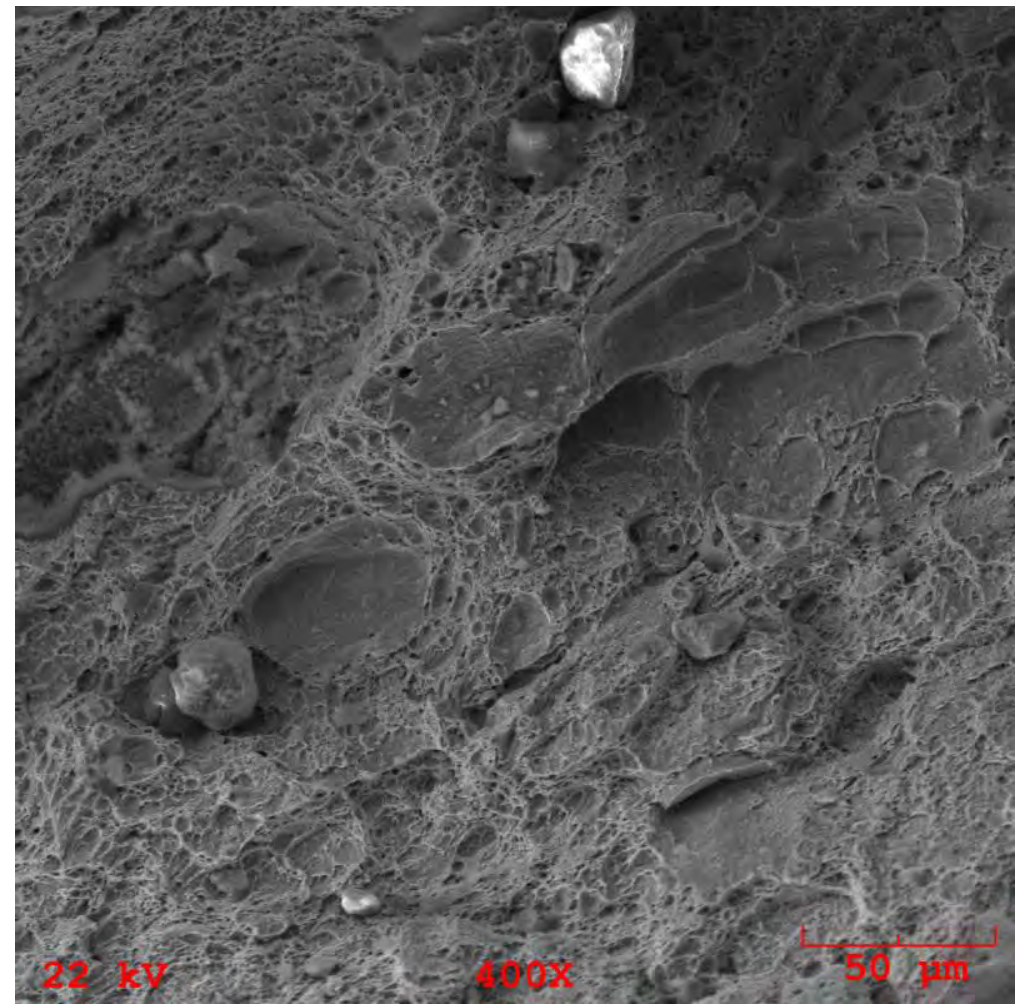

Figure 71: Sample 2 - SEM Image of Fracture Face near OD

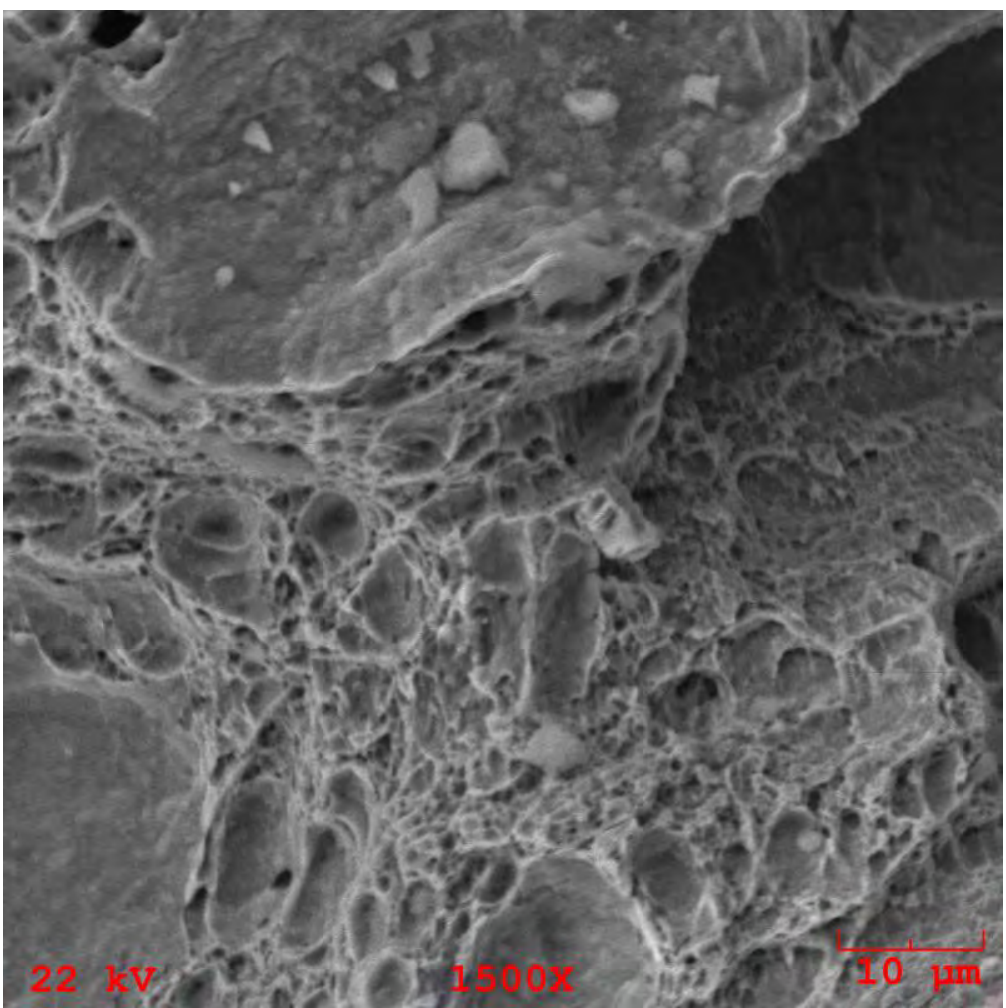

Figure 72: Sample 2 - SEM Image of Fracture Face near OD
Aiken Engineering Company

51 Pages 
Reference No: 602731

Issue: 01

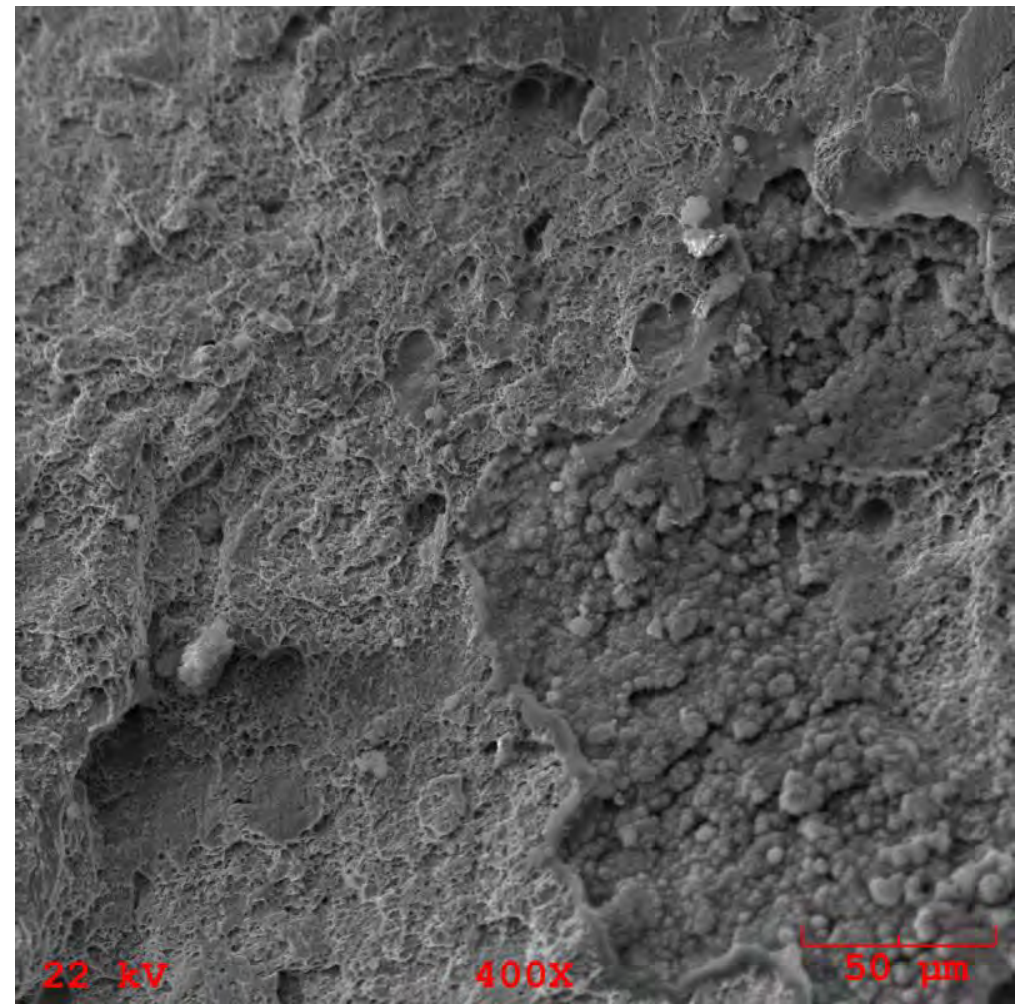

Figure 73: Sample 2 - SEM Image of Fracture Face near MW
Aiken Engineering Company

51 Pages

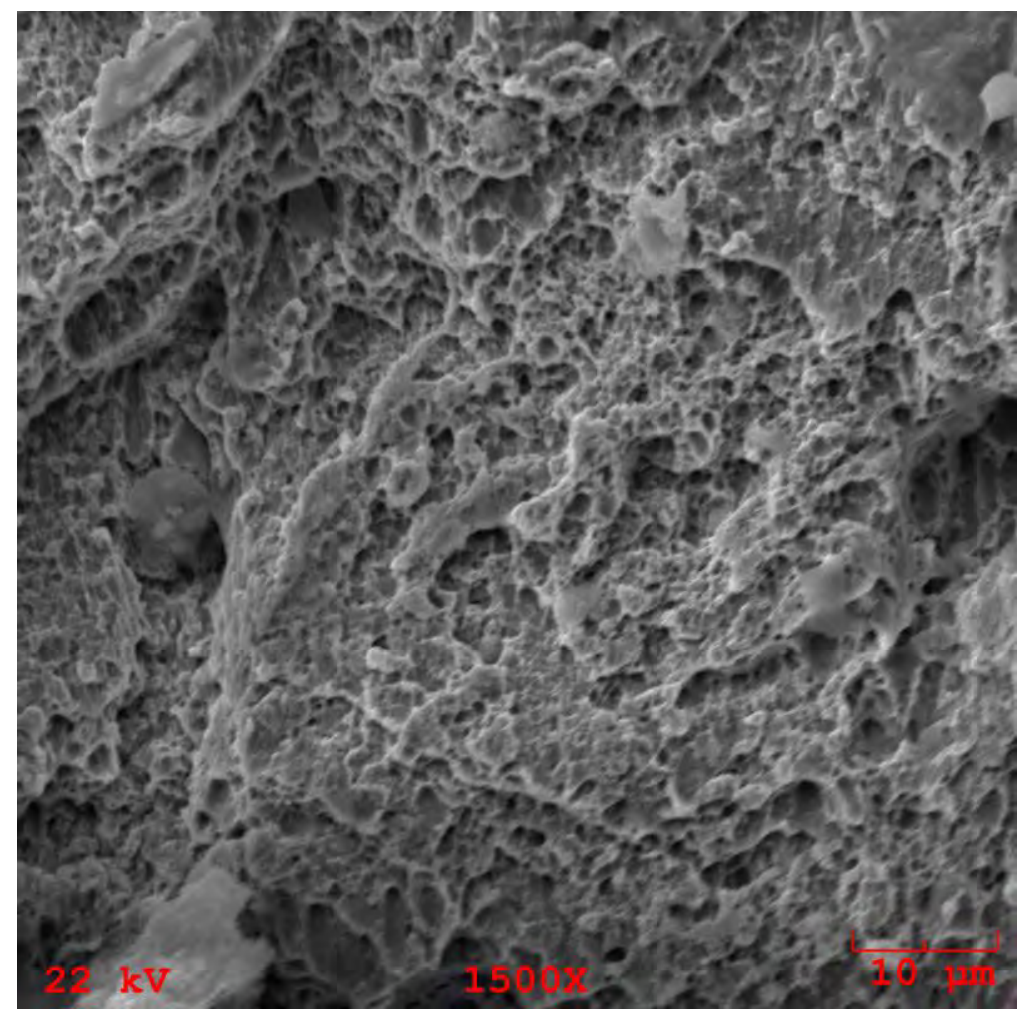

Figure 74: Sample 2 - SEM Image of Fracture Face near MW 
Reference No: 602731

Issue: 01
Aiken Engineering Company

51 Pages

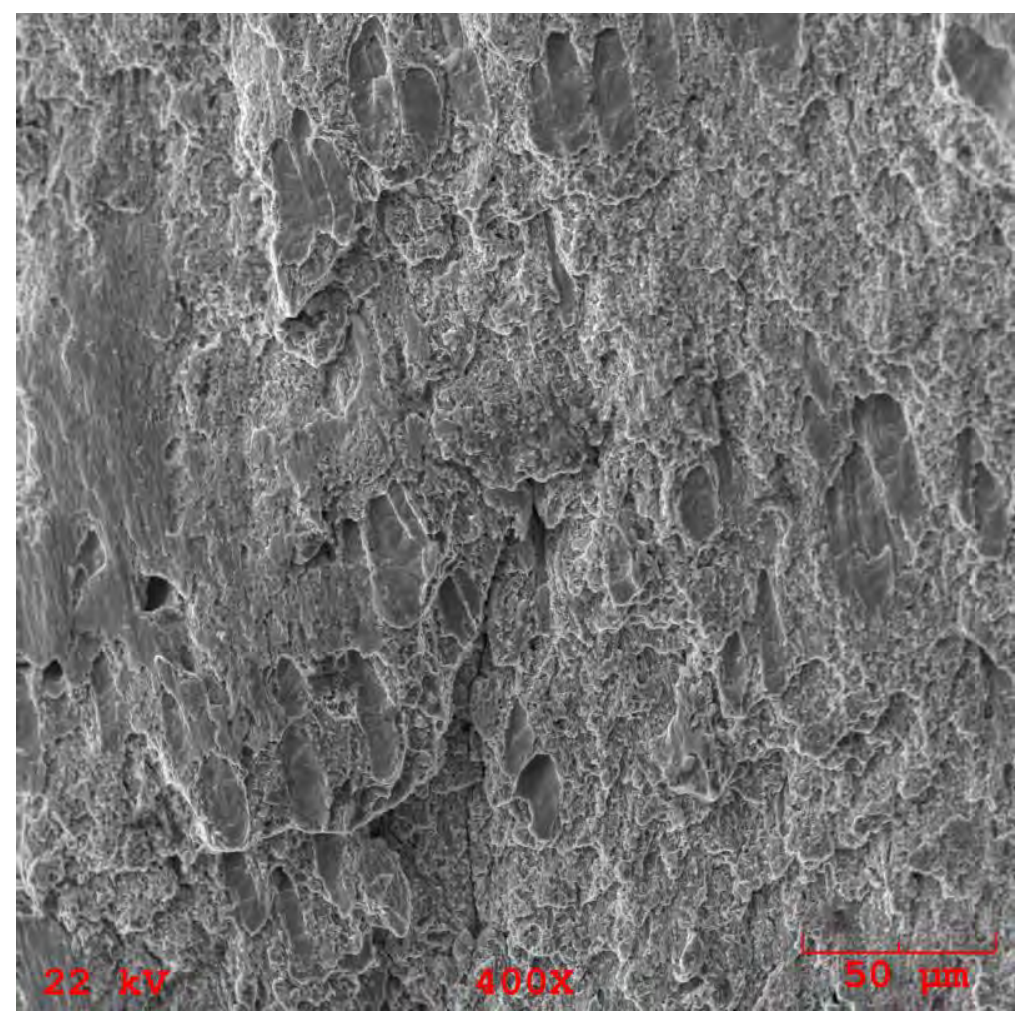

Figure 75: Sample 2 - Sample 2 - SEM Image of Fracture Face near ID

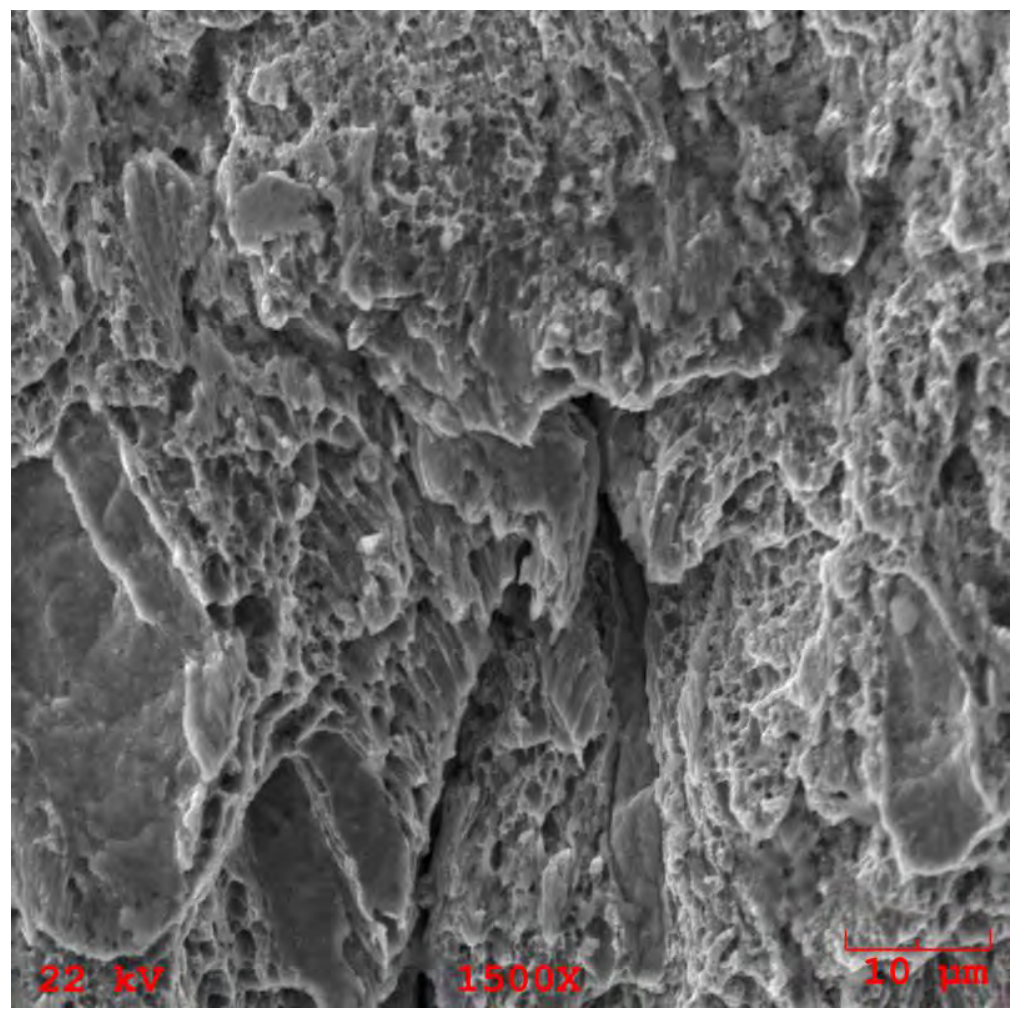

Figure 76: Sample 2 - Sample 2 - SEM Image of Fracture Face near ID 
Reference No: 602731

Issue: 01
Aiken Engineering Company

51 Pages

This page intentionally blank 
Appendix B: Omni Cutting Diagram for SSC Data
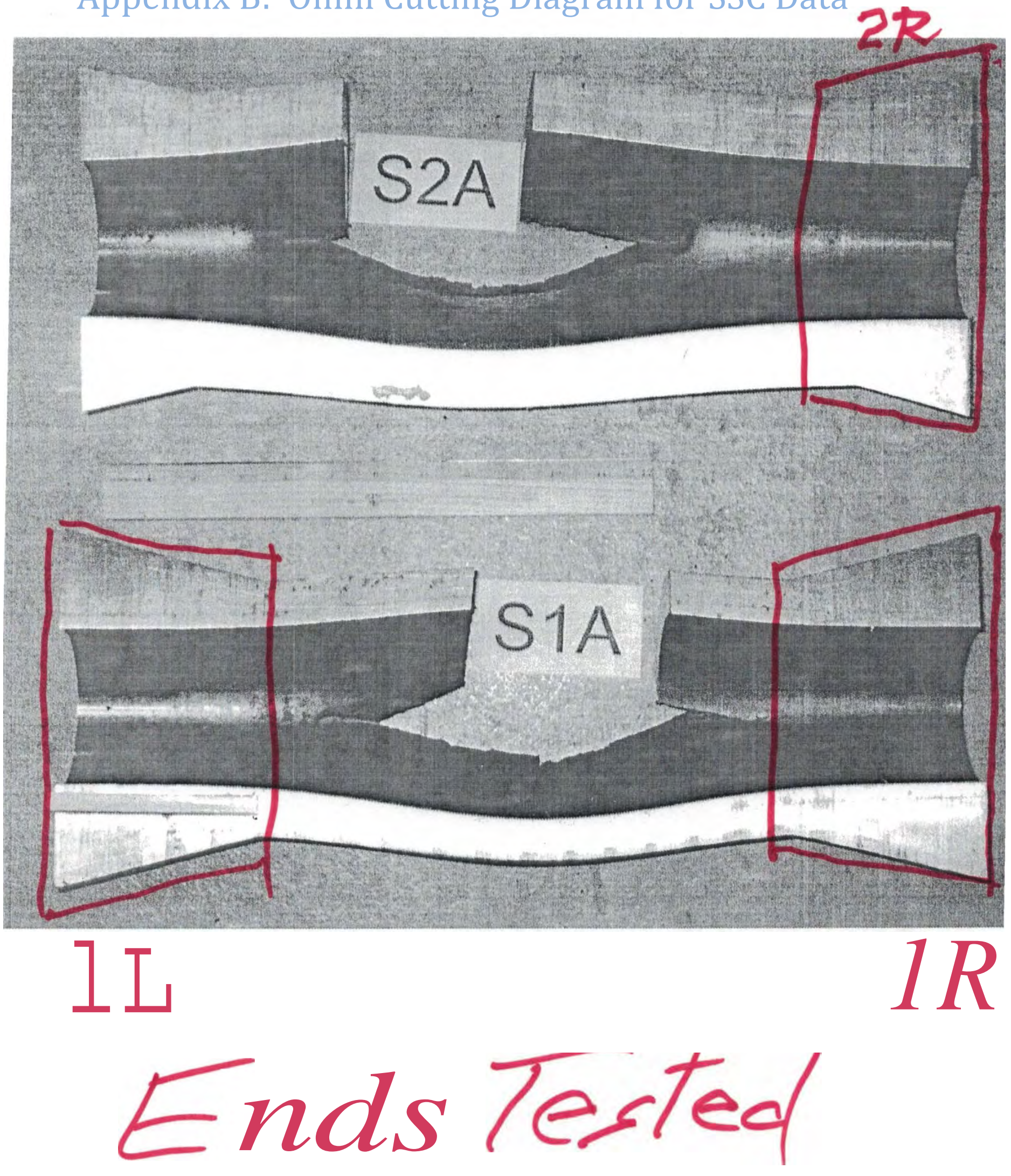


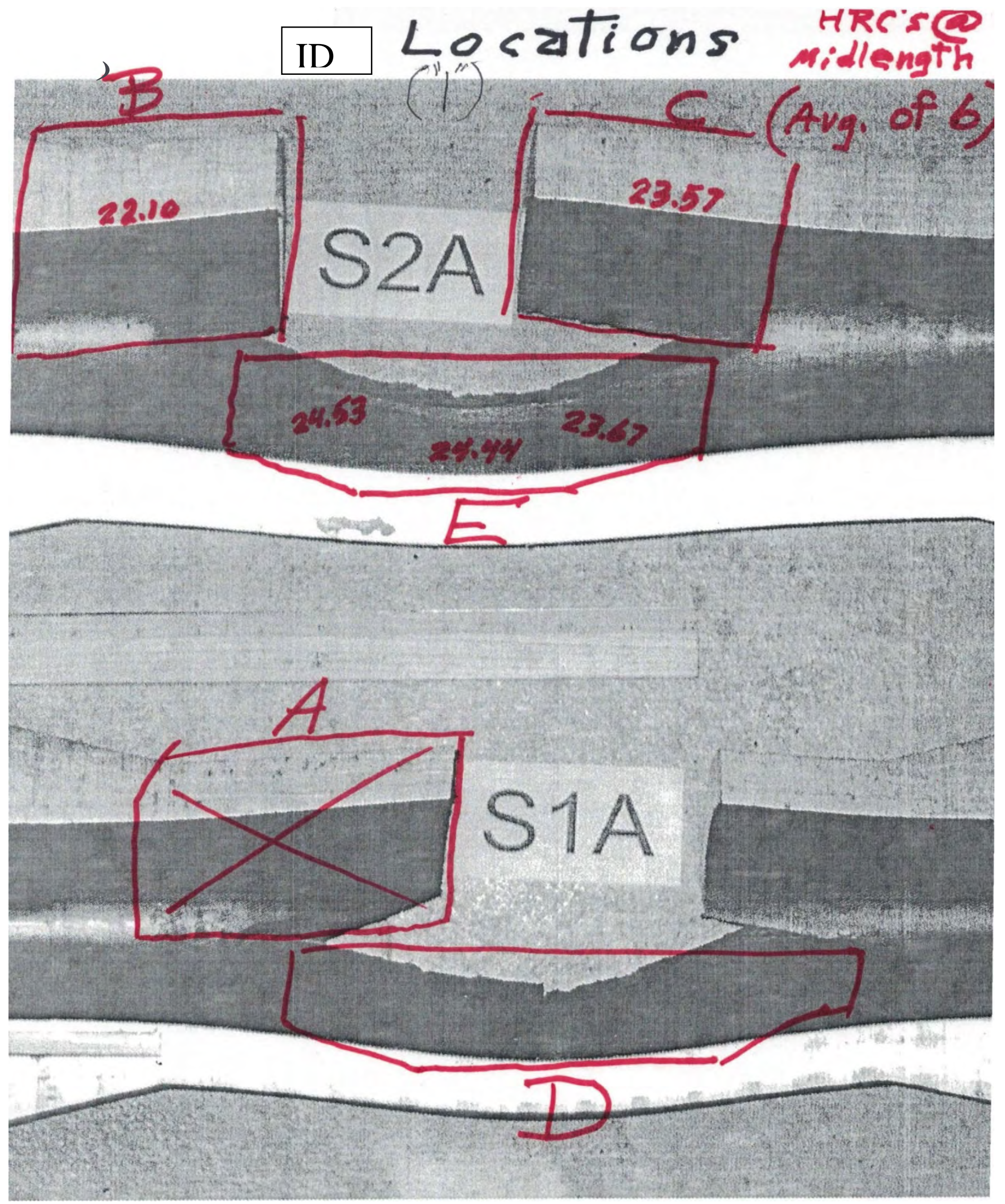




\section{Mid-Thickness Locations}
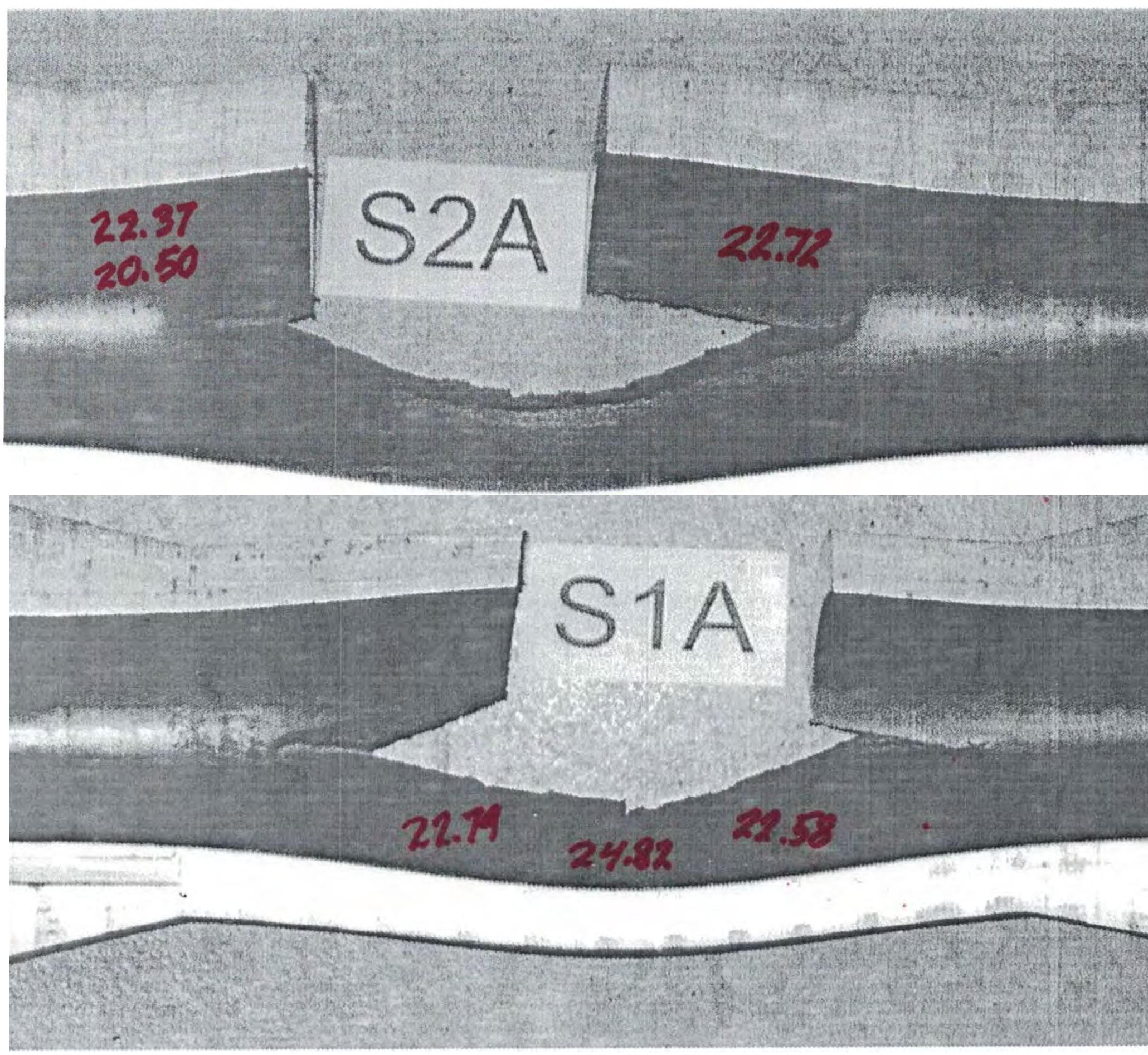


\section{OD Locations ("O")}
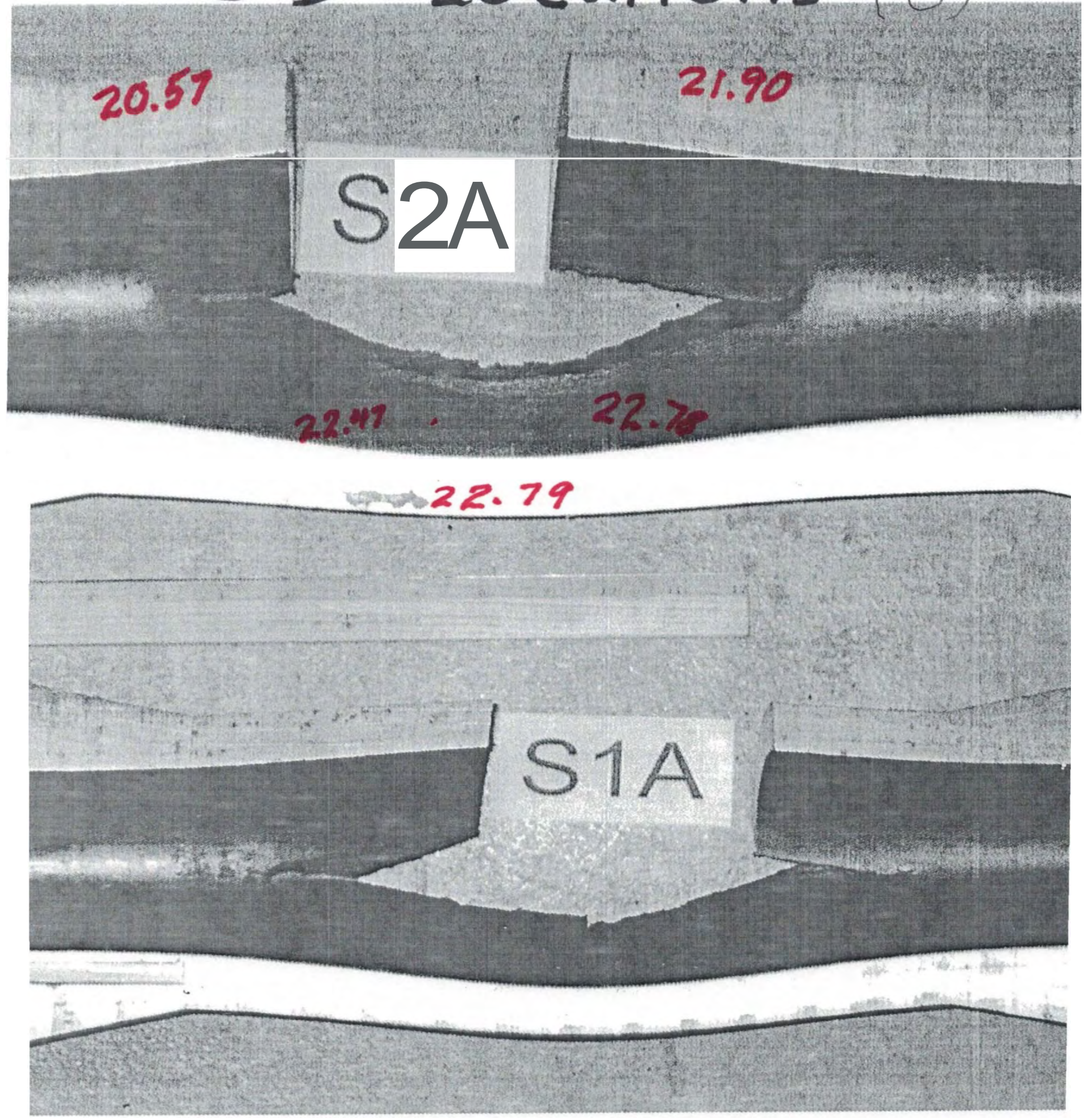


\section{Energy Systems Division}

Argonne National Laboratory

9700 South Cass Avenue, Bldg. 221*\#

Argonne, IL 60439

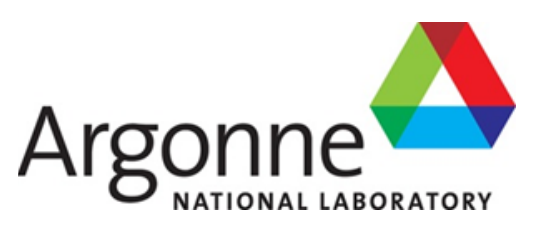

www.anl.gov

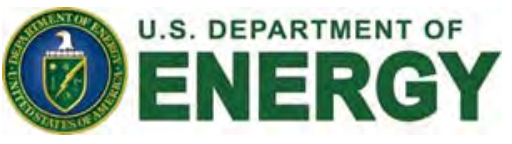

Argonne National Laboratory is a U.S. Department of Energy

Laboratory managed by UChicago Argonne, LLC 